\title{
Molecular and functional characterization of bacterial communities in organic farm and pasture soils
}

Sherie L. Edenborn

West Virginia University

Follow this and additional works at: https://researchrepository.wvu.edu/etd

\section{Recommended Citation}

Edenborn, Sherie L., "Molecular and functional characterization of bacterial communities in organic farm and pasture soils" (2007). Graduate Theses, Dissertations, and Problem Reports. 2587.

https://researchrepository.wvu.edu/etd/2587

This Dissertation is protected by copyright and/or related rights. It has been brought to you by the The Research Repository @ WVU with permission from the rights-holder(s). You are free to use this Dissertation in any way that is permitted by the copyright and related rights legislation that applies to your use. For other uses you must obtain permission from the rights-holder(s) directly, unless additional rights are indicated by a Creative Commons license in the record and/ or on the work itself. This Dissertation has been accepted for inclusion in WVU Graduate Theses, Dissertations, and Problem Reports collection by an authorized administrator of The Research Repository @ WVU.

For more information, please contact researchrepository@mail.wvu.edu. 
Molecular and Functional Characterization of Bacterial Communities in Organic Farm and Pasture Soils

By

Sherie L. Edenborn

Dissertation submitted to the Davis College of Agriculture, Forestry and Consumer Sciences, at West Virginia University in partial fulfillment of the requirements for the degree of

\title{
Doctor of Philosophy
} in Agricultural Sciences with a concentration in Environmental Microbiology

\section{Approved by}

\author{
Alan J. Sexstone, Ph.D., Chair \\ Gary K. Bissonnette, Ph.D. \\ Kenneth P. Blemings, Ph.D. \\ James B. Kotcon, Ph.D. \\ Daniel G. Panaccione, Ph.D.
}

\author{
Division of Plant and Soil Sciences \\ Morgantown, West Virginia \\ 2007
}

Keywords: Bacterial community structures, Organic farm, Pasture, Culturable bacteria, DGGE, CLPP, Small-celled bacteria, Spatial analysis

Copyright 2007 Sherie L. Edenborn 


\section{ABSTRACT \\ Molecular and Functional Characterization of Bacterial Communities in Organic Farm and Pasture Soils}

\section{Sherie L. Edenborn}

Culture-dependent denaturing gradient gel electrophoresis (CD DGGE) fingerprinting of the 16S rRNA gene was developed to characterize mixed soil bacterial communities recovered on agar plates. CD DGGE analyses resulted in clear banding patterns of sufficient complexity (16-32 major bands) and reproducibility to investigate differences in bacterial communities in silt loam soils. Replicate CD DGGE profiles from plates inoculated with less-dilute samples $\left(10^{-3}\right)$ had a higher band count and were more similar (72-77\%) than profiles from more-dilute samples (51-61\%). When CD DGGE fingerprints were compared to profiles constructed from 16S rRNA genes obtained from culture-independent clone libraries (CB DGGE profiles) $34 \%$ of the bands were unique to the culture-dependent profiles, $32 \%$ were unique to the culture-independent profiles and $34 \%$ were found in both communities. CD DGGE fingerprints of the 16S rRNA gene were used to compare culturable microbial communities in soils from an organic farm and pastures that were subjected to differing agronomic treatments. Multiple and simple correlation analyses revealed significant relationships between microbial biomass carbon $(\mathrm{MBC})$, potentially mineralizable nitrogen $(\mathrm{PMN})$, and variables derived from principal component analysis (PCA) of community-level physiological profiling (CLPP), as well as non-metric multidimensional dimensional scaling (NMDS) of CD DGGE data. All measures clearly separated soil types, but varied in their ability to distinguish among treatments within a soil type. Overall, MBC, PMN, and CLPP were most responsive to additions of compost (organic farm) and manure (pasture); while CD DGGE resolved differences in legume cropping (organic farm) and inorganic fertilization (pasture). Bacteria from filtered $(<0.45 \mu \mathrm{m})$ and non-filtered slurries of soils from an organic farm were cultivated on R2A agar for up to one month. According to CD DGGE analyses, filtered and unfiltered communities were highly dissimilar and distinct small-celled bacteria were isolated from soils collected one year apart. Filterable bacteria were classified by phylogenetic analyses as $\alpha-, \beta-, \gamma-$, or $\delta$-Proteobacteria or Bacteroidetes with the genera Polaromonas and Ramlibacter representing $23 \%$ of the non-chimeric sequences in clone libraries. Other sequences were associated with known copiotrophic ultramicrobacteria, endophytic nitrogen-fixing bacteria in the genera Herbospirillum and Azospirillum, and bacteria adapted to inter- or intracellular growth. Sequences obtained from slow-growing, pinpoint-sized colonies were highly similar to an amoeba-resistant bacterium affiliated with the genus Rhodoplanes, a putative diazotroph that may play a potentially important role in soil nitrogen dynamics. Finally, the spatial variability and heterogeneity of microbial substrate utilization in tilled and untilled organic farm soils were explored using CLPP coupled with multivariate and geostatistical analyses. Robust semivariograms based on the kinetics of substrate utilization in BIOLOG GN2 plates were constructed. Microbial substrate utilization was spatially structured in some untilled 
soils and subsurface tilled soils over ranges $>4 \mathrm{~m}$. Rotary tillage completely disrupted the spatial structure of substrate utilization in surface soils. Amines and amides were the only substrate classes that exhibited a tillage-induced loss of spatial structure at lower soil depths. Spatial structure at lower soil depths in untilled soils was most pronounced for utilization of amino acids, amines and amides. Collectively, data presented in this dissertation support arguments that culturable soil microbial communities provide nonredundant and useful information for characterization of selected agronomic perturbations. 


\section{ACKNOWLEDGMENTS}

I wish to acknowledge the United States Department of Agriculture (USDA) and the Division of Plant and Soil Science, West Virginia University, for providing support and funding for this research. I thank my graduate advisor, Dr. Alan Sexstone, for his support and encouragement, his willingness to let me "explore strange new worlds," and his help enhancing my ability to craft words with a quill pen. I am grateful to the members of my committee (Drs. Kenneth Blemings, Gary Bissonnette, James Kotcon, and Daniel Panaccione) for their time, energy, and expertise. I express profound gratitude to the "ladies of the laboratory" (Jolene Friedland, Yovita Sutanto, Kimberly Salinas, and Josh Chapman) and the faculty, staff, and graduate students of the Department of Plant Pathology and Environmental Microbiology for sharing their knowledge, hands, and time. It was a great privilege to work with such a friendly and mindful collective.

I am indebted to Dr. George Seidel for his assistance with statistical analysis, to Jolene Friedland for helping me master Excel, to Dr. Joseph Morton for his invaluable tutorial on Photoshop, and to Dr. Eugenia Pena Yewtukhiw for her helpful comments on geostatistical analysis. I also thank Tracy Thomas Wilson, the Editor of Edenbabble, for her assistance editing and formatting this dissertation, and Christine Coyle for sharing the commute from Pittsburgh every day.

Finally, I thank my family and friends. None of this would have been possible without their love, support, and encouragement. I am especially grateful to my daughter, Abby, for the patience and understanding she showed a very busy mother, and to my husband, Dr. Hank Edenborn, for being a mentor, a great partner and most importantly, my best friend. And last, but not least-Thanks Mom!-as always, you are my inspiration. 


\section{TABLE OF CONTENTS}

$\begin{array}{ll}\text { ABSTRACT } & \text { ii }\end{array}$

ACKNOWLEDGMENTS $\quad$ iv

TABLE OF CONTENTS $\quad$ v

LIST OF TABLES Viii

LIST OF FIGURES $\quad$ ix

INTRODUCTION 1

$\begin{array}{ll}\text { Objectives } & 6\end{array}$

$\begin{array}{lr}\text { References Cited } & 8\end{array}$

Chapter 1 : DGGE Fingerprinting of Culturable Soil Bacterial Communities

$\begin{array}{ll}\text { Complements Culture-independent Analysis } & 12\end{array}$

$\begin{array}{ll}\text { Abstract } & 12\end{array}$

$\begin{array}{ll}\text { Introduction } & 13\end{array}$

Materials and Methods 15

$\begin{array}{ll}\text { Results } & 20\end{array}$

$\begin{array}{ll}\text { Discussion } & 23\end{array}$

$\begin{array}{ll}\text { Conclusions } & 27\end{array}$

$\begin{array}{ll}\text { References Cited } & 28\end{array}$

Chapter 2 : Small-celled Bacteria from Organic Farm Soils Show Phylogenetic

Similarities to Diazotrophs and Bacteria that Favor Inter- and Intracellular Habitats 47

$\begin{array}{ll}\text { Abstract } & 47\end{array}$

Introduction $\quad 49$ 
Results

Discussion

$\begin{array}{ll}\text { Conclusions } & 68\end{array}$

$\begin{array}{ll}\text { References Cited } & 69\end{array}$

Chapter 3 : Response of Culturable Bacterial Communities in Upland Pasture and $\begin{array}{ll}\text { Organic Farm Soils to Agronomic Treatment } & 87\end{array}$

$\begin{array}{ll}\text { Abstract } & 87\end{array}$

$\begin{array}{ll}\text { Introduction } & 88\end{array}$

$\begin{array}{lr}\text { Materials and Methods } & 90\end{array}$

$\begin{array}{ll}\text { Results } & 96\end{array}$

$\begin{array}{ll}\text { Discussion } & 100\end{array}$

$\begin{array}{ll}\text { Conclusions } & 106\end{array}$

$\begin{array}{ll}\text { References Cited } & 107\end{array}$

Chapter 4 : Spatial Variability and Heterogeneity of Community-level Physiological

Profiles in Tilled and Untilled Soils from an Organic Farm 121

Abstract

Introduction

Materials and Methods

Results and Discussion

References Cited 
CURRICULUM VITAE 


\section{LIST OF TABLES}

\section{CHAPTER 1}

Table 1.1. Summary of studies, experimental design, and sampling strategy.

Table 1.2. Average number of CD DGGE bands and average percent similarity in dilution study.

\section{CHAPTER 3}

Table 3.1. Microbial biomass carbon (MBC) and potentially mineralizable nitrogen $(\mathrm{PMN})$ in organic farm and pasture soils.

\section{CHAPTER 4}

Table 4.1. Means and coefficients of variation (\% CV) for biomass and heterotrophic plate count data for vertical subsections of soil collected on day 347 .

Table 4.2. Summary of results from geostatistical analysis of AUC data for all BIOLOG GN2 substrates from day 822 .

Table 4.3. Summary of results from geostatistical analysis of AUC data from substrate classes from BIOLOG GN2 plates from day 822 .

Table 4.4. Pearson correlation coefficients between $\mathrm{CO}_{2}$ flux and $\mathrm{AUC}$ data for substrate classes from BIOLOG GN2 plates. 


\section{LIST OF FIGURES}

\section{CHAPTER 1}

Figure 1.1. Flowchart of protocols used to construct culture-dependent (CD DGGE) and cloning-based (CB DGGE) fingerprints of bacterial communities from organic farm soils.37

Figure 1.2. (a) CD DGGE profiles of $16 \mathrm{~S}$ rRNA genes amplified from soil bacterial communities grown on R2A media inoculated with $10^{-3}$ or $10^{-6}$ dilutions of soil from high $(\mathrm{H})$ and low (L) input plots from the WVU Organic Research Farm and incubated aerobically for 2 weeks at $25^{\circ} \mathrm{C}$.

Figure 1.3. UPGMA dendrograms constructed using Sorensen's similarity index generated from DGGE profile profiles of bacterial communities from replicate soil subsamples collected from (a) high and (b) low input plots at the West Virginia University Organic Research Farm.

Figure 1.4. CD DGGE profiles and UPGMA dendrograms constructed using Sorensen's similarity index generated from DGGE profile from soil bacterial communities $(a, b)$ grown on four different media and (c, d) subjected to different pretreatments (heat shock vs. no heat shock) and incubation conditions (aerobic vs. anaerobic) prior to plating on R2A media.

Figure 1.5. DGGE profiles of culture-independent and culture-dependent 16S rRNA genes of bacterial communities from organic farm soils.

Figure 1.6. Number of bands found in the composite DGGE gel when different combinations of culture-dependent profiles were included in the analysis.

\section{CHAPTER 2}

Figure 2.1. Number of small cell colonies on R2A plates inoculated with four dilutions of soils from the high-input (black bars) and low-input (white bars) plots at the market garden at the West Virginia University Organic Research Farm on June 26, 2003.

Figure 2.2. Appearance of bacteria colonies on R2A agar 24 hrs (white bars), 1 week (gray bars) and 1 month (black bars) for (a) nonfiltered communities $\left(10^{-7}\right.$ dilution) and (b) filtered $\left(10^{-2}\right.$ dilution).

Figure 2.3. PCR-DGGE fingerprint of partial $16 \mathrm{~S}$ rRNA genes from filtered and nonfiltered bacterial communities isolated from high- and low-input soils in (a) 2003 and

(b) 2004 .

Figure 2.4. UPGMA dendrogram of filtered and unfiltered bacterial communities in high- and low-input soils from the organic farm in June 2003 and 2004. 
Figure 2.5. Distribution of ARDRA patterns for $16 \mathrm{~S}$ rDNA clones from small-celled bacteria from (a) 2003 (b) and 2004..

Figure 2.6. (a) PCR-DGGE of partial $16 \mathrm{~S}$ rRNA genes and (b) neighbor-joining phylogenetic tree of $\alpha$ and $\delta$ Proteobacteria and Bacteroidites 16S rDNA sequences of clones from filterable bacteria from 2003 and 2004.

Figure 2.7. (a) PCR-DGGE of partial $16 \mathrm{~S}$ rRNA genes and (b) neighbor-joining phylogenetic tree of $\beta$ and $\gamma$ Proteobacteria 16S rDNA sequences of clones from smallcelled bacteria from 2003 and 2004 .

\section{CHAPTER 3}

Figure 3.1. Ordination biplots of principal components (PC1 and PC2) from CLPP analysis of organic farm and pasture soils subjected to varying fertility regimes and crop rotations from August and September 2004.

Figure 3.2. (a) DGGE gel of pooled PCR-amplified 16S rRNA genes from culturedependent bacterial communities of organic farm and pasture from August-September 2004 and (b) ordination plots of dimensions 1 and 2 from NMDS analysis of CD DGGE data.

Figure 3.3. Ordination plots of DGGE data from pasture soils in: (a) May and (b) May September, 2004.

Figure 3.4. Ordination plots DGGE data from organic farm market garden soils in: (a) June and (b) August, 2004. .

Figure 3.5. Scatterplots, trendlines and Pearson correlation coefficients between MBC and dimensions 1 and 2 from NMDS analysis of CD DDGE profiles from organic farm in August, 2004 (a, b) and pasture days 0, 21, 40 and 63 between May and September, 2004 (c, d).

\section{CHAPTER 4}

Figure 4.1. Dimensions and layout of plots for analyses done on days 347 following the primary tillage event (a) and sampling scheme and analyses for geospatial study done in plots (A) 456 days following the second tillage event (b)..............................................144

Figure 4.2. Generalized spherical semivariogram.

Figure 4.3. Ordination biplots of principal components (PC1 and PC2) from CLPP analysis of vertical subsections (a) no till and (b) till soils collected from plots A, B and C on day 347 following the initial tillage event in July 2003. 
Figure 4.4. Ordination biplots of principal components (PC1 and PC2) from CLPP analysis of vertical subsections of till and no-till soils collected on day 822 following the primary and secondary tillage events.

Figure 4.5. Variograms of AUC for (a) all substrates in the no till plot, (b) all substrates in the till plot, (c) carbohydrates in the no till plot (d), and carbohydrates in the till plot. 148 


\section{INTRODUCTION}

The productivity of agricultural soils is impacted by poor management and exploitive farming practices (Kaiser and Proffitt, 2004). As a result there has been an increased interest in the effects of agricultural stress on the sustainability and overall quality of soil (Parr et al., 1992). Because healthy ecosystems are characterized by high species diversity (Mader et al., 2002), and bacteria are known to play important roles in many biogeochemical cycles in soil, it has been suggested that the structural and functional diversity of bacterial communities can be used as indicators of changing soil quality (Parr et al., 1992).

Bacterial communities can be characterized using both culture-independent and culture-dependent methods. Over the past decade, culture-independent analyses of bacterial genes have become the preferred methods to profile the diversity of bacterial communities in environmental samples (Tiedje et al., 1999; Amann, 2000). Cultureindependent methods are thought by some investigators to be superior to culturedependent methods because they provide a more complete profile of total species richness (Amann, 1995; Ovreas and Torsvik, 1998). Others have argued that culturable bacteria are ecologically relevant because these are the members of the community that contribute most to biomass and activity (Ellis et al., 2003).

A current paradigm in microbial ecology states that less than $0.1-5 \%$ of bacterial cells observed directly in soil are able to be cultivated on bacteriological media (Ritz, 2007). It is also widely accepted that culture-dependent methods fail to detect novel groups, such as the Acidobacteria and Verrucomicrobia, which have been found to be 
numerically abundant and widespread in soil when analyzed using culture-independent methods (Hugenholtz et al., 1998; Barns et al., 1999). Recently, these ideas have been challenged. Studies have demonstrated that novel bacteria, once thought to be unculturable, can be grown in culture when conditions include longer incubation times and diverse media (Janssen et al., 2002; Joseph et al., 2003; Schoenborn et al., 2004; Stevenson et al., 2004; Sangwan et al., 2005). Joseph et al. (2003) reported that 60 different family-level groups were represented by a total of 350 isolates grown on dilute nutrient agar. Thirty-three percent of these isolates were not validly named or described species, and $27 \%$ belonged to novel family-level groups. Approximately $4 \%$ were classified into four family-level groups that have not been formally described but may contain validly-named species. Twenty-nine of the isolates (8\%) were characterized as Acidobacteria and one was from the division Verrucomicrobia. In a separate study, Janssen et al. (2002) were able to recover members Acidobacteria and Verrucomicrobia on dilute nutrient agar plates that were incubated for 12 weeks. Based on the actual viable counts $\left(6.03 \times 10^{7}-1.49 \times 10^{8} \mathrm{CFU} / \mathrm{g}\right.$ soil), they estimated that approximately $20 \%$ of the viable cells could be cultivated on dilute media.

Culture-independent profiles of bacterial communities are constructed by extracting DNA or cells directly from soil. In the late 1970s and early 1980s, microbial DNA was extracted from soils using a cell extraction method that removed soil microorganisms from soil particles prior to lysis (Faegri et al., 1977; Torsvik and Goksoyr, 1978; Holben et al., 1988). One limitation of this procedure is the low recovery of bacterial cells bound to soil particles (Steffan et al., 1988). Holben et al. (1988) and Steffan et al. (1988) reported recoveries of 33\% and 30\% of the bacterial cells in soil, 
respectively. Techniques such as mechanical blending have been used to increase the release of bacterial cells from soil. Lindahl and Bakken (1995) found that 30\% of cells could be released from soil after six minutes of dispersion in a Waring blender, while higher rates (50-87\%) were observed by Faegri et al. (1977) and Prieme et al. (1996). The ability to recover cells from soil is dependent on soil type. Hopkins et al. (1991) examined the recovery of cells from a clay loam (Hallsworth series-Typic Ochroaqualf), a sandy loam (Rivington series - a brown earth, Dystrochrept) and the peaty horizon from an upland stagnohumic-gley. They found that $56-61 \%$ of bacterial cells were released from all soils. In contrast, Frischer et al. (2000) reported that $96 \%$ of cells could be recovered from salt marsh sediments without phylogenetic bias.

Although cell extraction methods provided cleaner samples for extraction of DNA, the low recovery of cells from certain soils has limited the broad use of this technique. Ogram et al. (1987) developed a technique that involved direct lysis of cells attached to the soil matrix followed by the extraction of DNA. Various modifications of this technique have been developed to increase extraction efficiency (Zhou et al., 1996; Miller et al., 1999) and allow co-extraction of RNA with DNA (Griffiths et al., 2000; Hurt et al., 2001). Overall, the direct lysis method has been shown to result in much higher recoveries of DNA from soil samples (Steffan et al., 1988). However, substances such as humic acids interfere with the extraction, detection, and quantification of DNA (Zhou et al., 1996) and the amplification of genes using PCR. Theoretical calculations of extraction efficiency can be made based on the number of bacterial cells in soil before and after extraction and the average amount of DNA per cell. Zhou et al. (1996) used this approach to examine the efficiency of extraction from eight different types of soil. 
Extraction efficiency ranged from $26-92 \%$, with one soil showing higher cell counts in the soil post-extraction compared to pre-extraction. Based on their results, it was concluded that extraction efficiency was influenced by the clay content of the soil and the type of bacteria (gram-positive bacteria being more difficult to lyse than gram-negative bacteria). To study the potential loss of DNA via binding to the soil matrix, Frostegard et al. (1999) added varying amounts of naked lambda DNA to different soil types and then tried to recover it using different extraction methods. They found that grinding the soil increased the recovery of DNA from dry soil; however, no more than $6 \%$ of the added lambda DNA was ever recovered for any of the soil types.

A major criticism of culture-independent analyses is that they do not differentiate active cells from inactive cells. Stable isotope probing (SIP) is an emerging technology that links microbial activity to the organisms that are responsible for these activities (Boschker et al., 1998). Using this technique, a substrate labeled with a stable-isotope such as ${ }^{13} \mathrm{C}$ is added to an environmental sample, the labeled substrate is assimilated by certain cells in the population, and biomolecules containing the stable isotope are extracted and isolated from the total community and analyzed using standard methods such as polar lipid-derived fatty acid analysis, DGGE, or gene sequencing and cloning. Direct extraction of 16S rRNA from soil or co-extraction of DNA and RNA (Felske et al., 1998; Griffiths et al., 2000; Hurt et al., 2001) and selective removal of DNA from dead cells using ethidum monoazide (Nocker and Camper, 2006) are other approaches that have been used to characterize soil bacteria that may play a more active role in soil processes. 
Neither culture-independent nor culture-dependent techniques can provide an absolute picture of soil bacterial diversity, suggesting that a combined approach may be more robust. Lipson and Schmidt (2004) used culture-independent and culturedependent methods to study seasonal changes in bacterial communities in alpine soil of the Colorado Rocky Mountains. They concluded that seasonal shifts could be consistently demonstrated using both methods, although different groups of organisms were detected. Similar conclusions were drawn by Kisand and Wikner (2003), who compared the richness of estuarine bacterioplankton by using DNA-DNA hybridization of cultured isolates versus cloning and DGGE of 16S rRNA genes from cultureindependent samples. They demonstrated that similar taxa were detected by all three methods at the genus level and higher; however, there was very little overlap at the species level.

The importance of combining culture-dependent methods with cultureindependent analysis is being realized. Teske et al. (1996) stressed the ability of parallel analyses to provide a framework in which the strengths and biases of different methods can be evaluated. Joseph et al. (2003) and Ward (2006) pointed out that laboratory cultivation is needed to fully understand the biochemical and ecological potentials of bacteria that are currently only known from metagenomic and phylogenetic analysis of gene sequences. A recent debate in the journal FEMS Microbiology Ecology (volume 60(3): 2007) highlights the following question; "are studies of culturable communities still useful in the field of environmental microbial ecology?". Ritz (2007) contends that culturable organisms are of limited use because they represent a minor fraction of the soil community and their growth in culture does not reflect conditions that exist in situ. In 
contrast, Nichols (2007) points out that cultured organisms provide an essential complement to culture-independent studies by corroborating findings and providing a foundation for culture-independent analyses. In this dissertation, I provide information that is relevant to this debate by: i) developing an appropriate culture-dependent fingerprinting methodology to facilitate comparisons of culturable bacterial communities, ii) assessing culturable bacterial communities as a function of agronomic treatment, and iii) examining culturable small-celled bacteria, a numerically dominant, potentially important, and seldom-cultured fraction of the soil bacterial community. Specific objectives addressed by my research are listed below.

\section{Objectives}

1. To compare and contrast the culture-independent and culture-dependent methods to characterize soil bacterial communities in soils from an organic farm that have received different agronomic treatments. To develop and evaluate a DNA fingerprinting technique to characterize culturable bacterial communities in soil

\section{(Chapter 1).}

2. To culture and characterize small-celled soil bacteria, a numerically dominant fraction of the soil bacterial community that remains largely uncultivated (Chapter 2).

3. To evaluate the effects of fertility regimes used on an organic farm and upland pasture on the structure and function of culturable soil bacterial communities, microbial biomass carbon and potentially mineralizable nitrogen (Chapter 3 ). 
4. To contrast the effects of tillage and no tillage on the variability and spatial heterogeneity of microbial substrate utilization in organic farm soils using multivariate and geostatistical techniques (Chapter 4).

The results of each chapter stand on their own to address questions that must be answered in order to better understand the diversity and ecology of soil bacteria and assess how agronomic practices impact the structure and function of soil microbial communities. 


\section{References Cited}

Amann, R., 2000. Who is out there? Microbial aspects of biodiversity. Systematic and Applied Microbiology 23, 1-8.

Amann, R.I., 1995. Fluorescently labeled, ribosomal RNA-targeted oligonucleotide probes in the study of microbial ecology. Molecular Ecology 4, 543-553.

Barns, S.M., Takala, S.L., Kuske, C.R., 1999. Wide distribution and diversity of members of the bacterial kingdom Acidobacterium in the environment. Applied and Environmental Microbiology 65, 1731-1737.

Boschker, H.T.S., Nold, S.C., Wellsbury, P., Bos, D., De Graff, W., Pel, R., Parkes, R.J., Cappenberg, T.E., 1998. Direct linking of microbial populations to specific biogeochemical processes by ${ }^{13} \mathrm{C}$-labelling of biomarkers. Nature 392, 801-805.

Ellis, R.J., Morgan, P., Weightman, A.J., Fry, J.C., 2003. Cultivation-dependent and independent approaches for determining bacterial diversity in heavy-metalcontaminated soil. Applied and Environmental Microbiology 69, 3223-3230.

Faegri, A., Torsvik, V.D., Goksoyr, J., 1977. Bacterial and fungal activities in soil: separation of bacteria and fungi by a rapid fractionated centrifugation technique. Soil Biology and Biochemistry 9, 105-112.

Felske, A., Wolterink, A., Van Lis, R., Akkermans, A.D.L., 1998. Phylogeny of the main bacterial 16S rRNA sequences in Drentse a grassland soils (The Netherlands). Applied and Environmental Microbiology 64, 871-879.

Frischer, M.E., Danforth, J.M., Newton Healy, J.A., Saunders, F.M., 2000. Whole-cell versus total RNA extraction for analysis of microbial community structure with 16S rRNA-targeted oligonucleotide probes in salt marsh sediments. Applied and Environmental Microbiology 66, 3037-3043.

Frostegard, A., Courtios, S., Ramisse, V., Clerc, S., Bernillion, D., Le Gall, F., Jeannin, P., Nesme, X., Simonet, P., 1999. Quantification of bias related to the extraction of DNA directly from soil. Applied and Environmental Microbiology 65, 54095420 .

Griffiths, R.I., Whiteley, A.S., O'Donnell, A.G., Bailey, M.J., 2000. Rapid method for coextraction of DNA and RNA from natural environments for analysis of ribosomal DNA- and rRNA-based microbial community composition. Applied and Environmental Microbiology 66, 5488-5491.

Holben, W.E., Jansson, J.K., Chelm, B.K., Tiedje, J.M., 1988. DNA probe method for the 
detection of specific microorganisms in the soil bacterial community. Applied and Environmental Microbiology 54, 703-711.

Hopkins, D.W., Macnaughton, S.J., O'Donnell, A.G., 1991. A dispersion and differential centrifugation technique for representatively sampling microorganisms from soil. Soil Biology and Biochemistry 23, 217-225.

Hugenholtz, P., Goebel, B.M., Pace, N.R., 1998. Impact of culture-independent studies on the emerging phylogenetic view of bacterial diversity. Journal of Bacteriology $180,4765-4774$.

Hurt, R.A., Qui, X., Wu, L., Roh, Y., Palumnbo, A.V., Tiedje, J.M., Zhou, J., 2001. Simultaneous recovery of RNA and DNA from soils and sediments. Applied and Environmental Microbiology 67, 4495-4503.

Janssen, P.H., Yates, P.S., Grinton, B.E., Taylor, P.M., Sait, M., 2002. Improved culturability of soil bacteria and isolation in pure culture of novel members of the divisions Acidobacteria, Actinobacteria, Proteobacteria, and Verrucomicrobia. Applied and Environmental Microbiology 68, 2391-2396.

Joseph, S.J., Hugenholtz, P., Sangwan, P., Osborne, C.A., Janssen, P.H., 2003. Laboratory cultivation of widespread and previously uncultured soil bacteria. Applied and Environmental Microbiology 69, 7210-7215.

Kisand, V., Wikner, J., 2003. Combining culture-dependent and -independent methodologies for estimation of richness of estuarine bacterioplankton consuming riverine dissolved organic matter. Applied and Environmental Microbiology 69, $3607-3616$.

Lindahl, V., Bakken, L.R., 1995. Evaluation of methods for extraction of bacteria from soil. FEMS Microbiology Ecology 16, 135-142.

Lipson, D.A., Schmidt, S.K., 2004. Seasonal changes in an alpine soil bacterial community in the Colorado Rocky Mountains. Applied and Environmental Microbiology 70, 2867-2879.

Mader, P., Fliebbach, A., Dubois, D., Gunst, L., Fried, P., Niggli, U., 2002. Soil fertility and biodiversity in organic farming. Science 296, 1694-1697.

Miller, D.N., Bryant, J.E., Madsen, E.I., Ghiorse, W.C., 1999. Evaluation and optimization of DNA extraction and purification procedures for soil and sediment samples. Applied and Environmental Microbiology 65, 4715-4724.

Nichols, D., 2007. Cultivation gives context to the microbial ecologist. FEMS Microbiology Ecology 60, 351-357. 
Nocker, A., Camper, A.K., 2006. Selective removal of DNA from dead cells of mixed bacterial communities by use of ethidium monoazide. Applied and Environmental Microbiology 72, 1997-2004.

Ogram, A., Sayler, G.S., Gustin, D., Lewis, R.J., 1987. The extraction and purification of microbial DNA from sediments. Journal of Microbiological Methods 7, 57-66.

Ovreas, L., Torsvik, V., 1998. Microbial diversity and community structure in two different agricultural soil communities. Microbial Ecology 36, 303-315.

Parr, J.F., Papendick, R.I., Hornick, S.B., Meyer, R.E., 1992. Soil quality: Attributes and relationships to alternative and sustainable agriculture. American Journal of Alternative Agriculture 7, 5-11.

Prieme, A., Sitaula, J.I.B., Klemedtsson, A.K., Bakken, L.R., 1996. Extraction of methane-oxidizing bacteria from soil particles. FEMS Microbiology Ecology 21, 59-68.

Ritz, K., 2007. The plate debate: Culturable communities have no utility in contemporary environmental microbial ecology. FEMS Microbiology Ecology 60, 358-362.

Sangwan, P., Kovac, S., Davis, K.E.R., Sait, M., Janssen, P.H., 2005. Detection and cultivation of soil Verrucomicrobia. Applied and Environmental Microbiology $71,8402-8410$.

Schoenborn, L., Yates, P.S., Grinton, B.E., Hugenholtz, P., Janssen, P.H., 2004. Liquid serial dilution is inferior to solid media for isolation of cultures representative of the phylum-level diversity of soil bacteria. Applied and Environmental Microbiology 70, 4363-4366.

Steffan, R.J., Goksoyr, J., Bej, A.K., Atlas, R.M., 1988. Recovery of DNA from soils and sediments. Applied and Environmental Microbiology 54, 2908-2915.

Stevenson, B.S., Eichorst, S.A., Wertz, J.T., Schmidt, T.M., Breznak, J.A., 2004. New strategies for cultivation and detection of previously uncultured microbes. Applied and Environmental Microbiology 70, 4748-4755.

Teske, A., Sigalevich, P., Cohen, Y., Muyzer, G., 1996. Molecular identification of bacteria from a co-culture by denaturing gradient gel electrophoresis of $16 \mathrm{~S}$ ribosomal DNA fragments as a tool for isolation in pure cultures. Applied and Environmental Microbiology 62, 4210-4215.

Tiedje, J.M., Asuming-Brempong, S., Nusslein, K., Marsh, T.L., Flynn, S.J., 1999. Opening the black box of soil microbial diversity. Applied Soil Ecology 13, 109122. 
Torsvik, V.L., Goksoyr, J., 1978. Determination of bacterial DNA in soil. Soil Biology and Biochemistry 6, 7-12.

Ward, N., 2006. New directions and interactions in metagenomics research. FEMS Microbiology Ecology 55, 331-338.

Zhou, J., Bruns, M.A., Tiedje, J.M., 1996. DNA recovery from soils of diverse composition. Applied and Environmental Microbiology 62, 316-322. 


\title{
Chapter 1: DGGE Fingerprinting of Culturable Soil Bacterial Communities Complements Culture-independent Analysis
}

\begin{abstract}
Culture-dependent DGGE (CD DGGE) fingerprinting of the 16S rRNA gene was used to characterize mixed soil bacterial communities recovered on agar plates. Using R2A agar as a growth medium, CD DGGE analysis resulted in clear banding patterns of sufficient complexity (16-32 major bands) and reproducibility to investigate differences in bacterial communities in a silt loam soil. Replicate CD DGGE profiles from plates inoculated with less-dilute samples $\left(10^{-3}\right)$ had a higher band count and were more similar $(72-77 \%)$ than profiles from more-dilute samples (51-61\%). Different culture media and incubation conditions resulted in distinct community fingerprints and increased the cumulative number of unique bands detected. When CD DGGE fingerprints were compared to profiles constructed from $16 \mathrm{~S}$ rRNA genes obtained from cultureindependent clone libraries (CB DGGE profiles) 34\% of the bands were unique to the culture-dependent profiles, $32 \%$ were unique to the culture-independent profiles and 34\% were found in both communities. These data demonstrate that culture-independent DGGE profiles were supplemented by the distinct bands detected in culture-dependent profiles. CD DGGE can be a useful technique to follow the dynamics of distinct culturable fractions of the soil bacterial community.
\end{abstract}

Keywords: Culturable bacteria, DGGE, Plate wash, Bacterial community structure, Culture-dependent, Culture-independent. 


\section{Introduction}

A current paradigm in soil microbiology states that bacterial communities are highly diverse and only a small percentage of environmental bacteria can be isolated in pure culture using standard laboratory media (Janssen et al., 2002). As a result, various non-culturing methodologies that depend on nucleic acid extraction and gene amplification have superceded the isolation and identification of bacteria growing on agar plates and have become the preferred approach to the study of population dynamics and genetic diversity of soil microbial communities (Hugenholtz et al., 1998; Ellis et al., 2003). However, recent studies suggest that culture-dependent and culture-independent methods each recover and resolve distinct soil bacteria, which suggests that a suitable combination of these approaches would be useful to obtain a more comprehensive overview of the soil community. In general, culture-based methods better represent copiotrophs including high GC gram-positive bacteria, whereas culture-independent methods provide better profiles of difficult-to-culture but widespread genera such as Acidobacteria and Verrucomicrobia (Barns et al., 1999; Smit et al., 2001; Lipson and Schmidt, 2004). Since many culturable bacteria exhibit fast growth rates and larger cell sizes (Bakken and Olsen, 1987; Bakken 1997), it is probable they also exhibit more shortterm variation in community structure than slow-growing, difficult-to-culture bacteria. Ellis et al. (2003) have argued that culturable bacteria are important to soil ecosystem functions because of their higher total biomass and metabolic activity. Therefore, culturable bacteria may provide an ecologically-relevant complement to culture- 
independent community characterizations and serve as responsive indicators of physical, chemical, and biological changes in the soil environment.

Significant impediments to routine characterization of culturable bacterial communities include isolation and identification of representative pure culture collections from many individual soil samples. I have approached this problem by pooling the bacterial cells growing on individual agar plates. Total DNA was extracted from this culture-dependent "community", followed by polymerase chain reaction (PCR) amplification of the 16S rDNA gene, and development of a community fingerprint using denaturing gradient gel electrophoresis. Culture-dependent DGGE (CD DGGE) is complementary to the culture-independent DGGE methodology first proposed by Muyzer et al. (1993) and since widely employed to investigate the dynamics of soil microbial communities in relation to changing environmental factors (Muyzer and Smalla, 1998; Øvreås and Torsvik, 1998; Bruns et al., 1999; Smalla et al., 2001; McCaig et al., 2001; Girvan et al., 2003; Nicol et al., 2003; Salles et al., 2004).

The utility of CD DGGE for soil bacterial community characterization has not been systematically explored. Duineveld et al. (1998) and Ellis et al. (2003) previously used both culture-independent and CD DGGE to compare bacterial communities recovered from the rhizosphere of potted chrysanthemums and metal-contaminated soils, respectively. The two methods produced dissimilar community fingerprints; however, variable results obtained in the CD DGGE profiles suggested the need for better characterization and standardization of the technique.

The objectives of this study were to: 1) compare and contrast CD DGGE profiles with DGGE fingerprints constructed from 16S rRNA genes obtained from culture- 
independent clone libraries, and 2) evaluate the complexity and reproducibility of DGGE fingerprints of the $16 \mathrm{~S}$ rRNA genes from bacterial communities grown on agar plates. The results indicate acceptable reproducibility with the CD DGGE method and the ability to discern statistical differences between bacterial communities in different soil samples. I also demonstrate that by combining soil pre-treatments, incubation conditions, and various culture media, it was possible to resolve unique DGGE bands that were not resolved in culture-independent profiles.

\section{Materials and Methods}

\section{$\underline{\text { Soil sampling and experimental design }}$}

Soil samples were collected three times in June 2004, February 2005 and August 2005 from market garden plots at the West Virginia University (WVU) Organic Research Farm farm located in Morgantown, West Virginia, USA (39 $39^{\prime} 0.18^{\prime \prime} \mathrm{N} ; 79^{\circ}$ 56' 11.6" W). Four studies were conducted to address various technical questions about the CD DGGE procedure. Details of the studies conducted, the experimental design, and sampling strategy are presented in Table 1.1. Soils on the farm are Dormont and Guernsy silt loams: fine loamy, mixed, superactive, mesic, Oxyaquic Hapludalfs (Wright et al., 1982).

\section{Culture-dependent bacterial communities}

Twenty grams (dry weight) of composite soil samples from each plot were placed in sterile Waring blenders and agitated for one minute at high speed (3x with intermittent 
cooling on ice) in $180 \mathrm{ml}$ of sterile Winogradsky's salts solution (WSS; Zuberer, 1994). Blended suspensions were serially diluted in sterile WSS prior to inoculation $(100 \mu l)$ by spread plating onto 4 replicate agar plates. The media used included R2A agar, Tryptic Soy agar, Pseudomonas isolation agar (Difco, Detroit, MI), and Oil agar prepared as described by Sexstone and Atlas (1977). Unless otherwise noted, 1,000-fold $\left(10^{-3}\right)$ diluted soil was routinely used to obtain heterotrophic soil bacterial communities grown on agar plates and incubated aerobically for two weeks at $25^{\circ} \mathrm{C}$ (Figure 1.1). In study 4 , (Table 1.1, Figure 1.4), plates were incubated anaerobically and/or the diluted soil was heat shocked $\left(80^{\circ} \mathrm{C}\right.$ for $\left.15 \mathrm{~min}\right)$ prior to inoculation of the agar plates.

Culture-dependent DNA extraction and PCR amplification of the V3 region of the $16 \mathrm{~S}$ $\underline{\text { rRNA gene }}$

Cultured cells were washed sequentially from four replicate plates using WSS (4 ml) and a sterile disposable inoculating loop. The resulting cell suspensions were vortexed and frozen $\left(-20^{\circ} \mathrm{C}\right)$. DNA was extracted from aliquots of each thawed cell suspension $(1.8 \mathrm{ml})$ using the MoBio Microbial DNA extraction kit (MoBio Labs, Carlsbad, CA). The variable V3 region of the 16S rRNA gene from the domain Eubacteria was amplified using the PRBA338F primer with a GC clamp (5'ACTCCTACGGGAGGCAGCAG-3') and the PRUN518R primer (5'ATTACCGCGGCTGCTGG). The final 50- $\mu 1$ reaction mixture contained $1 \times$ PCR buffer (Promega, Madison, WI), $3.2 \mathrm{mM}$ of $\mathrm{MgCl}_{2}, 0.8 \mathrm{mM}$ of a mixture of deoxynucleotide triphosphates (Promega), $0.2 \%$ bovine serum albumin, $0.5 \mu \mathrm{M}$ (each) of the forward and reverse primers (Integrated DNA Technologies, San Diego, CA), 2.5 units of Taq DNA 
polymerase (Promega), and 50-200 ng of template DNA. The PCR protocol included a five-minute initial denaturation at $94^{\circ} \mathrm{C}, 30$ cycles of $92^{\circ} \mathrm{C}$ for 30 seconds, $55^{\circ} \mathrm{C}$ for 30 seconds, and $72^{\circ} \mathrm{C}$ for 30 seconds, followed by 7 minutes at $72^{\circ} \mathrm{C}$. PCR products were cleaned and concentrated using QIAquick PCR Purification Kit (Qiagen, Valencia, CA). The amount of PCR product in the samples was determined by agarose gel electrophoresis of samples and compared with a mass ladder (Fermentas Inc., Hanover, MD). Quantification of DNA in the PCR product was done by volume analysis using Quantity One Software (Biorad, Hercules, CA).

$\underline{\text { Culture-independent DGGE fingerprints derived from pooled 16S rDNA clone libraries }}$

In a preliminary study (unpublished data) I constructed conventional cultureindependent DGGE profiles by direct amplification of 16S rRNA genes from soil DNA (Muyzer et al., 1993). As observed by others, DGGE fingerprints constructed using this method had complex profiles and smeared regions that complicated the identification and scoring of bands (Øvreås and Torsvik, 1998; Nakatsu et al., 2000). Therefore, I employed an alternative culture-independent approach that allowed me to partition $16 \mathrm{~S}$ rDNA from soil by cloning PCR fragments into E. coli and then washing clones from plates in sufficient numbers to produce clear, interpretable DGGE profiles. This technique will be referred to as cloning-based DGGE (CB DGGE). An overview of the CB DGGE procedure and of the CD DGGE method are outlined in Figure 1.1.

Total soil DNA was extracted from sieved soil ( $\sim 0.5 \mathrm{~g}$ wet weight) using the MoBio Soil DNA extraction kit following the manufacturer's protocol. A Fastprep (FP120-Bio101, Savant Instruments, NY) machine was used for the bead-beating step of 
the experiment. The extracted DNA was used as a template for amplification of the $16 \mathrm{~S}$ rRNA gene using primers 27f (5' AGAGTTTGATCCTGGCTCAG-3') and 1492r (5'GGTTACCTTCTTACGACTT-3'). The final 100- $\mu$ l PCR mixture contained $1 \times$ PCR buffer (Promega), $1.8 \mathrm{mM}$ of $\mathrm{MgCl}_{2}, 200 \mu \mathrm{M}$ of a mix of deoxynucleotide triphosphates (Promega), $0.4 \%$ bovine serum albumin, $0.1 \mu \mathrm{M}$ (each) of forward and reverse primers (Integrated DNA technologies), 5 units of Taq polymerase (Promega), and $\sim 300 \mathrm{ng}$ of template DNA. The PCR protocol included 5-min initial denaturation at $94^{\circ} \mathrm{C}, 7$ cycles touchdown with annealing temperatures decreasing in one-degree increments from $61^{\circ} \mathrm{C}$ to $56^{\circ} \mathrm{C}\left(92^{\circ} \mathrm{C}\right.$ for $30 \mathrm{~s}$ (denaturation); $30 \mathrm{~s} \mathrm{(annealing);} \mathrm{and} 72^{\circ} \mathrm{C}$ for $90 \mathrm{~s}$ (elongation) for $30 \mathrm{~s}), 22$ cycles as follows $\left(92^{\circ} \mathrm{C}\right.$ for $30 \mathrm{~s}$ (denaturation); $55^{\circ} \mathrm{C}$ for $30 \mathrm{~s}$ (annealing), and $72^{\circ} \mathrm{C}$ for $90 \mathrm{~s}$ ), and $7 \mathrm{~min}$ at $72^{\circ} \mathrm{C}$. PCR products were pooled, cleaned and concentrated using QIAquick PCR Purification Kit (Qiagen). Four microliters of the cleaned PCR product $(\sim 15-20 \mathrm{ng} / \mu \mathrm{l})$ was then cloned using the Topo TA cloning kit for sequencing (Invitrogen, Carlsbad, CA). Cell suspensions were plated onto five or six Luria Broth (LB) plates with kanamycin $(50 \mu \mathrm{g} / \mathrm{ml})$. Transformed clones were washed from each plate using a total of $4 \mathrm{ml}$ of sterile WSS and a sterile disposable inoculating loop. Only positive recombinants are able to grow due to the disruption of the lethal E. coli gene $c c d B$; therefore, clones containing plasmids with no inserts are eliminated using this method (Bernard et al., 1994). The resulting cell suspensions were vortexed and frozen. Plasmid DNA was extracted from thawed aliquots of each cell suspension $(1.8 \mathrm{ml})$ using the QIAprep Spin Miniprep Kit (Qiagen). The DNA was used as a template for PCR amplification of the V3 region of the $16 \mathrm{~S}$ rRNA gene as described above. 


\section{Denaturing gradient gel electrophoresis}

Composite PCR products $(\sim 150 \mathrm{ng})$ were loaded into a polyacrylamide gel $(8 \%)$ with a $40 \%$ (16.8 $\mathrm{g}$ urea; $16 \mathrm{ml}$ formamide/100 $\mathrm{ml})$ to $60 \%(25.2 \mathrm{~g}$ urea; $24 \mathrm{ml}$ formamide $/ 100 \mathrm{ml})$ or a $40 \%-70 \%(29.4 \mathrm{~g}$ urea; $28 \mathrm{ml}$ formamide/100 ml ) denaturing gradient and electrophoresed for $14-16$ hours at $50 \mathrm{~V}$ and $60^{\circ} \mathrm{C}$ using the $\mathrm{DCode} \mathrm{TM}^{\mathrm{TM}}$ Universal Mutation Detection System (BioRad). The gel was visualized by silver staining using the protocol of Caetano-Anolles and Gresshoff (1994). The developed gel was scanned using Hewlett Packard ScanJet 7400c (Hewlett-Packard Co., Palo Alto, CA) at a resolution of $600 \mathrm{dpi}$ and saved in uncompressed TIFF format for further analysis.

\section{$\underline{\text { Statistical Analysis }}$}

Quantity One gel analysis software (BioRad) was used to analyze all DGGE gels. Band analysis was performed by setting background subtraction at 15 using the rolling disk method. Bands with intensity $<0.05$ were excluded from the analysis. Unweighted pair-group method with arithmetic mean (UPGMA) trees were generated in Quantity One based on Sorensen's similarity index. Bootstrap analysis $(1,000$ replications) was done with the DGGEStat program (Erik Van Hannen; http://ddgehelp.blogspot.com). Similarity matrices were calculated using Sorensen's index, and analysis of similarity (ANOSIM) was used to determine significant differences between DGGE banding profiles (R package Vegan; Oksanen, 2005). In ANOSIM, an R value greater than 0 indicates that the DGGE profiles between treatment groups are more dissimilar than profiles within groups. P values indicate the level of significance (Rees et al., 2004). Finally, the numbers of bands in each DGGE profile were compared using a 
one-way Analysis of Variance (ANOVA) and students t-test. Statistical analyses were done in R (R Core Development Team, 2004).

\section{Results}

CD DGGE analysis of bacterial communities from R2A plates inoculated with different $\underline{\text { dilutions of soil }}$

CD DGGE of the 16S rRNA gene was used to compare the bacterial communities that grew on R2A plates inoculated with different soil dilutions from high- and low-input soils (Figure 1.2a). More bands generally were observed in DGGE profiles of communities from plates inoculated with more concentrated soil suspensions (Table 1.2). The $10^{-3}$ profiles had an average of eight more bands than the $10^{-6}$ profiles, although the differences were not statistically significant (ANOVA, $\mathrm{P}<0.27$ ). A greater similarity was observed between replicate DGGE profiles of bacterial communities from the $10^{-3}$ dilution $(72-77 \%)$ compared to those from the $10^{-6}$ dilution $(51-61 \%)$. There were significant differences in the DGGE profiles between the $10^{-3}$ and $10^{-6}$ dilutions $(\mathrm{R}=0.41$, $\left.\mathrm{P}<0.05^{*}\right)$, but no significant differences between the $10^{-4}$ and $10^{-5}$ dilutions $(\mathrm{R}=0.25, \mathrm{P}<$ 0.07) as determined by ANOSIM, a non-parametric multivariate test. UPGMA analysis separated bacterial communities into two major clusters (Figure 1.2b), which suggested that the soil dilution used to inoculated the plates influenced the communities growing on the agar plates more than source of the soil (high- or low-input soil). No distinct clusters differentiated the $10^{-4}$ and $10^{-5}$ communities (data not shown). There were significantly more bands in the lower region (relative front $>0.60$ ) of the DGGE gel (Figure 1.2a) in the $10^{-3}$ samples as compared to the $10^{-6}$ samples ( $\mathrm{t}$-test, $\mathrm{P}<0.002 * *$ ). 
$\underline{\text { Impact of plot variability on CD DGGE profiles of soil bacterial communities }}$

Composite soils samples (10 cores per plot) were collected from the six treatment plots at the West Virginia University Organic Research Farm ( $\mathrm{n}=3$ for low-and high-input plots). CD DGGE profiles were constructed for four replicate sub-samples from each composite soil sample using $10^{-3}$ soil dilutions and R2A media (DGGE gels not shown). Cluster analysis (UPGMA) revealed that sub-samples were more similar to each other than to samples from replicate plots (Figure 1.3). Average percent similarity between replicate sub-samples was $84 \pm 6 \%$ for the high-input soils and $85 \pm 3 \%$ for the low-input soils. Among plots, the average percent similarity was $62 \pm 6 \%$ for high-input soils and $73 \pm 5 \%$ for low-input soils. ANOSIM indicated that the differences in DGGE profiles from different plots were highly significant for both the high-input samples $(\mathrm{R}=0.99, \mathrm{P}<$ $0.001 * * *)$ and low-input samples $(\mathrm{R}=0.96, \mathrm{P}<0.001 * * *)$.

\section{Comparison of CD DGGE profiles of soil bacterial communities subjected to different} $\underline{\text { culture conditions and pretreatments }}$

A single composite soil sample obtained from one low-input plot was subjected to different pretreatments and incubation conditions. UPGMA dendrograms (Figure 1.4b) revealed two distinct clusters of CD DGGE profiles of bacterial communities grown on different media (Figure 1.4a). One cluster was composed of communities capable of growing at low-nutrient concentrations (R2A) or on complex carbon sources (Oil agar). In contrast, communities in the second cluster were defined by media selective for copiotrophic bacteria (TSA and Pseudomonas isolation agar). Overall, the average 
percent similarity between replicates was $80 \pm 8 \%$ and between media $44 \pm 13 \%$. Either five and six more bands were observed from communities grown on R2A $(27 \pm 2)$ and Oil agar (26 \pm 3$)$ than on Tryptic soy agar $(21 \pm 4)$ and Pseudomonas isolation agar $(21 \pm$ 2). ANOSIM demonstrated significant differences in the DGGE profiles as a function of media type $\left(\mathrm{R}=0.98, \mathrm{P}<0.001^{* * *}\right)$. Incubating plates under anaerobic conditions and/or heat shocking the soil resulted in distinctly different communities (ANOSIM, $\mathrm{R}=1.00, \mathrm{P}$ $<0.001^{* * *}$; Figure 1.4c,d). The percent similarity among replicates exhibited an overall average of $80 \pm 6 \%$ and clear and distinct clusters were observed based on soil pretreatment. The percent similarity among treatments was the lowest observed in this study $(29 \pm 9 \%)$ indicating distinctly different communities. More bands were observed for communities that had been incubated aerobically (19-27) than anaerobically (12-19).

\section{Comparison of CB and CD DGGE fingerprints}

Culture-independent DGGE profiles constructed using the cloning-based approach are presented in Figure 1.5. Clone libraries of 16S rRNA genes conventionally are used for phylogenetic analysis of individual isolates; however, my results suggest that cloning is also an effective way to produce culture-independent DGGE fingerprints. I refer to this approach as cloning-based DGGE (CB DGGE) to distinguish this approach from conventional culture-independent analyses based on direct extraction and amplification of bacterial DNA in soil. Methods similar to CB DGGE previously have been employed to screen clone libraries (Muyzer and Smalla, 1998) and fractionate bacterial communities in biofilms into manageable subsets (Burr, 2006) but, to my knowledge, has not been used for comparison of soil bacterial communities. 
When approximately 1000 clones were pooled for CB DGGE from high-input soils, complex profiles were observed (61 bands; Figure 1.5, Lane 1). In contrast, 77 clones from the low-input library produced 31 distinct DGGE bands (Figure 1.5, Lane 2). CB DGGE profiles were compared with composite CD DGGE profiles obtained using pooled PCR samples from separate studies previously reported in Figure 1.2 though Figure 1.4 (Table 1.1, Figure 1.5). In contrast to CB DGGE profiles, very few bands were resolved in the lower region of the CD DGGE profiles. I found that the number of bands unique to the CB DGGE decreased when communities cultured using different media and incubation conditions were included in the comparison (Table 1.1, Figure 1.6). When all the culturable communities were included in the analysis, the number of bands detected only in the CD analysis (40) was comparable to the number found only in the CB profile (37). Including CD DGGE profiles from all studies increased the number of unique resolvable bands to 116 and the number shared in both $\mathrm{CB}$ and $\mathrm{CD}$ profiles to 39 .

\section{Discussion}

DGGE fingerprinting does not provide complete coverage of soil bacterial diversity since only a limited number of bands can be resolved in any fingerprint (Muyzer and Smalla, 1998; Nikolausz et al. 2005). Culture-independent analysis theoretically should provide improved coverage of community richness due to recovery of difficult-toculture bacteria; however, factors such as DNA extraction bias and relative abundance of 16S rRNA genes in the environmental samples will affect the fingerprints obtained. The relative contribution of culturable compared with difficult-to-culture bacteria to DGGE community profiles is not commonly reported. In this study, I compared culture- 
dependent and culture-independent DGGE fingerprints of 16S rRNA genes amplified from an organic farm soil. Communities recovered from culture plates were expected to represent a minor subset of the soil bacterial population due to physical, nutritional, and competitive selection on the growth medium employed. As summarized in Figures 1.5 and 1.6, this is not entirely what I observed. Culture-independent DGGE profiles contained some unique bands that resisted denaturation, migrated to the lower region of the gel, and may represent a difficult-to-culture fraction of the soil community. However, in upper regions of the gel there always were bands unique to culture-dependent DGGE analyses, even when a single growth medium (R2A) and soil dilution $\left(10^{-3}\right)$ were employed (Analysis 1, Figure 1.6). When additional soil dilutions, soil pretreatments, culture media and culture incubation conditions were included in the analyses, the cumulative number of bands detected increased as did the number of bands unique to the CD DGGE profiles (Analyses 2 and 3, Figure 1.6). In the final analysis 34\% of the bands were unique to the $\mathrm{CD}$ profiles, $32 \%$ were unique to the CI profiles and $34 \%$ were found in both communities. This demonstrates that culture-dependent and cultureindependent profiles each can resolve unique, diverse, and equally complex fractions of the soil bacterial community. Because culture-dependent and culture-independent methods likely profile distinct fractions of the soil bacterial community with unique ecological roles (Garland, 1999), CD DGGE can provide a useful complement to cultureindependent fingerprinting.

Other studies have reported improved assessment of soil bacterial diversity when both culture-independent and culture-dependent methods are used in combination (Teske et al. 1996; Kisand and Wikner, 2003; Lipson and Schmidt, 2004; Aislabie et al., 2006). 
In these studies, community diversity was determined from identification of cultured bacterial isolates and sequencing of cloned 16S rRNA genes amplified from soil community DNA (Dunbar et al. 1999; Lipson and Schmidt, 2004; Kisand and Wikner, 2003). This approach is informative, but not always efficient for routine studies that involve the processing of large numbers of soil samples. Molecular fingerprinting techniques such as DGGE remain one of the best ways to rapidly explore the diversity and dynamics of soil bacterial communities. If more detailed phylogenetic information is required, DGGE offers the advantage that individual bands can be excised, cloned and sequenced (Sekiguchi et al., 2002), although methodological difficulties such as comigration of bands with similar sequences (Gafan and Spratt, 2005), multiple bands from identical sequences (Nikolausz et al., 2005), formation of chimeric and heteroduplex molecules (Muyzer and Smalla, 1998) and limited phylogentic information from sequenced bands (Muyzer and Smalla, 1998) must be taken in to account.

Previous studies suggested that CD DGGE profiles of bacterial communities from culture plates are too variable for rigorous analyses of differences among soil treatments (Duineveld et al. 1998; Ellis et al. 2003). In the present study, I evaluated the effects of dilution, replication, and culture conditions on the complexity and reproducibility of CD DGGE fingerprints. Overall, the CD DGGE gels showed clear banding patterns of sufficient complexity to investigate differences in soil microbial communities. ANOSIMS demonstrated that DGGE profiles from replicate sub-samples of soils from different plots were significantly more similar than profiles between different plots, a prerequisite if the method is to be used for meaningful comparisons of bacterial communities from different soil samples. 
CD DGGE profiles from different soil dilutions demonstrated that the number of bands decreased and the structure of the bacterial communities shifted with dilution. Similar results have been observed using liquid cultures (Santegoeds et al., 1996; Jackson et al., 1998; Franklin et al., 2001), but are not commonly reported for growth on solid media. Replicate CD DGGE profiles from the least dilute plates were more similar (72-77\%) than those from the most dilute plates (51-61\%). Based on these results and those reported above, I recommend using a less-dilute sample $\left(10^{-3}\right)$ to achieve a higher band count and less variation between replicate samples if only a single dilution and medium are employed. If more comprehensive profiles are desired, it is advantageous to characterize communities from different dilution plates simultaneously.

Recent advances in cultivation methods promise improved isolation of difficultto-culture soil bacteria and a narrowing of the gap between taxa recovered using culturedependent and culture-independent approaches (Janssen et al., 2002; Joseph et al., 2003; Schoenborn et al., 2004; Stevenson et al., 2004; Davis et al., 2005; Tamaki et al., 2005). Previous studies reporting the diversity of culturable bacteria on solid media generally have relied on the use of highly dilute soils as inocula using the classical spread-plate method (Zuberer, 1994). The usual objective is to obtain a "countable plate" containing between 30 and 300 well-separated colonies in order to facilitate picking individual isolates in pure culture. Therefore, less-diluted samples with colonies too numerous to enumerate accurately are normally discarded without further evaluation. This practice excludes examination of culturable bacteria that are lost through dilution (Button, 1993) or bacteria that exploit unique niches created by the growth of other bacteria on crowded plates (Kassen and Rainey, 2004). For example, Dedysh et al. (2006) reported enhanced 
detection of Acidobacteria and Planctomycetes in co-cultures compared with pure cultures. They suggested that a method that includes mixed cultures may be superior to the "single-colony pick-up" approach for isolation of difficult-to-culture bacteria. In this study, I observed a higher band count on plates inoculated with less-dilute soils. Specifically notable was the collection of bands in the bottom region of the $10^{-3}$ profiles. Although the phylogenetic affiliations of individual bands were not assigned by sequence analysis, the absence of these bands on the countable $\left(10^{-6}\right)$ plate suggests that unique bacteria are lost under less crowded growth conditions.

\section{Conclusions}

Although bacterial growth under different metabolic conditions or on different types of solid media is inherently selective, the ability to partition complex soil bacterial communities into definable physiological subsets using a variety of isolation media and incubation conditions should be viewed as a potential strength of the CD DGGE technique. My results suggest that CD DGGE detected unique 16S rRNA genes that were not represented by CB DGGE profiles of a large clone library ( 1000 clones). Garland (1999) suggested the need to better understand the ecological interactions that exist between culturable and non-culturable types of bacteria because it is likely that changes in one fraction of a community lead to changes in others. Historically, culturedependent methods such as community-level physiological profiling (CLPP) and plate counts have proven useful models for screening relative shifts in the functional diversity and size of microbial communities, conducting exploratory investigations, and generating hypothesis. My results suggest CD DGGE is sufficiently reproducible to investigate the 
dynamics of culturable bacterial communities. Compared with culture-independent methods, CD DGGE requires more time for sample preparation. However, the ability of CD DGGE to partition soil bacteria into distinct subsets based on their growth characteristics provides a potential means to identify biological and environmental factors that influence bacterial community structure (Aislabie et al., 2006; Langenheder et al., 2006).

\section{References Cited}

Aislabie, J.M., Chhour, K., Saul, D.J., Miyauchi, S., Ayton, J., Paetzold, R.F. Balks, M.R., 2006. Dominant bacteria in soils of Marble Point and Wright Valley, Victoria Land, Antarctica. Soil Biology \& Biochemistry 38, 3041-3056.

Bakken, L. R., 1997. Culturable and nonculturable bacteria in soil. In: van Elsas, J. D., Trevors, T. J. and Wellington, E. M. H. (Eds.), Modern Soil Microbiology. Marcel Dekker, New York, pp. 47-61.

Bakken, L. R., Olsen, R. A., 1987. The relationship between cell size and viability of soil bacteria. Microbial Ecology 13, 103-114.

Barns, S. M., Takala, S.L., Kuske, C.R. 1999. Wide distribution and diversity of members of the bacterial kingdom Acidobacterium in the environment. Applied and Environmental Microbiology 65, 1731-1737.

Bernard, P., Gabant, P., Bhassi, E.M., Couturier, M., 1994. Positive-selection vectors using the F plasmid $c c d \mathrm{~B}$ killer gene. Gene 148, 71-74.

Bruns, M. A., Stephen, J. R., Kowalchuk, G. A., Prosser, J. I., Paul, E. A., 1999. Comparative diversity of ammonia oxidizer 16S rRNA gene sequences in native, tilled, and successional soils. Applied and Environmental Microbiology 65, 29943000 .

Burr, M.D., Clark, S.J, Spear, C.R., Camper, A.K., 2006. Denaturing gradient gel electrophoresis can rapidly display the bacterial diversity contained in $16 \mathrm{~S}$ rRNA clone libraries. Microbial Ecology, 51, 479-486.

Button, D. K., Schut, F., Quang, P., Martin, R., Robertson, B. R., 1993. Viability and isolation of marine bacteria by dilution culture: Theory, procedures, and initial 
results. Applied and Environmental Microbiology 59, 881-891.

Caetano-Anolles, G., Gresshoff, P. M., 1994. Staining nucleic acids with silver: An alternative to radioisotopic and fluorescent labeling. Promega Notes 45, 13-18.

Davis, K. E. R., Joseph, S. J., Janssen, P. H., 2005. Effects of growth medium, inoculum size, and incubation time on culturability and isolation of soil bacteria. Applied and Environmental Microbiology 71, 826-834

Dedysh, S. N., Pankratov, T. A., Belova, S. E., Kulichevskaya, I. S., Liesack, W., 2006. Phylogenetic analysis and in situ identification of Bacteria community composition in an acidic Sphagnum peat bog. Applied and Environmental Microbiology 72, 2110-2117.

Duineveld, B. M., Rosado, A. S., van Elsas, J. D., van Veen, J. A., 1998. Analysis of the dynamics of bacterial communities in the rhizosphere of the chrysanthemum via denaturing gradient gel electrophoresis and substrate utilization patterns. Applied and Environmental Microbiology 64, 4950-4957.

Dunbar, J., Takala, S., Barns, S. M., Davis, J. A., Kuske, C. R., 1999. Levels of bacterial community diversity in four arid soils compared by cultivation and 16S rRNA gene cloning. Applied and Environmental Microbiology 65, 1662-1669.

Ellis, R. J., Morgan, P., Weightman, A. J., Fry, J. C., 2003. Cultivation-dependent and independent approaches for determining bacterial diversity in heavy-metalcontaminated soil. Applied and Environmental Microbiology 69, 3223-3230.

Franklin, R. B., Garland, J. L., Bolster, C. H., Mills, A. L., 2001. Impact of dilution on microbial community structure and functional potential: Comparison of numerical simulations and batch culture experiments. Applied and Environmental Microbiology 67, 702-712.

Gafan, G.P., Spratt, D.A., 2005. Denaturing gradient gel electrophoresis gel expansion (DGGEGE) - an attempt to resolve the limitations of co-migration in the DGGE of complex polymicrobial communities. FEMS Microbiology Letters 253, 303307.

Garland, J.L., 1999. Potential and limitations of BIOLOG for microbial community analysis, in: Bell, C.R., Brylinsky, M., Johnson-Green, P. (Eds.), Microbial Biosystems: New Frontiers, Proceedings of the $8^{\text {th }}$ International Symposium on Microbial Ecology. Atlantic Canada Society for Microbial Ecology, Halifax, Canada, pp. 1-7.

Girvan, M. S., Bullimore, J., Pretty, J. N., Osborn, A. M., Ball, A. S., 2003. Soil type is the primary determinant of the composition of the total and active bacterial communities in arable soils. Applied and Environmental Microbiology 69, 1800- 
1809.

Hugenholtz, P., Goebel, B.M., Pace, N.R., 1998. Impact of culture-independent studies on the emerging phylogenetic view of bacterial diversity. Journal of Bacteriology $180,4765-4774$.

Jackson, C. R., Roden, E. E., Churchill, P. F., 1998. Changes in bacterial species composition in enrichment cultures with various dilutions of inoculum as monitored by denaturing gradient gel electrophoresis. Applied and Environmental Microbiology 64, 5046-5048.

Janssen, P. H., Yates, P. S., Grinton, B. E., Taylor, P. M., Sait, M., 2002. Improved culturability of soil bacteria and isolation in pure culture of novel members of the divisions Acidobacteria, Actinobacteria, Proteobacteria, and Verrucomicrobia. Applied and Environmental Microbiology 68, 2391-2396.

Joseph, S. J., Hugenholtz, P., Sangwan, P., Osborne, C. A., Janssen, P. H., 2003. Laboratory cultivation of widespread and previously uncultured soil bacteria. Applied and Environmental Microbiology 69, 7210-7215.

Kaiser, J., Proffitt, F., 2004. Wounding earth's fragile skin. Science 304, 1616-1618.

Kassen, R., Rainey, P.B., 2004. The ecology and genetics of microbial diversity. Annual Review of Microbiology 58, 207-231.

Kisand, V., Wikner, J., 2003. Combining culture-dependent and -independent methodologies for estimation of richness of estuarine bacterioplankton consuming riverine dissolved organic matter. Applied and Environmental Microbiology 69, 3607-3616.

Langenheder, S., Lindstrom, E. S., Tranvik, L. J. 2006. Structure and function of bacterial communities emerging from different sources under identical conditions. Applied and Environmental Microbiology 72, 212-220.

Lipson, D. A., Schmidt, S. K., 2004. Seasonal changes in an alpine soil bacterial community in the Colorado Rocky Mountains. Applied and Environmental Microbiology 70, 2867-2879.

McCaig, A. E., Glover, L. A., Prosser, J. I., 2001. Numerical analysis of grassland bacterial community structure under different land management regimens by using $16 \mathrm{~S}$ ribosomal DNA sequence data and denaturing gradient gel electrophoresis banding patterns. Applied and Environmental Microbiology 67, 4554-4559.

Muyzer, G., de Waal, E. C., Uitterlinden, A. G., 1993. Profiling of complex microbial populations by denaturing gradient gel electrophoresis analysis of polymerase 
chain reaction-amplified genes coding for 16S rRNA. Applied and Environmental Microbiology 59, 695-700.

Muyzer, G., Smalla, K., 1998. Application of denaturing gradient gel electrophoresis (DGGE) and temperature gradient gel electrophoresis (TGGE) in microbial ecology, Antonie van Leeuwenhoek 73,127 - 141.

Nakatsu, C. H., Torsvik, V.V, Øvreås, L., 2000. Soil community analysis using DGGE of $16 \mathrm{~S}$ rDNA polymerase chain reaction products. Soil Science Society of America Journal 64, 1382-1388.

Nicol, G. W., Glover, L. A., Prosser, J. I., 2003. Spatial analysis of archaeal community structure in grassland soil. Applied and Environmental Microbiology 69, 74207429.

Nikolausz, M., Sipos, R., Revesz, S., Szekely, A., Marialigeti, K., 2005. Observation of bias associated with re-amplification of DNA isolated from denaturing gradient gels. FEMS Microbiology Letters 244, 385-390.

Oksanen, J., 2005. Vegan: Community ecology package. http://cc.oulu.fi/ jarioksa/ [Online]

Øvreås, L., Torsvik, V. V., 1998. Microbial diversity and community structure in two different agricultural soil communities. Microbial Ecology 36, 303-315.

R Core Development Team, 2004. R: A language and environment for statistical computing. Vienna, Austria. http://www.R-project.org

Rees, G.N., Baldwin, D.S., Watson, G.O., Perryman, S., Nielsen, D.L., 2004. Ordination and significance testing of microbial community composition derived from terminal restriction fragment length polymorphisms: Application and multivariate statistics. Antonie van Leeuwenhoek 86, 339-347.

Salles, J. F., van Veen, J. A., van Elsas, J. D., 2004. Multivariate analyses of Burkholderia species in soil: Effect of crop and land use history. Applied and Environmental Microbiology 70, 4012-4020.

Santegoeds, C. M., Nold, S. C., Ward, D. M., 1996. Denaturing gradient gel electrophoresis used to monitor the enrichment culture of aerobic chemoorganotrophic bacteria from a hot spring cyanobacterial mat. Applied and Environmental Microbiology 62, 3922-3928.

Schoenborn, L., Yates, P. S., Grinton, B. E., Hugenholtz, P., Janssen, P. H., 2004. Liquid serial dilution is inferior to solid media for isolation of cultures representative of the phylum-level diversity of soil bacteria. Applied and Environmental Microbiology 70, 4363-4366. 
Sekiguchi, H., Watanabe, M., Nakahara, T., Xu, B., Uchiyama, H. 2002. Succession of bacterial community structure along the Changjiang river determined by denaturing gradient gel electrophoresis and clone library analysis. Applied and Environmental Microbiology 68, 5142-5150.

Sexstone, A. J., Atlas, R. M., 1977. Response of microbial populations in arctic tundra soils to crude oil. Canadian Journal of Microbiology 23, 1327-1333.

Smalla, K., Wieland, G., Buchner, A., Zock, A., Parzy, J., Kaiser, S., Roskot, N., Heuer, H., Berg, G., 2001. Bulk and rhizosphere soil bacterial communities studied by denaturing gradient gel electrophoresis: Plant-dependent enrichment and seasonal shifts revealed. Applied and Environmental Microbiology 67, 4742-4751.

Smit, E., Leeflang, P., Gommans, S., van den Broek, J., van Mil, S., Wernars, K., 2001. Diversity and seasonal fluctuations of the dominant members of the bacterial soil community in a wheat field as determined by cultivation and molecular methods. Applied and Environmental Microbiology 67, 2284-2291.

Stevenson, B. S., Eichorst, S. A., Wertz, J. T., Schmidt, T. M., Breznak, J. A., 2004. New strategies for cultivation and detection of previously uncultured microbes. Applied and Environmental Microbiology 70, 4748-4755.

Tamaki, H., Sekiguchi, Y., Hanada, S., Nakamura, K., Nomura, N., Matsumura, M., Kamagata, Y., 2005. Comparative analysis of bacterial diversity in freshwater sediment of a shallow eutrophic lake by molecular and improved cultivationbased techniques. Applied and Environmental Microbiology 71, 2162-2169.

Teske, A., Wawer, C., Muyzer, G., Ramsing, NB., 1996. Distribution of sulfate-reducing bacteria in a stratified fjord (Mariager Fjord, Denmark) as evaluated by mostprobable-number counts and denaturing gradient gel electrophoresis of PCRamplified ribosomal DNA fragments. Applied and Environmental Microbiology $62,1405-1415$.

Wright, E.L., Delp, C.H., Sponaugle, K.,. Cole, C., Ammons, J.T., Gorman, J., Childs, F.D., 1982. Soil Survey of Marion and Monongalia Counties, West Virginia. U.S. Depart. of Agriculture, Soil Conservation Service.

Zuberer, D. A., 1994. Recovery and enumeration of viable bacteria. In: Weaver, R. W. (Ed.), Methods of Soil Analysis, Part 2. Microbiological and Biochemical Properties. Soil Science Society of America, Madison, Wisconsin, pp. 119-144. 
Table 1.1. Summary of studies, experimental design ${ }^{\mathrm{a}}$, and sampling strategy.

\begin{tabular}{|c|c|c|c|c|c|c|}
\hline & $\begin{array}{l}\text { Sampling } \\
\text { Date }\end{array}$ & $\begin{array}{l}\text { Crops Planted in Spring } \\
\text { Prior to Sampling }\end{array}$ & $\begin{array}{l}\text { Type of Community } \\
\text { Characterization }\end{array}$ & $\begin{array}{l}\text { Plots Sampled } \\
\text { (No. of plots) }\end{array}$ & $\begin{array}{l}\text { No. of Replicate } \\
\text { Soil Sub } \\
\text { Samples } \\
\text { Per Plot }^{\text {d }}\end{array}$ & $\begin{array}{l}\text { Lane No. in } \\
\text { Composite } \\
\text { DGGE Gel }^{\mathrm{i}} \\
\text { (Figure 1.5) }\end{array}$ \\
\hline \multirow[t]{4}{*}{$1^{\mathrm{e}}$} & Jun. 2004 & Tomatoes and Peppers & CB DGGE & High-input (4) & 1 & 1 \\
\hline & & & & Low-input (4) & 1 & 2 \\
\hline & & & CD DGGE & High-input (4) & 1 & 3 \\
\hline & & & & Low-input (4) & 1 & 4 \\
\hline \multirow[t]{2}{*}{$2^{f}$} & Feb. 2005 & Peas and Beans & $\begin{array}{l}\text { CD DGGE } \\
\text { (plot variability) }\end{array}$ & High-input (3) & 4 & 5,6 \\
\hline & & & & Low-input (3) & 4 & \\
\hline \multirow[t]{2}{*}{$3^{g}$} & Feb. 2005 & Peas and Beans & $\begin{array}{l}\text { CD DGGE } \\
\text { (dilutions) }\end{array}$ & High-input (3) & 1 & 7,8 \\
\hline & & & & Low-input (3) & 1 & \\
\hline $4^{\mathrm{h}}$ & Aug. 2005 & Tomatoes and Peppers & $\begin{array}{l}\text { CD DGGE } \\
\text { (media/pre-treatment) }\end{array}$ & Low-input (1) & $\begin{array}{l}3 \text { per media or } \\
\text { pre-treatment }\end{array}$ & $9-14$ \\
\hline
\end{tabular}


${ }^{a}$ The field experiment, which was established in 2000, is a completely randomized design with four plots (4.9 x $\left.7.6 \mathrm{~m}\right)$ per treatment. Treatments included fertility input (compost and green manure) and annual crop rotation among four plant families (Fabaceae, Solanaceae, Cucurbitaceae, and Asteraceae). High-input plots received composted dairy manure (22.4 $\mathrm{Mg} \mathrm{ha}^{-1}$ based on wet weight) applied 1-3 days prior to planting and green manure (rye and vetch) tilled into the soil 1-3 prior to planting. Low-input plots received only green manure applied as described above. Fertility treatments were applied annual since 2000 .

${ }^{\mathrm{b}}$ Culture-dependent (CD) and cloning-based (CB) denaturing gradient gel electrophoresis (DGGE). Sub-samples of bulk soils collected from each plot were processed for CB DGGE and/or CD DGGE as outlined in Figure 1.1.

${ }^{\mathrm{c}}$ Ten soil cores $(16 \mathrm{~cm}$ depth $\mathrm{x} 2 \mathrm{~cm}$ diameter) were collected from each plot at $\sim 1.5$ meter intervals along two transects at midpoint between crop rows. Soil samples were bulked, placed into plastic bags, and immediately transported back to the laboratory, where they were sieved $(<2 \mathrm{~mm})$ and stored at $4^{\circ} \mathrm{C}$ overnight.

${ }^{\mathrm{d}}$ For CB DGGE analysis soil sub-samples were composed of $\sim 0.5 \mathrm{~g}$ of bulked soil from each plot. For CD DGGE analysis sub-samples were composed of $20 \mathrm{~g}$ of the bulked soil from each plot that was processed as outlined in Figure 1.1. CD DGGE profiles presented in each lane in Figure 1.2 through Figure 1.4 were constructed from one sub-sample each.

${ }^{\mathrm{e}}$ Initial comparison of CB DGGE and CD DGGE profiles. Pooled DGGE profiles from study 1 are presented in Figure 1.5.

${ }^{\mathrm{f}}$ Effects of plot variability on CD DGGE profiles. Replicate DGGE profiles were constructed from $50 \mathrm{~g}$ sub-samples of soil from composite samples collected from each treatment plot. UPGMA dendrograms for study 3 are presented in Figure 1.3.

${ }^{g}$ Effects of soil inoculum size on CD DGGE profiles. Each sub-sample was diluted $\left(10^{-3}, 10^{-4}, 10^{-5}\right.$ and $\left.10^{-6}\right)$, and the individual dilutions were plated onto R2A agar as outlined in Figure 1.1. DGGE profiles and UPGMA dendrograms for the $10^{-3}$ and $10^{-6}$ dilutions are presented in Figure 1.2.

${ }^{\mathrm{h}}$ Effects of media and pre-treatment on CD DGGE profiles. DGGE profiles and UPGMA dendrograms for study 4 are presented in Figure 1.4.

i Composite gel with CB DGGE profiles and pooled CD DGGE profiles presented in Figure 1.5 and analyzed in Figure 1.6. 
Table 1.2. Average number of CD DGGE bands and average percent similarity in dilution study.

\begin{tabular}{lcccc}
\hline Sample & $\begin{array}{c}\text { Average no. } \\
\text { of bands }\end{array}$ & $( \pm \mathrm{SD})$ & Average percent similarity \\
& 26 & $(1.5)$ & 77.2 & $(2.41)$ \\
\hline High-input $10^{-3}$ & 26 & $(3.8)$ & 72.0 & $(11.41)$ \\
High-input $10^{-4}$ & 25 & $(5.3)$ & 67.8 & $(16.13)$ \\
High-input $10^{-5}$ & 17 & $(2.6)$ & 51.0 & $(4.98)$ \\
High-input $10^{-6}$ & 26 & $(0.6)$ & 72.1 & $(3.17)$ \\
\hline Low-input $10^{-3}$ & 18 & $(2.9)$ & 70.4 & $(9.47)$ \\
Low-input $10^{-4}$ & 26 & $(3.0)$ & 72.7 & $(9.64)$ \\
Low-input $10^{-5}$ & 19 & $(5.7)$ & 61.3 & $(8.78)$ \\
Low-input $10^{-6}$ & & & & \\
\hline
\end{tabular}

$$
{ }^{a} n=3
$$




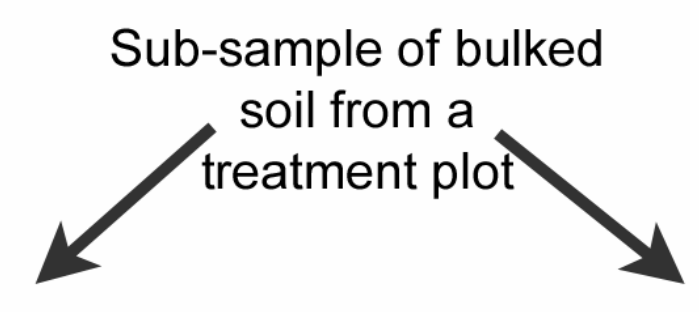

Extract soil DNA.

Disperse and dilute soil.

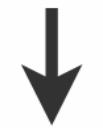

$20 \mathrm{~g} \mathrm{soil} / 180 \mathrm{ml} \mathrm{WSS}\left(10^{-1}\right)$

$1 / 10$ dilution $\left(10^{-2}\right)$

Amplify 165 rRNA genes using primers $27 \mathrm{~F}$ and $1492 \mathrm{R}$.

Clone 16S rRNA genes into pCR 4-TOPO.

Transform One Shot

TOP10 E. coli cells.

Plate cells onto LB +

kanamycin.
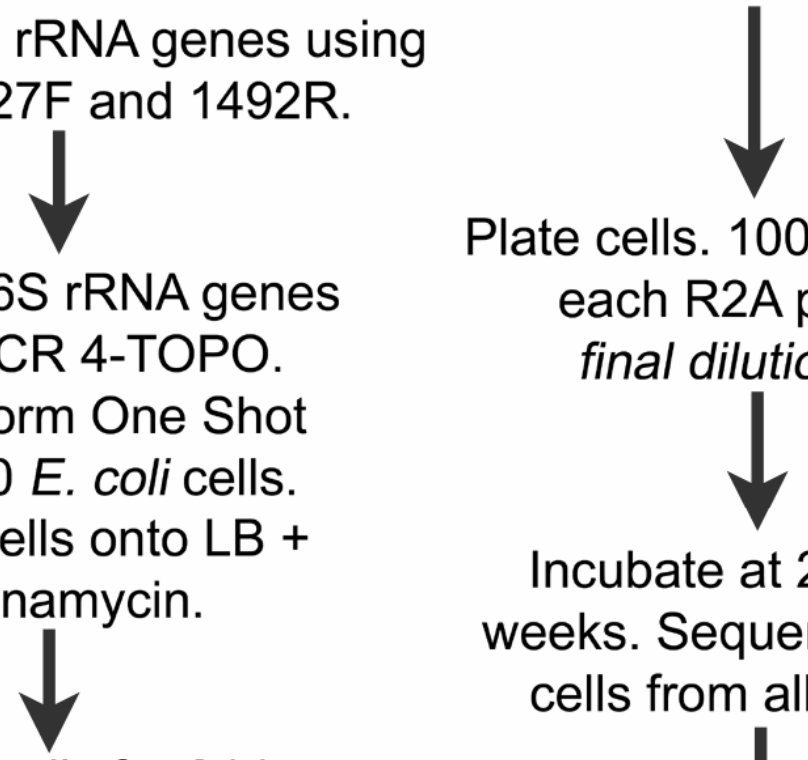

Plate cells. 100 microliter to each R2A plate (4). final dilution $-10^{-3}$

Incubate cells for $24 \mathrm{hrs}$.

Wash clones from LB plates.

Extract plasmid DNA from pooled cells.

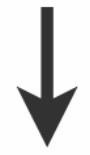

Amplify V3 of 16S rRNA gene using primers PRB338F and PRUN518R.
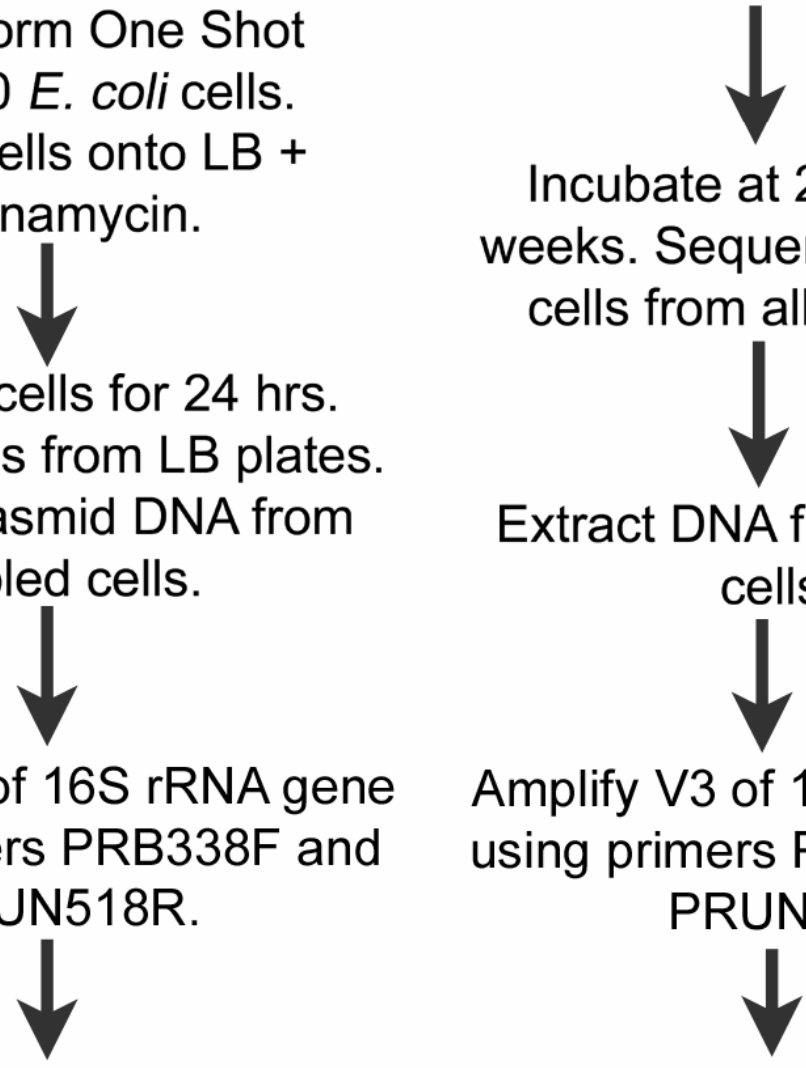

Incubate at $25^{\circ} \mathrm{C}$ for 2

weeks. Sequentially wash cells from all 4 plates.

Extract DNA from pooled cells.

Amplify V3 of 16S rRNA gene using primers PRAB338F and PRUN518R.

\section{CB DGGE}

CD DGGE 
Figure 1.1. Flowchart of protocols used to construct culture-dependent (CD DGGE) and cloning-based (CB DGGE) fingerprints of bacterial communities from organic farm soils. In study 3 , additional dilutions were used $\left(10^{-4}, 10^{-5}\right.$ and $\left.10^{-6}\right)$ to construct CD DGGE profiles. 
(a)

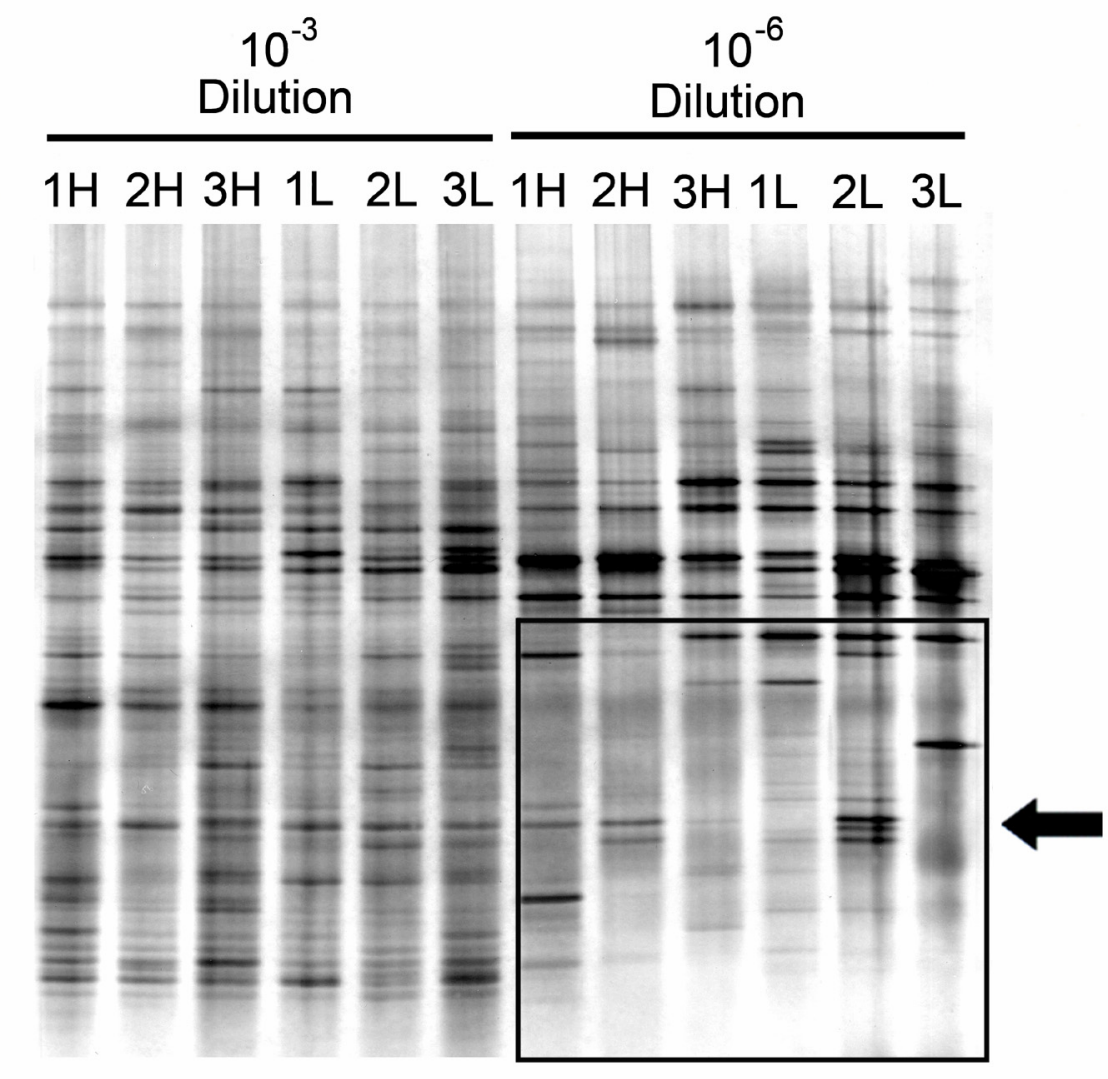

Similarity Based on Sorensen's Index

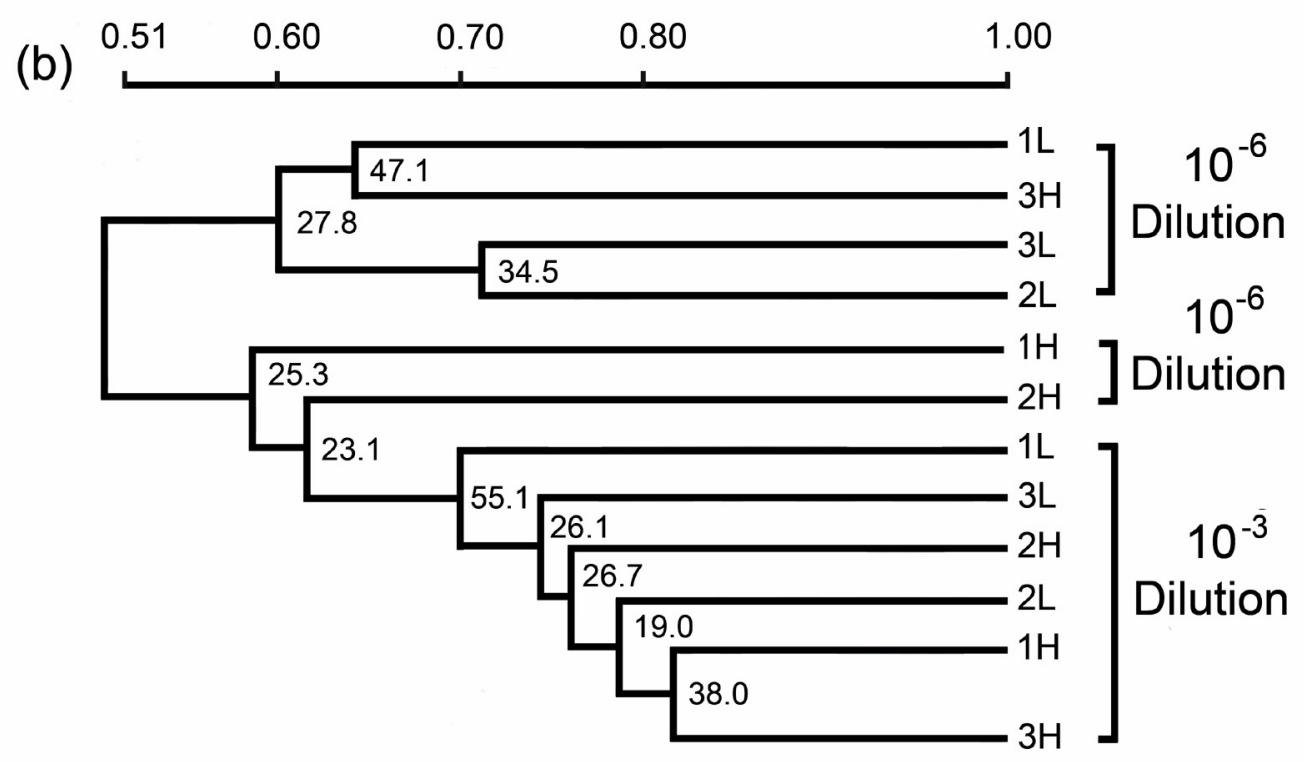


Figure 1.2. (a) CD DGGE profiles of $16 \mathrm{~S}$ rRNA genes amplified from soil bacterial communities grown on R2A media inoculated with $10^{-3}$ or $10^{-6}$ dilutions of soil from high (H) and low (L) input plots from the WVU organic research farm and incubated aerobically for 2 weeks at $25^{\circ} \mathrm{C}$. Samples were analyzed on a 40-60\% DGGE gradient for 14 hours at $50 \mathrm{~V}$. Box and arrow highlight fewer bands with relative fronts $>0.6$ in the $10^{-6}$ compared with the $10^{-3}$ dilution. (b) UPGMA dendrograms constructed using Sorensen's similarity index generated from the above DGGE profiles. Bootstrap values are given at nodes (1,000 resamplings). 
Similarity Based on Sorensen's Index

(a)

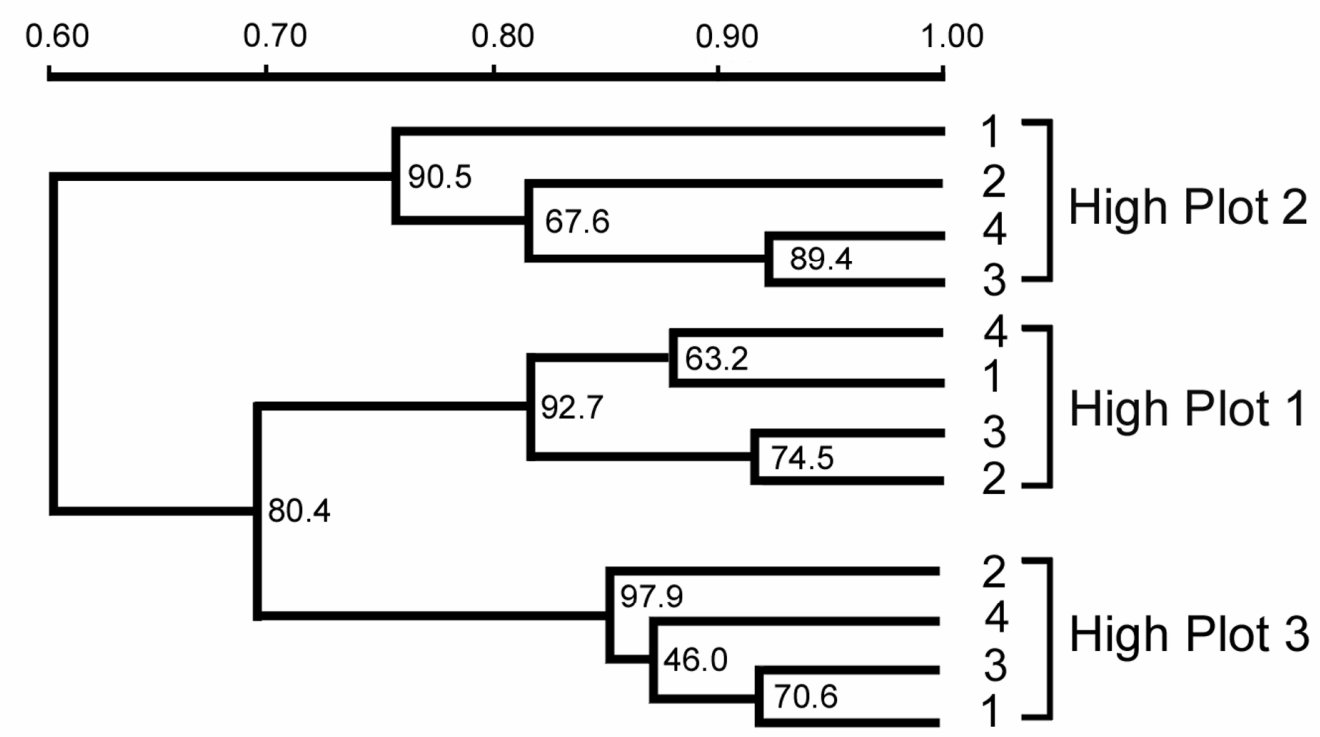

Similarity Based on Sorensen's Index

(b) $\begin{array}{rrrrrrr}0.71 & 0.75 & 0.80 & 0.85 & 0.90 & 0.95 & 1.00\end{array}$

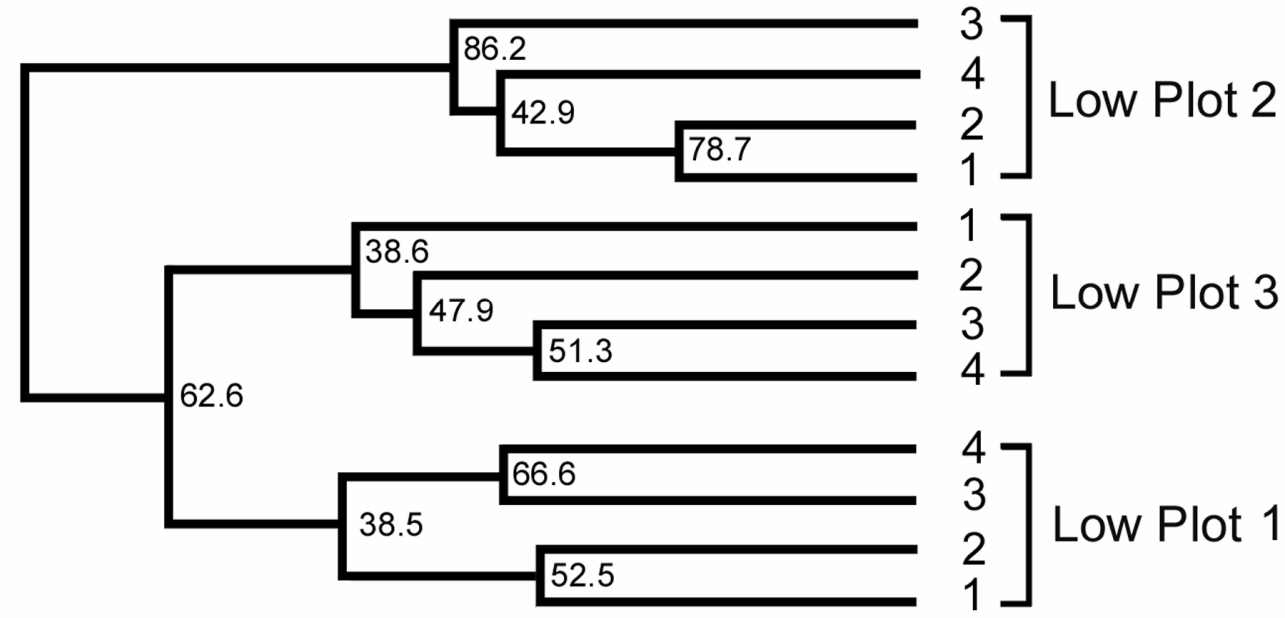


Figure 1.3. UPGMA dendrograms constructed using Sorensen's similarity index generated from DGGE profiles of bacterial communities from replicate soil sub-samples collected from (a) high and (b) low input plots at the West Virginia University organic research farm. Bootstrap values are given at nodes (1,000 resamplings). 
(a)

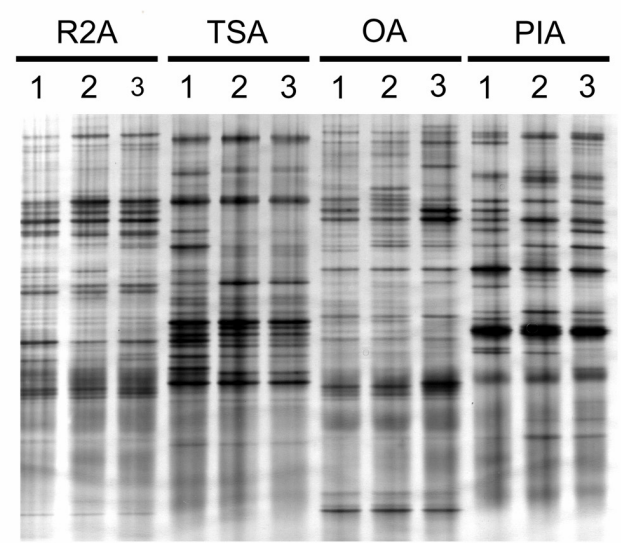

(c)

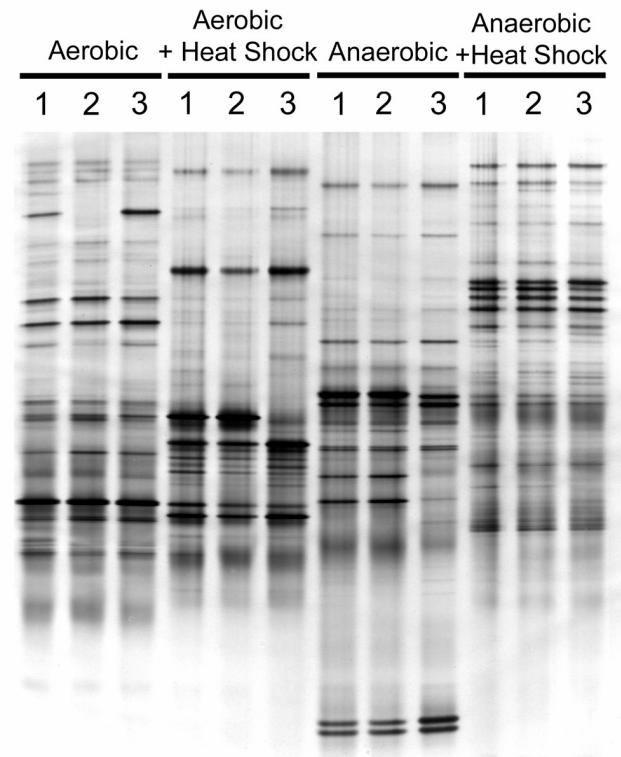

(b) Similarity Based on Sorensen's Index

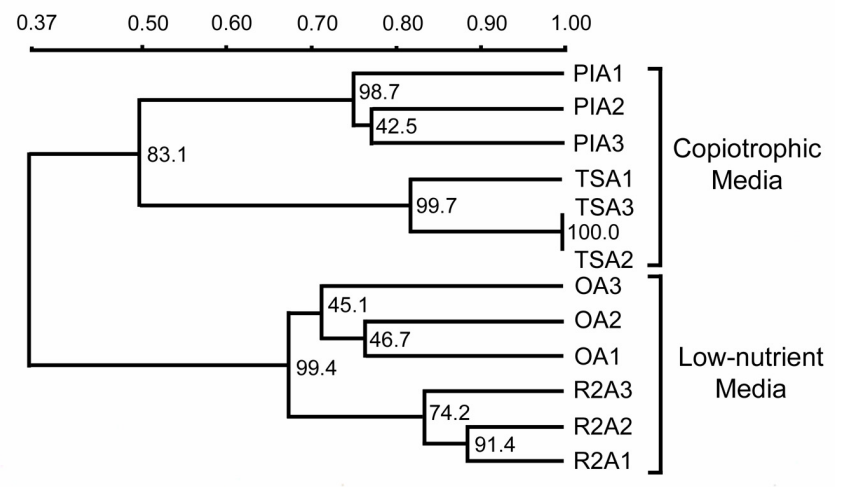

(d)

Similarity Based on Sorensen's Index

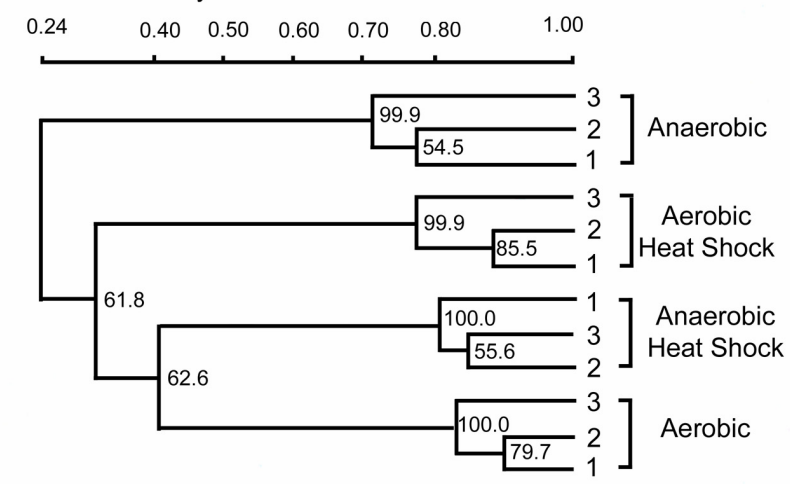


Figure 1.4. CD DGGE profiles and UPGMA dendrograms constructed using Sorensen's similarity index generated from DGGE profile from soil bacterial communities $(a, b)$ grown on four different media and $(c, d)$ subjected to different pretreatments (heat shock vs. no heat shock) and incubation conditions (aerobic vs. anaerobic) prior to plating on R2A media. Media included: R2A Agar (R2A), Tryptic Soy Agar (TSA), Oil Agar (OA) and Pseudomonas Isolation Agar (PIA). Heatshocked samples were incubated at $80^{\circ} \mathrm{C}$ for 15 minutes. Samples were run on a $40-70 \%$ DGGE gradient for 16 hours at $50 \mathrm{~V}$. Bootstrap values are given at nodes (1,000 resamplings). 


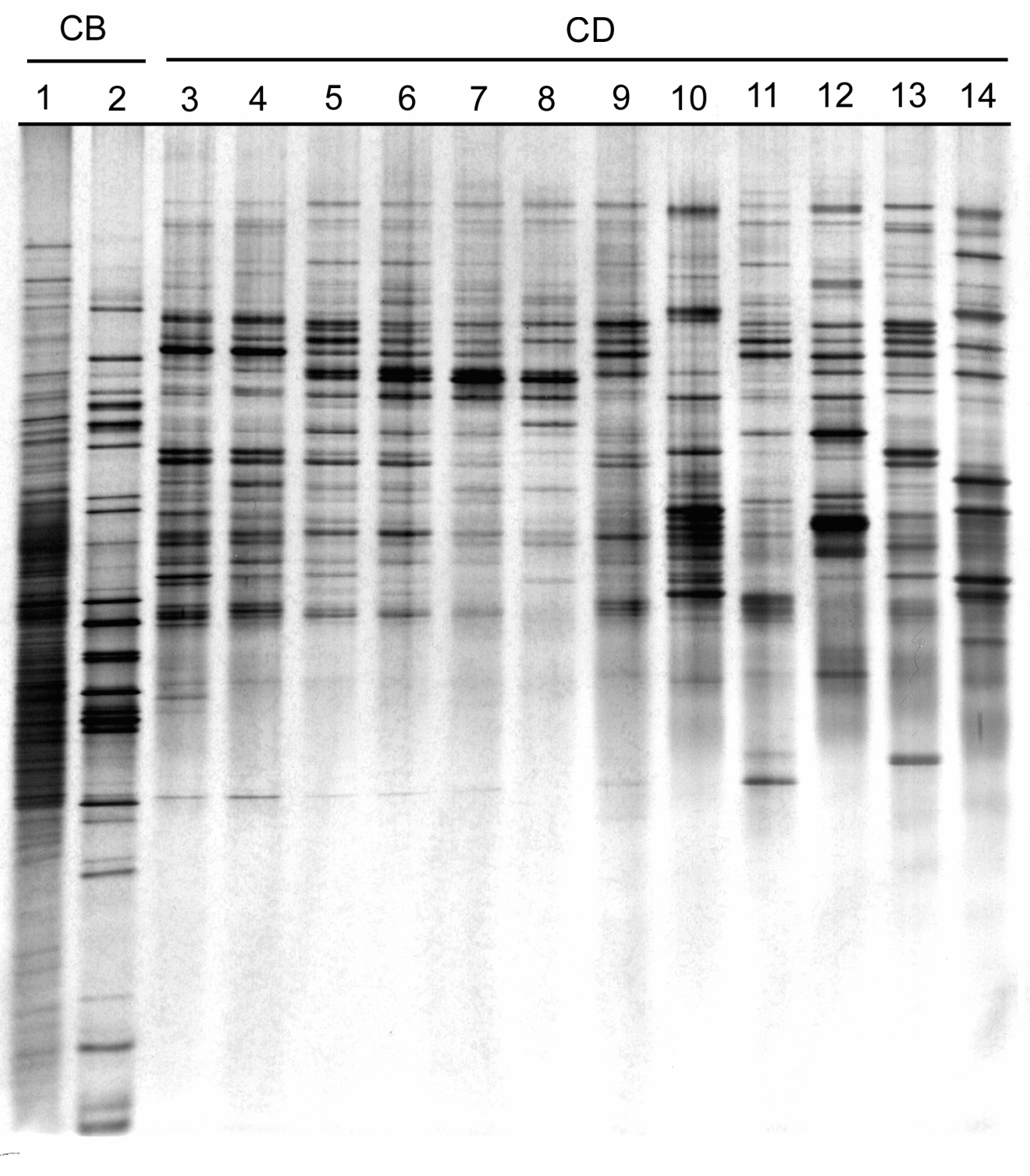


Figure 1.5. DGGE profiles of culture-independent (CB DGGE) and culture-dependent (CD DGGE) 16S rRNA genes of bacterial communities from organic farm soils. Profiles were constructed using pooled 16S rRNA genes from the studies outlined in Table 1.1. Lanes 1 and 2 represent CB DGGE profiles of clones $(\sim 1000)$ from high-input soil collected in study 1 and clones $(\sim 77)$ from low-input soil collected in study 1 , respectively. The pooled CD DGGE profiles are from: high-input plots (4) in study 1 (Lane 3); low-input plots (4) in study 1 (Lane 4); high-input plots (12) in study 2 (Lane 5); low-input plots (12) in study 2 (Lane 6); high- and low-input dilution plates $10^{-3}$ and $10^{-4}(12)$ in study 3 (Lane 7); high- and low-input dilution plates $10^{-5}$ and $10^{-6}(12)$ in study 3 (Lane 8); R2A agar (3) in study 4 (Lane 9); Tryptic Soy Agar (3) in study 4 (Lane 10); Oil Agar (3) in study 4 (Lane 11); Pseudomonas Isolation Agar (3) in study 4 (Lane 12); anaerobically incubated plates with and without heat shock (6) in study 4 (Lane 13); and aerobically incubated plates with and without heat shock (6) in study 4 (Lane 14). Numbers is parentheses indicate the number of sub-samples included in each pooled profile. 


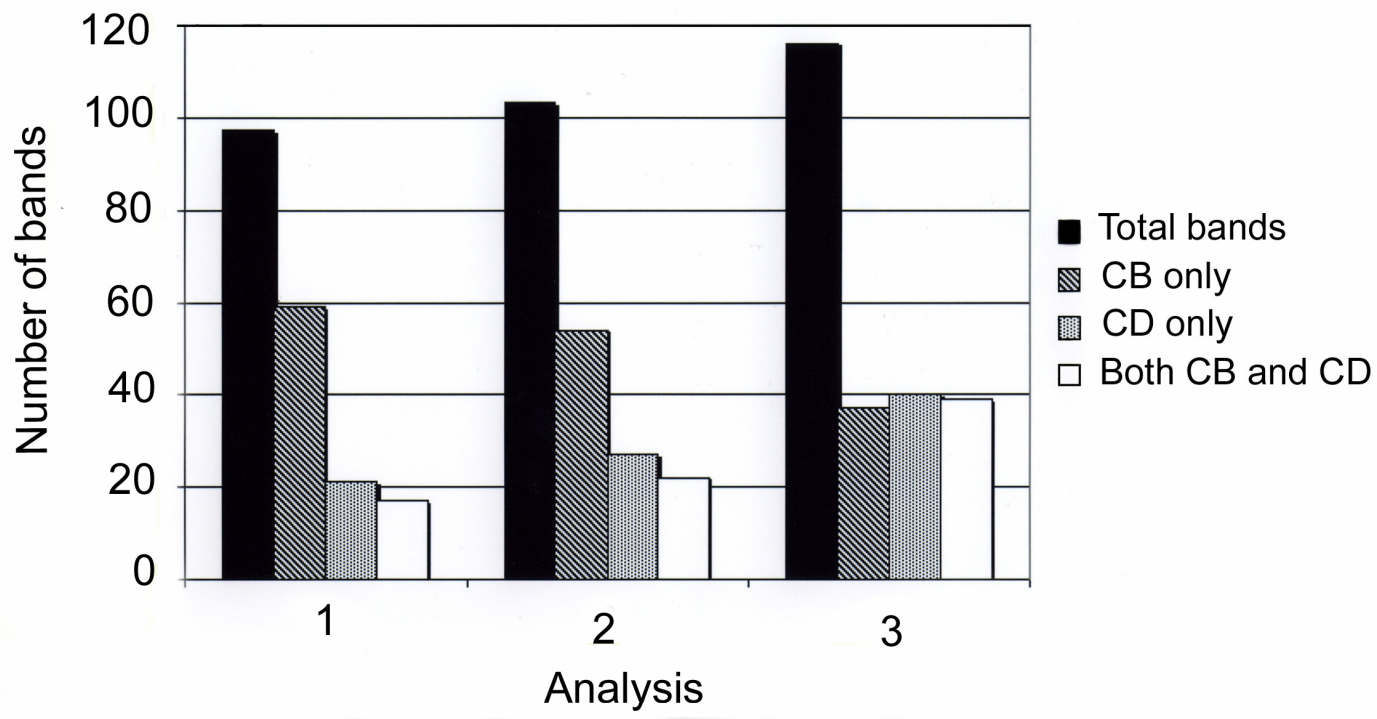

Figure 1.6. Number of bands found in the composite DGGE gel (Figure 1.5) when different combinations of culture-dependent profiles were included in the analysis. Analysis 1, lanes 1-4; Analysis 2, lanes 1-8; Analysis 3, profiles from all lanes. Samples included in each lane are defined in Table 1. 


\title{
Chapter 2: Small-Celled Bacteria from Organic Farm Soils Show Phylogenetic Similarities to Diazotrophs and Bacteria that Favor Inter- and Intracellular Habitats
}

\begin{abstract}
The numerically dominant bacteria in soil have cell diameters $<0.5 \mu \mathrm{m}$; however, the phylogenetic identities of these organisms remain largely unknown, in part because small-celled bacteria are rarely grown in culture. In the present study, bacteria from filtered $(<0.45 \mu \mathrm{m})$ and nonfiltered slurries of organic farm soils were cultivated on R2A agar. The majority of colonies from the filtered samples were recovered from the $10^{-3}$ and $10^{-4}$ dilutions of compost-amended soils after incubation at $25^{\circ} \mathrm{C}$ for up to one month. To avoid a loss of diversity associated with sub-culturing, the colonies from primary isolation plates were pooled and $16 \mathrm{~S}$ rRNA genes were PCR-amplified from DNA extracted from these "communities" of culturable bacteria. DGGE analysis of the 16S rRNA genes from the filtered and unfiltered communities indicated that the filterable soil bacteria were not similar to the dominant organisms cultured from unfiltered samples and that distinct small-celled bacteria were isolated from soils collected one year apart. Phylogenetic analysis of 16S rRNA genes from the filtered bacteria were classified as $\alpha-$, $\beta$-, $\gamma$-, or $\delta$-Proteobacteria or Bacteroidetes. The 16S rRNA genes affiliated with the genera Polaromonas and Ramlibacter represent $23 \%$ of the non-chimeric sequences in the clone libraries. Other sequences were associated with known copiotrophic ultramicrobacteria from soil, endophytic nitrogen-fixing bacteria in the genera Herbospirillum and Azospirillum, and bacteria that are adapted to inter- or intracellular growth. Almost half of the sequences from the slow-growing, pinpoint-sized colonies
\end{abstract}


were highly similar to an amoeba-resistant bacterium that is affiliated with the genus Rhodoplanes, a putative diazotroph that may play a potentially important role in soil nitrogen dynamics.

Keywords: Soil, Ultramicrobacteria, Small cells, 16S rRNA, DGGE, N-fixation, Endophytes, Intracellular bacteria. 


\section{Introduction}

Bacteria residing naturally in soil are typically much smaller than bacteria grown in laboratory cultures. Cells in culture tend to have cell diameters $>0.5 \mu \mathrm{m}$ (Bae et al., 1972), while direct microscopic observations indicate that 65 to $78 \%$ of the bacteria in soil have diameters < $0.5 \mu \mathrm{m}$ (Bakken, 1985; Christensen et al., 1999). Although smallcelled bacteria (diameter $<0.5 \mu \mathrm{m}$ ) are known to represent a numerically-dominant class of soil bacteria, there is limited information regarding the phylogenetic and physiological diversity of this community because they do not grow readily in culture (Bakken and Olsen, 1987).

Soil bacteria with small volumes or cell diameters are often referred to as "dwarf" bacteria (Bae and Casida, 1973; Bakken and Olsen, 1987; Rutz and Kieft, 2004). Smallcelled bacteria can be further classified as ultramicrocells (UMCs), which are dormant, stress-resistant cells that are smaller versions of otherwise larger-sized cells; and

ultramicrobacteria (UMB), which are cells with consistent volumes less than $0.1 \mu^{3}$ (Schut et al., 1997; Cavicchioli and Ostrowski, 2003). Studies suggest that small-celled soil bacteria have the same amount of DNA as larger bacteria (Bakken and Olsen, 1989) but can be distinguished from larger cells based on their growth rates, metabolic profiles and community fingerprints (Bååth, 1994; De Fede et al., 2001; De Fede and Sexstone, 2001). Based on phospholipid fatty acid analyses, Lindahl et al. (1997) suggested that small-celled soil bacteria were primarily gram-positive organisms. However, both lizuka et al. (1998) and Rutz and Kieft (2004) have isolated 16S rRNA sequences from small soil bacteria that are related to Proteobacteria as well as gram-positive bacteria. Smallcelled bacteria affiliated with the Verrucomicrobiales (Janssen and Schuhmann, 1997), 
Actinobacteria (Hahn et al., 2003) and archeae (Huber et al., 2002; Rutz and Kieft, 2004) also have been isolated or detected.

To recover small-celled bacteria from soil, it is necessary to exclude fastergrowing species from the inoculum. Extinction dilution techniques have previously been used to isolate ultramicrobacteria from marine waters (Schut et al., 1993) and rice paddy soil (Janssen and Schuhmann, 1997). De Fede and Sexstone (2001) also used extinction dilution to recover small-celled bacterial communities from agricultural and forest soils. Although this technique has proven useful, it requires that the target bacteria be present in high number (Button et al., 1993) and amenable to growth in liquid culture. Bacteria that are lost through dilution may represent novel organisms (Edenborn and Sexstone, 2007).

Evidence suggests that liquid serial dilution is inferior to solid media for the recovery of diverse bacteria in culture (Schoenborn et al., 2004). Bacteria from undiluted soils can be recovered by inoculating filtrates of soil slurries directly onto agar plates. Direct filtration was not useful for the recovery of marine ultramicrobacteria (Cavicchioli and Ostrowski, 2003), but was used successfully by Iizuka et al. (1998) to recover fastgrowing cophiotrophic UMB from soil. Recent studies have demonstrated that incubation periods from 10 weeks to three months may be necessary to grow difficult-toculture bacteria such as the Acidobacteria and Verrucomicrobia (Janssen et al., 2002; Joseph et al., 2003). Therefore, improved recovery of small-celled bacteria may be achieved by using direct filtration in combination with longer incubation periods and low-nutrient media (Janssen et al., 2002). To assess the feasibility of this approach, I used direct filtration to isolate small-celled bacteria from organic farm soils in June of consecutive years. Because my primary objective was to explore the potential to 
cultivate small-celled bacteria rather than to isolate pure cultures, I pooled colonies that had been washed or picked from the primary isolation plates and constructed 16S rRNA clone libraries from community DNA. This method was used to minimize the significant loss of diversity that can occur when co-cultures containing one or more different types of bacteria are separated during subculturing (Dedysh et al., 2006). Further, this approach allowed me to compare bacterial communities using a culture-dependent DGGE fingerprinting technique (Edenborn and Sexstone, 2007).

\section{Materials and Methods}

\section{$\underline{\text { Study site and soil sampling }}$}

Soil samples were collected in June of 2003 and 2004 from high- and low-input plots at the market garden at the West Virginia University (WVU) Organic Research Farm located in Morgantown, West Virginia, USA (39 $\left.39^{\prime} 0.18^{\prime \prime} \mathrm{N} ; 7^{\circ} 56^{\prime} 11.6^{\prime \prime} \mathrm{W}\right)$. High-input plots received composted dairy manure (22.4 Mg ha ${ }^{-1}$ based on wet weight) applied 1-3 days prior to planting and green manure (rye and vetch) tilled into the soil 13 days prior to planting. Low-input plots received only green manure applied as described above. Soils on the farm are Dormont and Guernsy silt loams: fine loamy, mixed, superactive, mesic, Oxyaquic Hapludalfs (Wright et al., 1982). Ten soil cores (16 cm depth $\mathrm{x} 2 \mathrm{~cm}$ diameter) were aseptically collected from each plot at $\sim 1.5$ meter intervals along two transects located midpoint between crop rows. Soil samples were bulked, sieved $(<2 \mathrm{~mm})$, placed into plastic bags, and immediately transported back to the laboratory, where they were stored at $4^{\circ} \mathrm{C}$ overnight. In 2003, soils were collected from 
one low-input and one high-input plot. In 2004, soils were collected from replicate $(\mathrm{n}=4)$ high- and low-input plots.

$\underline{\text { Enumeration and cultivation of filterable and nonfilterable soil bacteria }}$

Composite soil samples from each plot were placed in sterile Waring blenders and agitated for one minute at high speed (3x with intermittent cooling on ice) in sterile Winogradsky's salts solution (WSS) (Zuberer, 1994). The primary soil dilutions were $50 \mathrm{~g} / 200 \mathrm{~mL}$ WSS (1/5) in 2003 and $20 \mathrm{~g} / 180 \mathrm{~mL}$ WSS (1/10) in 2004. The blended slurries from 2003 were serially diluted in sterile $0.1 \%(\mathrm{w} / \mathrm{v})$ Bacto peptone (Difco, Detroit, MI), and aliquots from each dilution were inoculated by spreading either $50 \mu 1$ (2003) or $100 \mu \mathrm{l}$ (2004) onto replicate R2A agar (Difco, Detroit, MI). The final dilutions of soil on the plates ranged from $10^{-2}$ to $10^{-7}$. To isolate small-celled bacteria, 5-10 mL of each soil dilution from 2003 (Figure 2.1) were filtered immediately through a series of $0.45 \mu \mathrm{m}$ polyethersulfone syringe filters (Whatman International, Clifton, NJ). In 2004, $25 \mathrm{~mL}$ of soil suspension from the blender was placed into a sterile centrifuge tube and allowed to settle overnight at $4^{\circ} \mathrm{C}$. Five $\mathrm{mL}$ were then removed from the top of the suspension and filtered through a $0.45 \mu \mathrm{m}$ disposable polypropylene filter unit (Nalgene Nunc International, Rochester, NY). The resulting filtrates were plated directly onto replicate plates of R2A agar ( $n=3$ in $2003 ; n=27$ in 2004). All plates were incubated aerobically at $25^{\circ} \mathrm{C}$ for up to one month along with control plates that received no inoculum or $100 \mu \mathrm{L}$ of the sterile peptone $(0.1 \%)$ diluent that had been filtered as described for the soil samples. The colony forming units (CFUs) on each plate were counted at 24 hours, one or two weeks and one month using a Quebec colony counter and 
the colony morphologies were visually characterized based on pigmentation and colony size. Two colony classes were operationally defined based on colony diameter: small colonies $(<1 \mathrm{~mm})$ and large colonies $(>1 \mathrm{~mm})$.

DNA extraction from bacterial communities on agar plates

Pooled samples of culturable bacteria were obtained by: 1) sequentially washing cells from replicate plates using WSS (4 ml) and a sterile disposable inoculating loop (Edenborn and Sexstone, 2007); or, 2) picking and pooling individual colonies. In 2003, plate washes of both nonfiltered and filtered bacteria were obtained from replicate $(n=3)$ dilution plates $\left(10^{-3}, 10^{-4}, 10^{-5}\right.$ and $\left.10^{-6}\right)$ from one high- and one low-input soil sample. In 2004 , nonfiltered bacterial communities from the $10^{-2}$ dilution from replicate $(\mathrm{n}=4)$ highand low-input plots were collected using the plate washing technique, and filtered bacteria were picked and pooled based on colony size. All of the resulting cell suspensions were vortexed and frozen $\left(-20^{\circ} \mathrm{C}\right)$. DNA was extracted from aliquots of each thawed cell suspension $(1.8 \mathrm{ml})$ using the MoBio Microbial DNA extraction kit (MoBio Laboratories, Carlsbad, CA).

$\underline{\text { PCR-DGGE analysis of bacterial communities and 16S rRNA clones }}$

The variable V3 region of the 16S rRNA gene from the domain Eubacteria was amplified using the PRBA338F primer with a GC clamp and the PRUN518R primer as previously described (Edenborn and Sexstone, 2007). PCR products were pooled, cleaned and concentrated using QIAquick PCR Purification Kit (Qiagen, Valencia, CA, ), and the amount of PCR product in the samples was estimated by agarose gel 
electrophoresis of samples and a mass ladder (Fermentas Inc., Hanover, MD). PCR samples from bacterial communities or individual clones were loaded into a polyacrylamide gel $(8 \%)$ with a $40 \%(16.8 \mathrm{~g}$ urea; $16 \mathrm{ml}$ formamide/100 $\mathrm{ml})$ to $60 \%$ ( $25.2 \mathrm{~g}$ urea; $24 \mathrm{ml}$ formamide/100 $\mathrm{ml}$ ) or a $45 \%$ (18.9 $\mathrm{g}$ urea; $18 \mathrm{ml}$ formamide/100 ml) to $75 \%$ ( $31.5 \mathrm{~g}$ urea; $30 \mathrm{ml}$ formamide/100 ml) denaturing gradient and electrophoresed for $14-16$ hours at $50 \mathrm{~V}$ and $60^{\circ} \mathrm{C}$ in the DCode ${ }^{\mathrm{TM}}$ Universal Mutation Detection System (Biorad, Hercules, CA). The gels were stained with silver according to the protocol of Caetano-Anolles and Gresshoff (1994). The stained gel was scanned with a Hewlett Packard ScanJet 7400c (Hewlett-Packard Co., Palo Alto, CA) at a resolution of 600 dpi and saved in uncompressed TIFF format for further analysis. DGGE gels were analyzed using Quantity One gel analysis software (BioRad). Band analysis was performed by setting background subtraction at 15 using the rolling disk method. Bands with intensity $<10 \%$ of the maximum intensity observed in the profile were excluded from the analysis. Similarity matrices and unweighted pair-group method with arithmetic mean (UPGMA) trees were generated in Quantity One using Sorensen's index.

$\underline{\text { PCR amplification, cloning and sequencing of 16S rRNA genes from filtered bacteria }}$

The 16S rRNA genes in pooled DNA samples of filtered bacteria were amplified using primers 27f (5'-AGAGTTTGATCCTGGCTCAG-3') and 1492r (5'-GGTTACCTTCTTACGACTT-3'). The final 100- $\mu$ PCR mixture contained $1 \times$ PCR buffer (Promega, Madison, WI), $1.8 \mathrm{mM}$ of $\mathrm{MgCl}_{2}, 200 \mu \mathrm{M}$ of a equal mix of deoxynucleotide triphosphates (Promega), $0.4 \%$ bovine serum albumin, $0.1 \mu \mathrm{M}$ (each) of forward and reverse primers (Integrated DNA Technologies) $5 \mathrm{U}$ of Taq DNA 
polymerase (Promega), and $\sim 300 \mathrm{ng}$ of template DNA. The PCR protocol included 5min initial denaturation at $94^{\circ} \mathrm{C}$, six touchdown cycles of annealing temperatures decreasing in $1^{\circ} \mathrm{C}$ increments from $61^{\circ} \mathrm{C}$ to $56^{\circ} \mathrm{C}\left(92^{\circ} \mathrm{C}\right.$ for $30 \mathrm{~s}$ (denaturation); $30 \mathrm{~s}$ (annealing); and $72^{\circ} \mathrm{C}$ for $90 \mathrm{~s}$ (elongation) for $30 \mathrm{~s}$ ), 22 cycles as follows $\left(92^{\circ} \mathrm{C}\right.$ for $30 \mathrm{~s}$ (denaturation); $55^{\circ} \mathrm{C}$ for $30 \mathrm{~s}$ (annealing), and $72^{\circ} \mathrm{C}$ for $90 \mathrm{~s}$ ), and $7 \mathrm{~min}$ at $72^{\circ} \mathrm{C}$. Four microliters of the cleaned PCR $(\sim 15-20 \mathrm{ng} / \mu \mathrm{l})$ product was then cloned using the Topo TA cloning kit for sequencing (Invitrogen, Carlsbad, CA), and transformed cell suspensions were plated onto 5 or 6 Luria broth agar plates $(5 \mathrm{~g} \mathrm{NaCl}, 5 \mathrm{~g}$ Yeast Extract (Difco), $10 \mathrm{~g}$ Bactopeptone (Difco), and $15 \mathrm{~g}$ agar per L) containing kanamycin (50 $\mu \mathrm{g} / \mathrm{ml})$. Clones with full-sized ( $\sim 1400 \mathrm{bp})$ inserts were identified using colony PCR with the M13 forward and reverse primers and subjected to amplified ribosomal DNA restriction analysis (ARDRA) analysis using RsaI and HhaI (New England Biolabs, Ipswich, MA). Restriction digests were done separately and then combined prior to electrophoresis. Plasmid DNA was extracted from selected clones using the QIAprep Spin Miniprep Kit (Qiagen).

Prior to sequencing, the V3 region of $16 \mathrm{~S}$ rRNA from each clone was amplified and associated with bands in the community using the DGGE protocol described above. Partial 16S rRNA genes associated with specific DGGE and ARDRA patterns were sequenced by a commercial sequencing facility (Davis Sequencing, Davis, CA) using the T7 sequencing primers. Putative chimeric sequences were identified using the program Bellerophon (Huber et al., 2004) and a multiple alignment with closely-related bacterial sequences was performed using the NAST alignment tool on the Greengenes website (DeSantis et al., 2006a; DeSantis et al., 2006b). Further, the classification tool in 
Greengenes was used to associate each sequence with a bacterial division. Aligned sequences were manually refined and imported into the Mega software package version 3.1 (Kumar et al., 2004). A neighbor-joining tree was constructed based on 950 bp of the 16S rRNA gene using the Kimura two-parameter substitution model with complete deletion of gapped sequences. Bootstrap analysis (1,000 resamplings) was done to estimate the statistical reliability of the groupings. Bootstrap values greater than $70 \%$ are indicated at tree nodes. The percent similarities between the known and unknown sequences in the final tree were determined using the gapped BLAST protocol (BLAST 2 sequences) on the NCBI website (Tatusova and Madden, 1999).

\section{Results}

Cultivation of filterable bacteria from organic farm soils

In 2003, filterable bacteria were recovered from 10-fold dilutions of high- and low-input soils that had been directly plated onto R2A medium and incubated aerobically for two weeks at $25^{\circ} \mathrm{C}$ (Figure 2.1). A total of $216 \mathrm{CFUs}$ were counted among all plates; $67 \%$ were from high-input soils and 33\% from low-input soils. Eighty-seven percent of the colonies observed on the plates had been inoculated with filtrate from the $10^{-3}$ and $10^{-}$ ${ }^{4}$ soil dilutions. Only five CFUs were present on plates inoculated with the $10^{-6}$ filtrate. Forty-one percent of the CFUs classified as small colonies $(<1 \mathrm{~mm}$ at 14 days $)$ were pinpoint-sized and $13 \%$ had yellow or orange pigments. In 2004, filterable cells from a 10-fold soil dilution were directly plated on R2A agar plates and incubated aerobically at $25^{\circ} \mathrm{C}$. In contrast to the results from 2003 , very few colonies were observed after a oneweek incubation period (Figure 2.2.); however, at one month, a total of 360 CFUs were 
counted on all plates ( $82 \%$ from the high-input soil and $18 \%$ from the low-input soil). As previously observed, a large percentage (53\%) of the colonies were pinpoint-sized. No growth was observed on any of the control plates.

\section{DGGE analysis of filtered and nonfiltered soil bacterial communities from R2A}

plates

In this study, composite CD DGGE fingerprints of filtered and nonfiltered bacterial communities were constructed by pooling partial 16S rRNA genes recovered from bacteria growing on R2A plates that had been inoculated with different soil dilutions (2003 samples) or soils from replicate treatment plots (2004 samples) (Figure 2.3). A $40-60 \%$ DGGE gradient was used for the 2003 samples. However, a $45-75 \%$ gradient was needed to resolve bands in the 2004 fingerprints. The number of bands observed in the 2003 and 2004 fingerprints ranged from 27 to 37 for the nonfiltered community and from 20 to 31 for the filtered community. In both 2003 and 2004, the most intensely-stained bands in the nonfiltered community were present in the upper region of the gel (as indicated by the black arrows in Figure 2.3) and were not detected in profiles of filterable bacteria. In contrast, many of the bands in fingerprints of the filterable bacteria were detected in the lower regions of the gel (Figure 2.3) and were present at different levels of intensity in the profiles from the nonfiltered community. Based on Sorensen's index, the percent similarities between filterable and nonfilterable profiles ranged from $14-19 \%$ in 2003 and $10-15 \%$ in 2004 . The similarity between the community fingerprints from the high- and low-input soils (Figure 2.3) were: $44 \%$ (nonfilterable; 2003), 40\% (filterable; 2003), 69\% (nonfilterable; 2004) and 33\% 
(filterable; 2004). Finally, a DGGE analysis of all samples using the same gradient (45$75 \%$; gel not shown) was done to evaluate temporal shifts in community structure. An UPGMA dendrogram (Figure 2.4) suggested that both the filtered and unfiltered communities from 2003 were only slightly similar (22 and 29\%, respectively) to those from 2004. Comparison of filtered communities on the same gradient (45-75\%) revealed considerably more bands in the lower region of the gel in the 2004 fingerprint than in the 2003 profile (Figures 2.6a and 2.7a). This resulted in a very low similarity (7\%) between fingerprints. Intensity profiles of aligned DGGE fingerprints were generated using Quantity One software, and peaks related to each band were visually inspected. Peaks that clearly were present in the filtered community but not present in the nonfiltered community included 1, 11, and 13 (2003) and 6, 10, 14, 21 and 22 (2004) (Figure 2.3).

Phylogenetic diversity of filterable soil bacterial communities

Pooled 16S rRNA genes from the filterable bacterial communities from 2003 and 2004 were used to construct four clone libraries that were affiliated with isolation source (high-input and low-input soil) and colony size (large colony, $>1 \mathrm{~mm}$ and small colony, $<1 \mathrm{~mm})$. From these libraries, 105 clones with inserts of the expected size $(\sim 1400 \mathrm{bp})$ were isolated and classified using DGGE and ARDRA. DGGE analysis of the V3 region was used to associate the 16S rRNA genes from clones with bands in the original DGGE profiles of the filterable bacterial communities (Figures 2.3, 2.6a, and 2.7a). ARDRA was done to identify potentially different $16 \mathrm{~S}$ rRNA genes associated with each band. A numerical identification code was given to clones with unique RFLP types that specified 
the DGGE band number and a unique ARDRA type associated with that band (eg., 5.1 refers to ARDRA pattern 1 associated with band 5). If bands were detected in both years, a third number was used to designate year 1 or year 2 (eg. 8.1.1, band 8, ARDRA pattern 1, year 1). The distribution of clones from 2003 and 2004 is presented in Figure 2.5. In general, multiple ARDRA patterns were associated with most bands. There also was more redundancy in the clones from 2003 compared to 2004. Most notable was clone 3.2, which dominated the 2003 library and was associated with both the high-and lowinput soil.

The 16S rRNA genes from 78 clones with unique ARDRA patterns and three clones associated with pattern 3.2 were partially sequenced. Fourteen of the sequences were identified as putative chimeras based on analysis using the program Bellerophon, and were removed from the analyses. The remaining 67 sequences were assigned to major phyla using the classification tool in Greengenes, and phylogenetic clusters were inferred from a neighbor-joining tree. Sequences were assigned to the $\alpha$-Proteobacteria (36\%), $\beta$-Proteobacteria $(37 \%), \gamma$-Proteobacteria $(16 \%), \delta$ - Proteobacteria $(4 \%)$ and Bacteroidetes (6\%). Sub-clusters were identified in each group using the letters A through J (Figures 2.6b and 2.7b). In general, sequences associated with the same DGGE bands clustered together, and there was often very little difference in the sequences associated with distinct intra-band ARDRA patterns. As suggested by the DGGE fingerprints, there was little overlap between the sequences obtained from the 2003 and 2004 samples.

Thirty-seven percent of the ARDRA clones from 2003 were associated with the genera Polaromonas, Ramlibacter and Variovorax in the $\beta$-Proteobacteria family 
(Figure 2.6; cluster D). All of the operational taxonomic units (OTUs) in cluster D except clone 1.1 were 98 to $99 \%$ similar to Polaromonas ginsengisoli str. Gsoil 115 (AB245355) based on local alignment using the gapped BLAST algorithm. Clone 1.1 was more similar (95\%) to the Variovorax and Ramlibacter sequences. Bacteria associated with sequences in this cluster were isolated from high- and low-input soils from 2003.

OTUs represented in clusters B, C and G (Figure 2.6) were associated with filterable bacteria characterized in other studies. Clones 10.1 and 12.1 formed a tight phylogenetic cluster (97\% similarity) to an ultramicrobacterium (AB008503) isolated by lizuka et al. (1998) (Figure 2.6; cluster B). Phylogenetic analysis and pair-wise alignment indicated that these sequences were similar to Herbaspirillum sp. (96 to 97\%) and Oxalicibacterium flavum (94 to 98\%). Both of these sequences were obtained from 2004 clones with a larger-colony size $(>1 \mathrm{~mm})$. Four sequences from the 2003 highinput soils (Figure 2.6; cluster G) also were highly similar (99\%) to a second ultramicrobacterium (AB008508). The phylogenetic affiliation of these clones with Xanthomonas campestris was supported by high sequence similarity (94 to 97\%) and bootstrap values. Finally, the six sequences in cluster C showed 92 to $93 \%$ similarity with a 16S rRNA sequence from a deep-groundwater bacterium that was able to pass through a $0.2 \mu \mathrm{m}$ filter (Miyoshi et al., 2005) and a 92 to $97 \%$ similarity with a sequence from a clone associated with a deep-sea coral (DQ395940). The cultured representative Denitratisoma oestradiolicum str, AcBE2-1 (AY879297) had a 92 to 93\% similarity with the sequences in cluster $\mathrm{C}$. 
The last cluster in the $\beta$-Proteobacteria (Figure 2.6; cluster A) was composed of sequences associated with clones from 2004 with small-sized colonies $(<1 \mathrm{~mm})$. Pairwise alignments in BLAST indicated that clone 22.2 was $97 \%$ similar to Methylovorus mays. Clones 2.2, 2.3 and 2.4 were 92 to $94 \%$ similar to Methylophilus sp. and 91 to 97\% similar to Siderooxidans paludicola (DQ386858). Other sequences classified in the Gammaproteobacteria were associated (92 to 97\% similarity) with Lysobacter $s p$. (Figure 2.6; cluster E) and Thermomonas dokdonensis (Figure 2.6; cluster F).

The 16S rRNA sequences classified as $\alpha$-Proteobacteria were broadly divided into two groups; those associated with bacteria with a large-colony size from predominantly high-input soils (Figure 2.7; clusters $\mathbf{H}$ and I) and bacteria with very small colony size (Figure 2.7; cluster J). Cluster I was highly similar (97 to 98\%) to the sequence for the purple nonsulfur bacterium Phaeospirillum fulvum and cluster $\mathrm{H}$ was loosely affiliated (91 to 92\%) with the nitrogen-fixing genera Azospirillum. The smallcolony isolates (Figure 2.7; cluster $\mathbf{J}$ ) were associated with known intracellular bacteria and ultramicrobacteria. Sequences 6.1 and 6.2 were $88 \%$ similar to Rickettsia conorii and Rickettsia sibirica and formed a cluster in the $\alpha$-Proteobacteria that was supported by bootstrap analysis. Clone 15.2 .1 had a $98 \%$ similarity to Sphingomonas sp. and clones 22.5, 21.1 and 8.22 had some relatedness (87 to 93\%) to Paravibaculum lavamentivorans, Bradyrhizobium japonicum, Beijerincki indica, Rhizobium and Rhodoplanes elegans. Specifically notable was the number of sequences in cluster J $(15.5 .2,22.6,22.8,22.7,22.1$, and 22,4$)$ that were found to be similar (95 to $96 \%$ ) to a bacterium isolated using amoebal co-culture (DQ123621) and to Rhodoplanes elegans, D25311 (94 to 96\%). The remaining sequences were classified as $\delta$-Proteobacteria and 
Bacteroidetes. Four clones in Bacteroidetes cluster were related to the known isolates in the genus Flexibacter (91 to 96\%). However, the three clones associated with DGGE band number 14 and classified as $\delta$-Proteobacteria had 16S rRNA genes significantly different from the closest validated species. Only $84 \%$ similarity was observed between

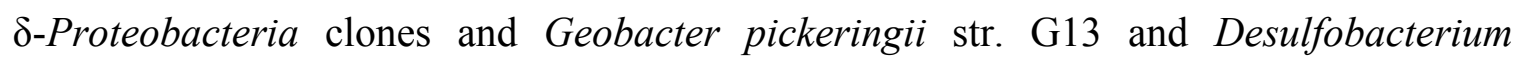
catecholicum str. DSM388.

\section{Discussion}

The majority of active bacteria in soil have cell diameters that are less than 0.5 $\mu \mathrm{m}$ (Christensen et al., 1999); however, the identities of these organisms are largely unknown because small-celled bacteria resist cultivation (Bakken and Olsen, 1987). Although it is possible to characterize 16S rRNA genes in filtered samples using molecular cloning technology (Rutz and Kieft, 2004), this approach is complicated by the probable presence of naked DNA from larger-sized cells in filtrates. Further, cloned genes do not provide a platform to study the physiology and ecology of small-celled bacteria. Therefore, efforts must be made to isolate cultured representatives of bacteria with small cell sizes. In this study, I characterized communities of filterable bacterial cells $(<0.45 \mu \mathrm{m})$ that grew on primary isolation plates in order to assess the diversity of bacteria that may serve as model organisms for future studies.

A significant number of small-celled bacteria were observed on R2A agar following direct filtration of soil through $0.45 \mu \mathrm{m}$ filters. In 2003, most CFUs were found on plates inoculated with the least dilute soils, and only five CFUs were present on the $10^{-6}$ plate, which was one dilution above $\left(10^{-7}\right)$ the "countable" plate $(30-300$ 
colonies). In 2004, colonies from the filtered samples appeared on growth plates after an incubation period of 1 month. However, there was no increase in the number of colonies on plates that had been inoculated with the most dilute $\left(10^{-7}\right)$ unfiltered samples after two weeks. These data suggest that direction filtration may improve the recovery of culturable small-celled bacteria from soil.

Often a high percentage of bacterial isolates that appear on primary agar plates are lost during subsequent efforts to obtain representative isolates in pure cultures (Ellis et al., 2003). Therefore, I opted to use a plate wash technique (Edenborn and Sexstone, 2007) to isolate total DNA from bacterial communities on primary isolation plates. followed by PCR amplification of the 16S rDNA gene and CD DGGE analysis to screen communities from filtered and unfiltered soil samples for similarities and differences. Fingerprint analysis indicated that the filterable bacteria were not similar to the dominant organisms growing from the unfiltered soil samples. Distinct filterable bacteria were isolated in 2003 and 2004, perhaps due to the varied approaches used to isolate small cells or inherent variations in the soil bacterial communities. The parallel changes in both the filtered and unfiltered communities suggest real spatial and temporal shifts in these communities. However, it also is probable that filtration of less dilute soil slurries in 2004 increased our recovery of rare taxa that may not have been cultivated in 2003.

Although I did not attempt to classify the filtered bacteria as ultramicrobacteria (UMB) or ultramicrocells (UMC), several of the 16S rRNA genes in the 2003 samples were highly similar to the two aerobic copiotrophic UMB isolated by Iizuka et al. (1998). The 16S rRNA genes from clones 12.1 and 10.2 were $97 \%$ similar to the UMB isolate MY14, which has a cell volume of $0.07 \pm 0.03 \mu \mathrm{m}^{3}$, a doubling time of 7.4 hours in 
tryptic soy broth, and a 16 S rRNA gene sequence with $95 \%$ similarity to Paucimonas lemoignei X92555 (previously classified as Pseudomonas lemoignei). I included the 16S rRNA sequences for $P$. lemoignei in the phylogenetic analysis to demonstrate the relationship of clones 10.1 and 12.1 and the known UMB. However, the 16S rRNA sequences of UMB MY14 and clones 10.1 and 12.1 were more closely related to those of Herbaspirillum sp. and Oxalicibacterium flavum than P. lemoignei. UMB related to MY14 has been previously designated as the nearest neighbor to endophytic nitrogenfixing isolates classified as Herbaspirillum frisingense (Kirchhof et al., 2001). Bacteria in this genus typically have cell widths between $0.5-0.7 \mu \mathrm{m}$ (Elbeltagy et al., 2001); therefore, they could have moved through the filter via cell flexture (Haller et al., 2000). However, it has been shown that populations of Herbaspirillum rapidly fall below detection limits following inoculation into soil but recolonize and multiply when plants are introduced (Olivares et al., 1996). Therefore, smaller forms of Herbaspirillum cells may represent dormant or viable-but-non-culturable cells that persist in soil. Interestingly, we also found sequences associated with the endophytic nitrogen-fixing bacterium Azospirillum in the 2004 clone library.

A second group of clones (Figure 2.6; cluster G) had 16S rRNA gene sequences that were $99 \%$ similar to a second fast-growing, copiotrophic UMB strain DYO1 (Iizuka et al., 1998). The sequences from our study and that of Isizuka et al. (1998) showed 94 to 97\% similarity to the 16S rRNA genes of the plant pathogen Xanthomonas campestris. The cells in the genus Xanthomonas have diameters ranging from $0.2-0.6 \mu \mathrm{m}$ and lengths from 0.8-2.9 $\mu \mathrm{m}$ (Swings and Civerolo, 1993), which suggests that these cells could easily pass through a $0.45 \mu \mathrm{m}$ filter. UMB are thought to be organisms that thrive 
primarily under nutrient-limited conditions (Roszak and Colwell, 1987). However, Fegatella et al. (1998) have pointed out that the obligate intracellular parasite Rickettsia prowazekii represents an UMB that lives in nutrient-rich cytoplasm. As a plant pathogen, $X$. campestris gains entry into the intracellular spaces in xylem tissue through hydathodes, stomates or wounds, and then kills plant cells by activating genes in the plant via bacterial effector proteins across membranes (Büttner and Bonas, 2002). Although $X$. campestris is not an obligate resident inside plant cells, the characteristics of this bacterium appear to be adapted for the niche that it occupies in situ. A small cell size can facilitate entry and survival in plant tissue and the ability to respond rapidly to nutrients can prove useful when cytoplasmic contents are released from dying cells. The other sequences classified in the $\gamma$-Proteobacteria were similar to the 16S rRNA genes from the genera Lysobacter and Thermonomas, which are also members of the family Xanthomonadaceae.

In contrast to the filtered bacteria from 2003, most of the colonies from the 2004 samples did not appear on the culture plates until one month following inoculation. A large percentage of these colonies were pinpoint-sized. Torrella and Morita (1981) originally described autochthonous ultramicrobacteria as very small bacteria that form colonies on agar very slowly and are unable to be detected with the naked eye after 24 hours of growth. Our colonies could be seen without magnification; however, they were not detected until plates had been incubated for one month. Therefore, these pinpoint colonies could represent oligotrophic UMB. Analysis of the 16S rRNA sequences from the filterable bacteria indicated that most of the bacteria from 2004 with a very small colony size were related to bacteria in the genera Rickettsia, Sphingomonas, 
Bradyrhizobium, Rhizobium, Parvibaculum, Beijerinckia, Methylophilus, Methylovorus, and Rhodoplanes. Several of these genera included bacteria that are noted for growing inside animal or plant cells (Rickettsia, Rhizobium and Bradyrhizobium). Others, related to the bacteria Sphingomonas and Methylophilus, were among the ultrasmall bacteria $\left(<0.1 \mu \mathrm{m}^{3}\right)$ isolated from a 120,000-year-old glacial ice core in Greenland (Miteva and Brenchley, 2005). Rutz and Kieft (Rutz and Kieft, 2004) also reported isolating clones of dwarf bacteria that were related to Sphingomonas from desert soils.

Interestingly, the majority of the small-colony sequences from our study were highly similar (95-96\%) to an isolate "Rhodoplanes sp. strain laus-2," that was isolated using an amoebal co-culture technique from a hospital water network (Thomas et al., 2006). This strain was characterized as a very slow-growing gram-negative bacterium that formed loose colorless colonies on CYE agar incubated at $32^{\circ} \mathrm{C}$ for 3 weeks. Buckley et al. (2007) recently used stable isotope probing with ${ }^{15} \mathrm{~N}_{2}$ to demonstrate that bacteria in the genus Rhodoplanes may represent a new and important group of freeliving nitrogen-fixing bacteria. It is known that protozoa living in the rhizosphere increase the nitrogen available to plants by releasing nutrients from consumed bacterial biomass (Bonkowski, 2004); however, the role of protozoa as hosts for symbiotic nitrogen-fixing bacteria has only recently been demonstrated (Kneip et al., 2007).

Significantly more filterable bacteria were isolated from soils amended with compost (high-input) compared to those that were not (low-input). The added nutrients in compost may have promoted the resuscitation of starved cells or selected for copiotrophic organisms. The clones that affiliated with the ultramicrobacteria characterized as $X$. campestris were isolated only from high-input plots and appeared on 
the primary isolation plate within 2 weeks, which supports the characterization of this UMB as fast-growing and copiotrophic. Other sequences related to Phaeospirillum fulvum also were found only in high-input soils. However, the dominant clones in the 2003 library were found in both high- and low-input soils. Sequences related to Polaromonas, Ramlibacter and Variovorax (cluster D) comprised 37\% of the clones in the 2003 library. Rutz and Kieft (2004) reported cloning a 16S rRNA gene (AF443568) from dwarf bacteria from shrubland soils that was related to Ramlibacter and Acidovorax. This sequence, which was 92 to $94 \%$ similar to our sequences in cluster D, made up 35\% of the clones isolated from soils collected from beneath creosote bush canopies, but was not detected in soils collected from open areas between bushes. These data suggest that the bacterium associated with this sequence persists in soils with higher levels of carbon and nitrogen. However, we obtained clones associated with cluster D that were isolated from soils both with and without compost. A common near neighbor in both of these studies, Ramlibacter tataouinesis, is a pleomorphic bacterium that was isolated from a meteorite found in desert soils, produces yellow-orange pigments, and forms cysts and 'nanometric' rods (diameter of $0.2 \mu \mathrm{m}$ ) (Heulin et al., 2003). The ecological role of this bacterium in temperate soil is unclear; however, evidence suggests that it may be involved in the transformation of inorganic elements in soil. In culture, this bacterium has been shown to preferentially colonize orthopyroxene crystals (Benzerara et al., 2004b) and control precipitation of calcium phosphate (Benzerara et al., 2004a). The other near neighbors in cluster D belonged to the genera Polaromonas and Variovorax. Like Ramlibacter tataouinesis, several species of Polaromonas are adapted to live in extreme environments such as the Antarctic seas, Alaskan soil and oligotrophic caves and 
karsts (Irgens et al., 1996; Barton, 2006; Sizova and Panikov, 2007). Other species, however, have been isolated from naphthalene-contaminated sediments (Jeon et al., 2004) and tap water (Kaempfer et al., 2006), which suggests that bacteria in this genus are cosmopolitan organisms with broad niches. Although the reported cell diameters of most Polaromonas are $>0.5 \mu \mathrm{m}$, the possibility that $\mathrm{UMC}$ form in response to environmental stress or starvation cannot be excluded.

The remaining 16S rRNA sequences for the clones libraries were affiliated with the $\delta$-Proteobacteria and Flexibacter-Cytophaga-Bacteroidetes (CFB) group. The Flexibacter are known to be highly pleomorphic, forming long threads that fragment into very short rods as cultures age (Reichenbach and Kleinig, 1974). Members of the CFB division have been found in associations with many organisms including: the arbuscular mycorrhizal fungi Glomus geosporum and Glomus constrictum (Roesti et al., 2005), Charophycean green algae (Fisher et al., 1998), and the nematodes Cephalobus brevicauda (Salinas et al., 2007) and Eubostrichus dianae (Polz et al., 1999). Barbieri et al. (2000) also identified an uncultured CFB-affiliated bacterium in the subgroup Sphingobacter that was found within the mycelium of the ectomycorrhizal fungus Tuber borchii. In this study, the nearest neighbor ( $91-93 \%$ similarity) to three of the clones from 2003 was a Flexibacter clone (DQ279370) associated with Tuber magnatum.

\section{Conclusions}

A small cell size is a phenotypic trait that helps bacteria adapt to and survive in different environments. Some bacteria exhibit plasticity in cell size and may only become small under stressful conditions, while others maintain a fixed cell volume. 
Selective forces that favor a small cell size include nutrient availability, passive dispersal, sieving through geological strata and predation by protozoa and nematodes (Young, 2006; Salinas et al., 2007). Small cell sizes are also associated with bacteria that have host-dependent life strategies (Iizuka et al., 1998). In contrast to other studies (Rutz and Kieft, 2004; Miteva and Brenchley, 2005), we did not find any clones related to smallcelled gram-positive bacteria. However, we isolated 16S rRNA genes from culturable small-celled soil bacteria that are highly similar to known soil ultramicrobacteria, filterable bacteria recovered in groundwater and desert soils, and bacteria that favor intracellular, endophytic or epibiotic growth. There also were many 16S rRNA sequences that were affiliated with bacteria that are well-established or newly discovered nitrogen-fixing bacteria. Although these bacteria were not isolated in pure culture and their dimensions were not confirmed, their growth on agar plates and unique community fingerprints are evidence that they represent viable soil bacteria that are not routinely recovered using the classical spread-plate method (Zuberer, 1994). By expanding efforts to cultivate filterable soil bacteria, we can target the numerically-dominant bacteria in soil and improve our ability to "culture the unculturable."

\section{References Cited}

Bååth, E., 1994. Thymidine and leucine incorporation in soil bacteria with different cell size. Microbial Ecology 27, 267-278.

Bae, H.C., Casida, L.E., Jr., 1973. Responses of indigenous microorganisms to soil incubation as viewed by transmission electron microscopy of cell thin sections. Journal of Bacteriology 113, 1462-1473.

Bae, H.C., Cota-Robles, E.H., Casida, L.E., 1972. Microflora of soil as viewed by transmission electron microscopy. Applied Microbiology 23, 637-648. 
Bakken, L.R., 1985. Separation and purification of bacteria from soil. Applied and Environmental Microbiology 49, 1482-1487.

Bakken, L.R., Olsen, R.A., 1987. The relationship between cell size and viability of soil bacteria. Microbial Ecology 13, 103.

Bakken, L.R., Olsen, R.A., 1989. DNA content of soil bacteria of different cell size. Soil Biology and Biochemistry 21, 789-793.

Barbieri, E., Potenza, L., Rossi, I., Sisti, D., Giomaro, G., Rossetti, S., Beimfohr, C., Stocchi, V., 2000. Phylogenetic characterization and in situ detection of a Cytophaga-Flexibacter-Bacteroides phylogroup bacterium in Tuber borchii Vittad. ectomycorrhizal mycelium. Applied and Environmental Microbiology 66, 5035-5042.

Barton, H.A., 2006. Introduction to cave microbiology: a review for the non-specialist. Journal of Cave and Karst Studies 68, 43-54.

Benzerara, K., Barakat, M., Menguy, N., Guyot, F., Del Luca, G., Audrain, C., Heulin, T., 2004a. Experimental colonization and alteration of orthopyroxene by the pleomorphic bacteria Ramlibacter tataouinensis. Geomicrobiology Journal 21, 341-349.

Benzerara, K., Menguy, N., Guyot, F., Skouri, F., de Luca, G., Barakat, M., Heulin, T., 2004b. Biologically controlled precipitation of calcium phosphate by Ramlibacter tataouinensis. Earth and Planetary Science Letters 228, 439-449.

Bonkowski, M., 2004. Protozoa and plant growth: the microbial loop in soil revisited. New Phytologist 162, 617-631.

Buckley, D.H., Huangyutitham, V., Hsu, S.-F., Nelson, T.A., 2007. Stable isotope probing with ${ }^{15} \mathrm{~N}_{2}$ reveals novel non-cultivated diazotrophs in soil. Applied and Environmental Microbiology, 73:3196-3204.

Büttner, D., Bonas, U., 2002. Getting across-bacterial type III effector proteins on their way to the plant cell. EMBO Journal 21, 5313-5322.

Button, D.K., Schut, F., Quang, P., Martin, R., Robertson, B.R., 1993. Viability and isolation of marine bacteria by dilution culture: Theory, procedures, and initial results. Applied and Environmental Microbiology 59, 881-891.

Caetano-Anolles, G., Gresshoff, P.M., 1994. Staining nucleic acids with silver: an alternative to radioisotopic and fluorescent labeling. Promega Notes 45, 13-18.

Cavicchioli, R., Ostrowski, M., 2003. Ultramicrobacteria. In: Encyclopedia of Life Sciences. Macmillan Publishers Ltd., Nature Publishing Group / www.els.net, 
London.

Christensen, H., Hansen, M., Sørensen, J., 1999. Counting and size classification of active soil bacteria by fluorescence in situ hybridization with an rRNA oligonucleotide probe. Applied and Environmental Microbiology 65, 1753-1761.

De Fede, K.L., Sexstone, A.J., 2001. Differential response of size-fractionated soil bacteria in BIOLOG microtiter plates. Soil Biology and Biochemistry 33, 15471554.

De Fede, K.L., Panaccione, D.G., Sexstone, A.J., 2001. Characterization of dilution enrichment cultures obtained from size-fractionated soil bacteria by BIOLOG community-level physiological profiles and restriction analysis of $16 \mathrm{~S}$ rRNA genes. Soil Biology and Biochemistry 33, 1555-1562.

Dedysh, S.N., Pankratov, T.A., Belova, S.E., Kulichevskaya, I.S., Liesack, W., 2006. Phylogenetic analysis and in situ identification of bacterial community composition in an acidic Sphagnum peat bog. Applied and Environmental Microbiology 72, 2110-2117.

DeSantis, T.Z., Dalevi, D., Huber, T., Andersen, G.L., Hu, P., Keller, K., Larsen, N., Hugenholtz, P., Brodie, E.L., Rojas, M., 2006a. Greengenes, a chimera-checked $16 \mathrm{~S}$ rRNA gene database and workbench compatible with ARB. Applied and Environmental Microbiology 72, 5069-5072.

DeSantis, T.Z., Jr., Piceno, Y.M., Phan, R., Andersen, G.L., Larsen, N., Hugenholtz, P., Keller, K., Brodie, E.L., 2006b. NAST: a multiple sequence alignment server for comparative analysis of 16S rRNA genes. Nucleic Acids Research 34, 394-399.

Edenborn, S.L., Sexstone, A.J., 2007. DGGE fingerprinting of culturable soil bacterial communities complements culture-independent analyses. Soil Biology and Biochemistry 39, 1570-1579.

Elbeltagy, A., Nishioka, K., Sato, T., Suzuki, H., Ye, B., Hamada, T., Isawa, T., Mitsui, H., Minamisawa, K., 2001. Endophytic colonization and in planta nitrogen fixation by a Herbaspirillum sp. isolated from wild rice species. Applied and Environmental Microbiology 67, 5285-5293.

Ellis, R.J., Morgan, P., Weightman, A.J., Fry, J.C., 2003. Cultivation-dependent and -independent approaches for determining bacterial diversity in heavy-metalcontaminated soil. Applied and Environmental Microbiology 69, 3223-3230.

Fegatella, F., Lim, J., Kjelleberg, S., Cavicchioli, R., 1998. Implications of rRNA operon copy number and ribosome content in the marine oligotrophic ultramicrobacterium Sphingomonas sp. strain RB2256. Applied and Environmental Microbiology 64, 4433-4438. 
Fisher, M.M., Wilcox, L.W., Graham, L.E., 1998. Molecular characterization of epiphytic bacterial communities on charophycean green algae. Applied and Environmental Microbiology 64, 4384-4389.

Hahn, M.W., Lünsdorf, H., Wu, Q., Schauer, M., Hofle, M.G., Boenigk, J., Stadler, P., 2003. Isolation of novel ultramicrobacteria classified as Actinobacteria from five freshwater habitats in Europe and Asia. Applied and Environmental Microbiology $69,1442-1451$.

Haller, C.M., Rolleke, S., Vybiral, D., Witte, A., Velimirov, B., 2000. Investigation of $0.2 \mu \mathrm{m}$ filterable bacteria from the Western Mediterranean Sea using a molecular approach: dominance of potential starvation forms. FEMS Microbiology Ecology $31,153-161$.

Heulin, T., Barakat, M., Christen, R., Lesourd, M., Sutra, L., De Luca, G., Achouak, W., 2003. Ramlibacter tataouinensis gen. nov., sp. nov., and Ramlibacter henchirensis sp. nov., cyst-producing bacteria isolated from subdesert soil in Tunisia. International Journal of Systematic and Evolutionary Microbiology 53, 589-594.

Huber, H., Hohn, M.J., Rachel, R., Fuchs, T., Wimmer, V.C., Stetter, K.O., 2002. A new phylum of archaea represented by a nanosized hyperthermophilic symbiont. Nature 417, 63-66.

Huber, T., Faulkner, G., Hugenholtz, P., 2004. Bellerophon: A program to detect chimeric sequences in multiple sequence alignments. Bioinformatics 20, 23172319.

Iizuka, T., Yamanaka, S., Nishiyama, T., Hiraishi, A., 1998. Isolation and phylogenetic analysis of aerobic copiotrophic ultramicrobacteria from urban soil. Journal of General and Applied Microbiology 44, 75-84.

Irgens, R.L., Gosink, J.J., Staley, J.T., 1996. Polaromonas vacuolata gen. nov., sp. nov., a psychrophilic, marine, gas vacuolate bacterium from Antarctica. International Journal of Systematic and Evolutionary Microbiology 46, 822-826.

Janssen, P.H., Schuhmann, A., 1997. Novel anaerobic ultramicrobacteria belonging to the Verrucomicrobiales lineage of bacterial descent isolated by dilution culture from anoxic rice paddy soil. Applied and Environmental Microbiology 63, 1382.

Janssen, P.H., Yates, P.S., Grinton, B.E., Taylor, P.M., Sait, M., 2002. Improved culturability of soil bacteria and isolation in pure culture of novel members of the divisions Acidobacteria, Actinobacteria, Proteobacteria, and Verrucomicrobia. Applied and Environmental Microbiology 68, 2391-2396.

Jeon, C.O., Park, W., Ghiorse, W.C., Madsen, E.L., 2004. Polaromonas 
naphthalenivorans sp. nov., a naphthalene-degrading bacterium from naphthalene-contaminated sediment. International Journal of Systematic and Evolutionary Microbiology 54, 93-97.

Joseph, S.J., Hugenholtz, P., Sangwan, P., Osborne, C.A., Janssen, P.H., 2003. Laboratory cultivation of widespread and previously uncultured soil bacteria. Applied and Environmental Microbiology 69, 7210-7215.

Kaempfer, P., Busse, H.-J., Falsen, E., 2006. Polaromonas aquatica sp. nov., isolated from tap water. International Journal of Systematic and Evolutionary Microbiology 56, 605-608.

Kirchhof, G., Eckert, B., Stoffels, M., Baldani, J.I., Reis, V.M., Hartmann, A., 2001. Herbaspirillum frisingense sp. nov., a new nitrogen-fixing bacterial species that occurs in C4-fibre plants. International Journal of Systematic and Evolutionary Microbiology 51, 157-168.

Kneip, C., Lockhart, P., VoSz, C., Maier, U.-G., 2007. Nitrogen fixation in eukaryotes new models for symbiosis. BMC Evolutionary Biology 7, 55.

Kumar, S., Tamura, K., Nei, M., 2004. MEGA3: Integrated software for molecular evolutionary genetics analysis and sequence alignment. Briefings in Bioinformatics 5, 150-163.

Lindahl, V., Frostegård, A., Bakken, L., Bååth, E., 1997. Phospholipid fatty acid composition of size fractionated indigenous soil bacteria. Soil Biology and Biochemistry 29, 1565-1569.

Miteva, V.I., Brenchley, J.E., 2005. Detection and isolation of ultrasmall microorganisms from a 120,000-year-old Greenland glacier ice core. Applied and Environmental Microbiology 71, 7806-7818.

Miyoshi, T., Iwatsuki, T., Naganuma, T., 2005. Phylogenetic characterization of 16S rRNA gene clones from deep-groundwater microorganisms that pass through 0.2micrometer-pore-size filters. Applied and Environmental Microbiology 71, 10841088.

Olivares, F.L., Baldani, V.L.D., Reis, V.M., Baldani, J.I., Döbereiner, J., 1996. Occurrence of the endophytic diazotrophs Herbaspirillum spp. in roots, stems, and leaves, predominantly of Gramineae. Biology and Fertility of Soils 21, 197200.

Polz, M.F., Harbison, C., Cavanaugh, C.M., 1999. Diversity and heterogeneity of epibiotic bacterial communities on the marine nematode Eubostrichus dianae. Applied and Environmental Microbiology 65, 4271-4275. 
Reichenbach, H., Kleinig, H., 1974. The pigments of Flexibacter elegans: Novel and chemosystematically useful compounds. Archives of Microbiology 101, 131-144.

Roesti, D., Ineichen, K., Braissant, O., Redecker, D., Wiemken, A., Aragno, M., 2005. Bacteria associated with spores of the arbuscular mycorrhizal fungi Glomus geosporum and Glomus constrictum. Applied and Environmental Microbiology 71, 6673-6679.

Roszak, D.B., Colwell, R.R., 1987. Metabolic activity of bacterial cells enumerated by direct viable count. Applied and Environmental Microbiology 53, 2889-2893.

Rutz, B.A., Kieft, T.L., 2004. Phylogenetic characterization of dwarf archaea and bacteria from a semiarid soil. Soil Biology and Biochemistry 36, 825-833.

Salinas, K.A., Edenborn, S.L., Sexstone, A.J., Kotcon, J.B., 2007. Bacterial preferences of the bacterivorous soil nematode Cephalobus brevicauda (Cephalobidae): Effect of bacterial type and size. Pedobiologia 51, 55-64.

Schoenborn, L., Yates, P.S., Grinton, B.E., Hugenholtz, P., Janssen, P.H., 2004. Liquid serial dilution is inferior to solid media for isolation of cultures representative of the phylum-level diversity of soil bacteria. Applied and Environmental Microbiology 70, 4363-4366.

Schut, F., Prins, R.A., Gottschal, J.C., 1997. Oligotrophy and pelagic marine bacteria: Facts and fiction. Aquatic Microbial Ecology 12, 177-202.

Schut, F., De Vries, E.J., Gottschal, J.C., Robertson, B.R., Harder, W., Prins, R.A., Button, D.K., 1993. Isolation of typical marine bacteria by dilution culture: Growth, maintenance, and characteristics of isolates under laboratory conditions. Applied and Environmental Microbiology 59, 2150-2160.

Sizova, M., Panikov, N., 2007. Polaromonas hydrogenivorans sp. nov., a psychrotolerant hydrogen-oxidizing bacterium from Alaskan soil. International Journal of Systematic and Evolutionary Microbiology 57, 616-619.

Swings, J.G., Civerolo, E.L., 1993. Xanthomonas. Chapman and Hall, London.

Tatusova, T.A., Madden, T.L., 1999. BLAST 2 SEQUENCES, a new tool for comparing protein and nucleotide sequences. FEMS Microbiology Letters 174, 247-250.

Thomas, V., Herrera-Rimann, K., Blanc, D.S., Greub, G., 2006. Biodiversity of amoebae and amoeba-resisting bacteria in a hospital water network. Applied and Environmental Microbiology 72, 2428-2438.

Torrella, F., Morita, R.Y., 1981. Microcultural study of bacterial size changes and microcolony and ultramicrocolony formation by heterotrophic bacteria in 
seawater. Applied and Environmental Microbiology 41, 518-527.

Wright, E.L., Delp, C.H., Sponaugle, K.,. Cole, C., Ammons, J.T., Gorman, J., Childs, F.D., 1982. Soil Survey of Marion and Monongalia Counties, West Virginia. U.S. Depart. of Agriculture, Soil Conservation Service.

Young, K.D., 2006. The selective value of bacterial shape. Microbiology and Molecular Biology Reviews 70, 4.

Zuberer, D.A., 1994. Recovery and enumeration of viable bacteria. In: Weaver, R.W. (Ed.), Methods of soil analysis, part 2. Microbiological and biochemical properties. Soil Science Society of America, Madison, Wisconsin, pp. 119-144. 


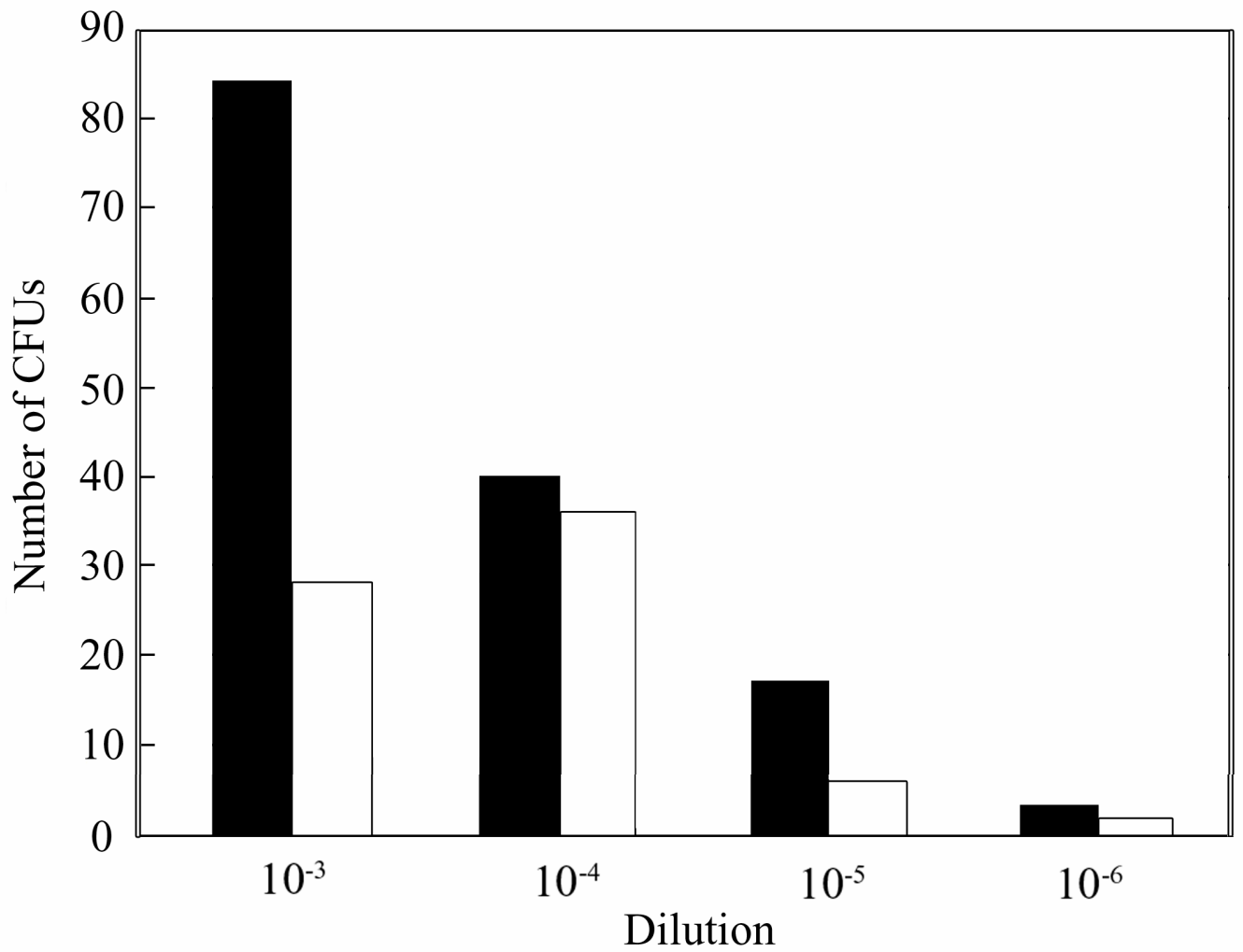

Figure 2.1. Number of small cell colonies on $\mathrm{R} 2 \mathrm{~A}$ plates inoculated with four dilutions of soils from the high-input (black bars) and low-input (white bars) plots at the market garden at the West Virginia University organic research farm on June 26, 2003. Plates were incubated for 2 weeks at $25^{\circ} \mathrm{C}$. 
(a)

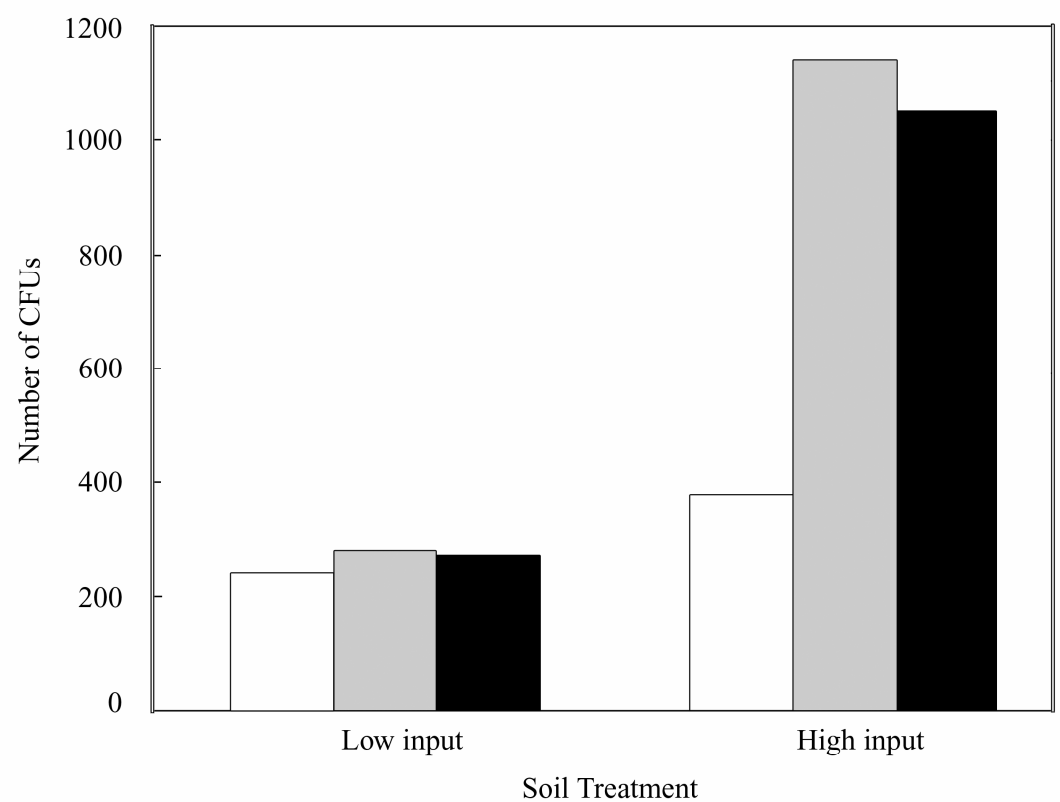

(b)

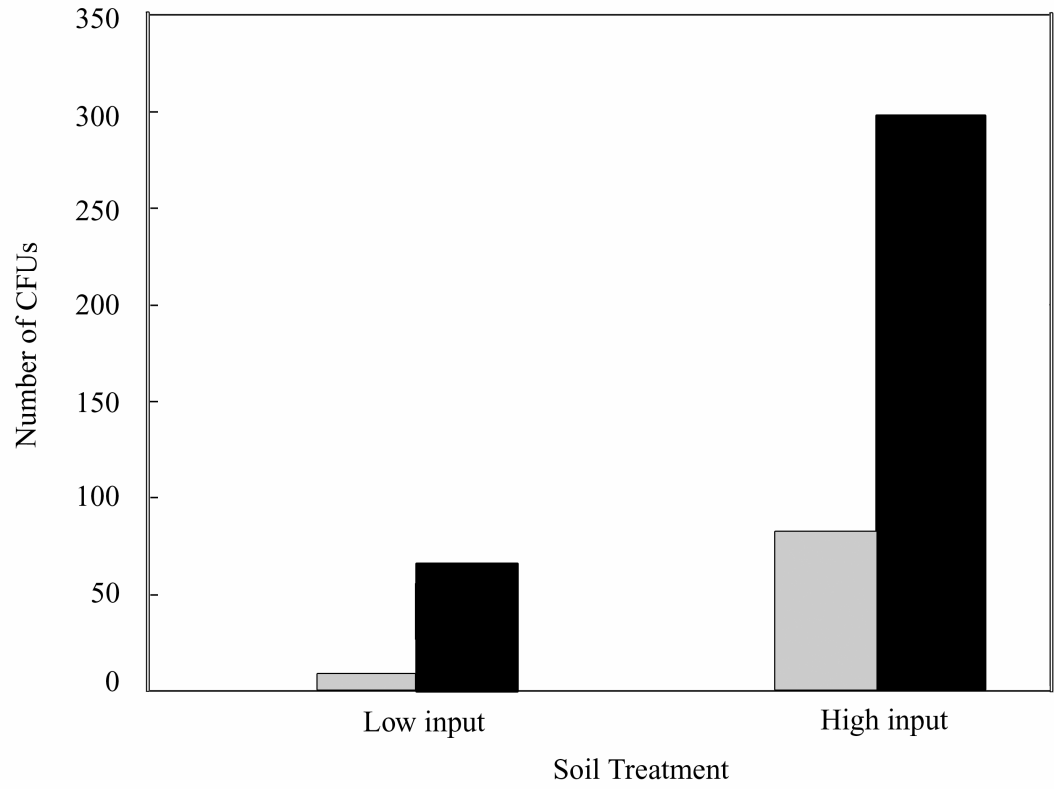


Figure 2.2. Appearance of bacterial colonies on R2A agar $24 \mathrm{hrs}$ (white bars), 1 week (gray bars) and 1 month (black bars) for (a) nonfiltered communities $\left(10^{-7}\right.$ dilution) and (b) filtered $\left(10^{-2}\right.$ dilution). Bacteria were isolated from soil collected from high- and lowinput plots located at the West Virginia University organic market garden on June 8, 2004. 


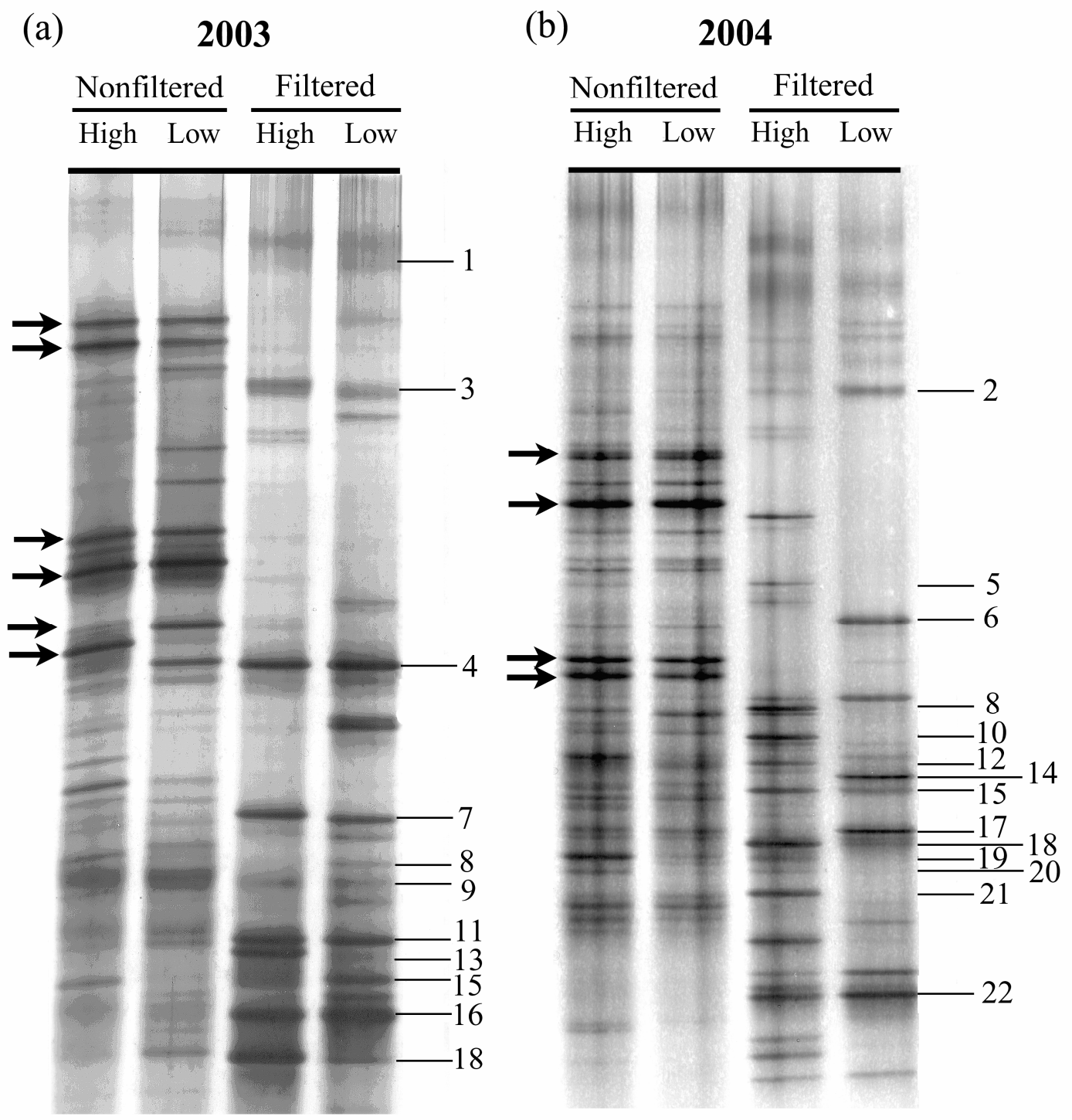

Figure 2.3. PCR-DGGE fingerprint of partial $16 \mathrm{~S}$ rRNA genes from filtered and nonfiltered bacterial communities isolated from high- and low-input soils in (a) 2003 and (b) 2004. Band numbers are associated with sequenced 16S clones presented in Figures 2.6 and 2.7. Black arrows designate bands referenced in text. 
Similarity Based on Sorensen's Index

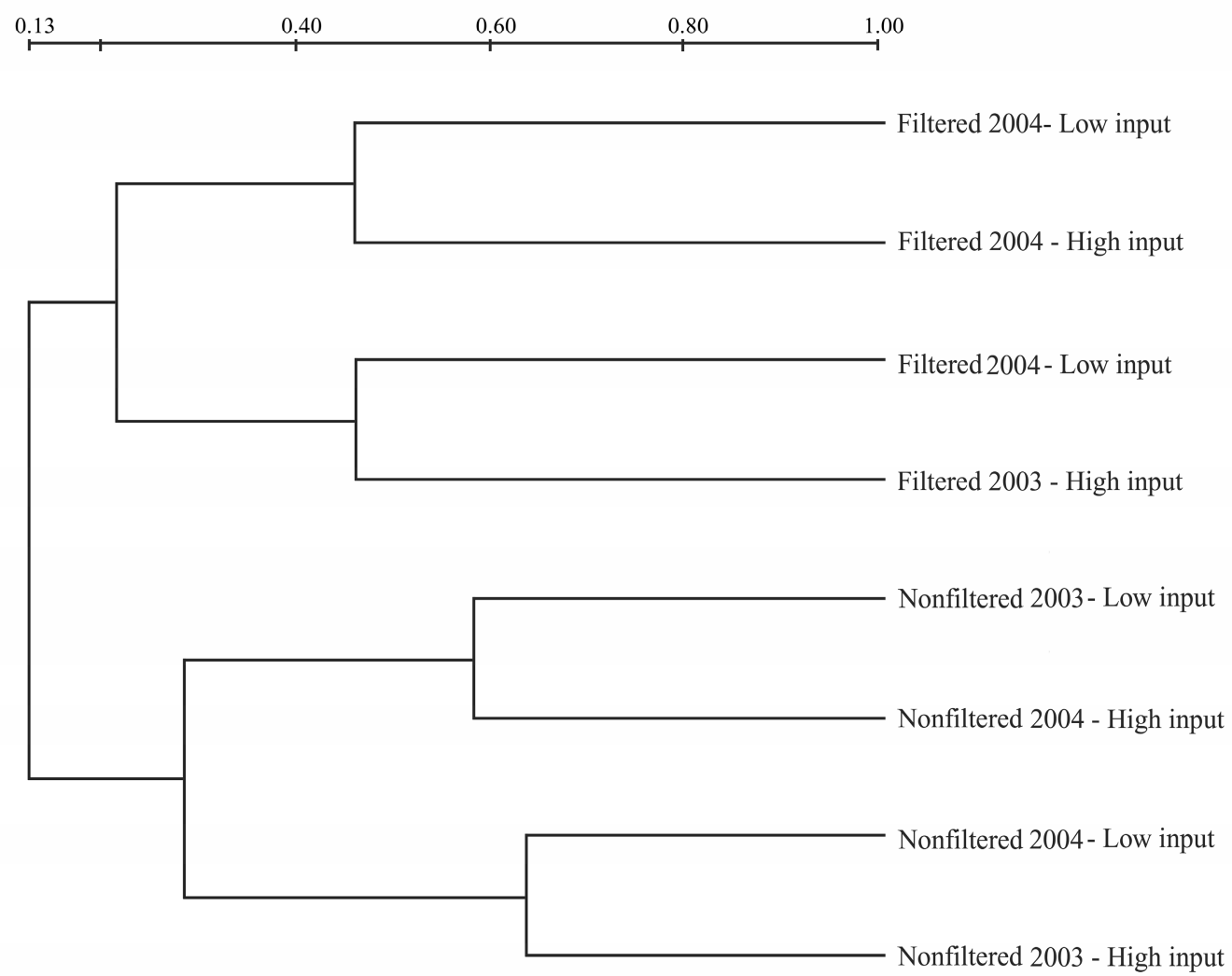

Figure 2.4. UPGMA dendrogram of filtered and unfiltered bacterial communities in high- and low-input soils from the organic farm in June 2003 and 2004. 

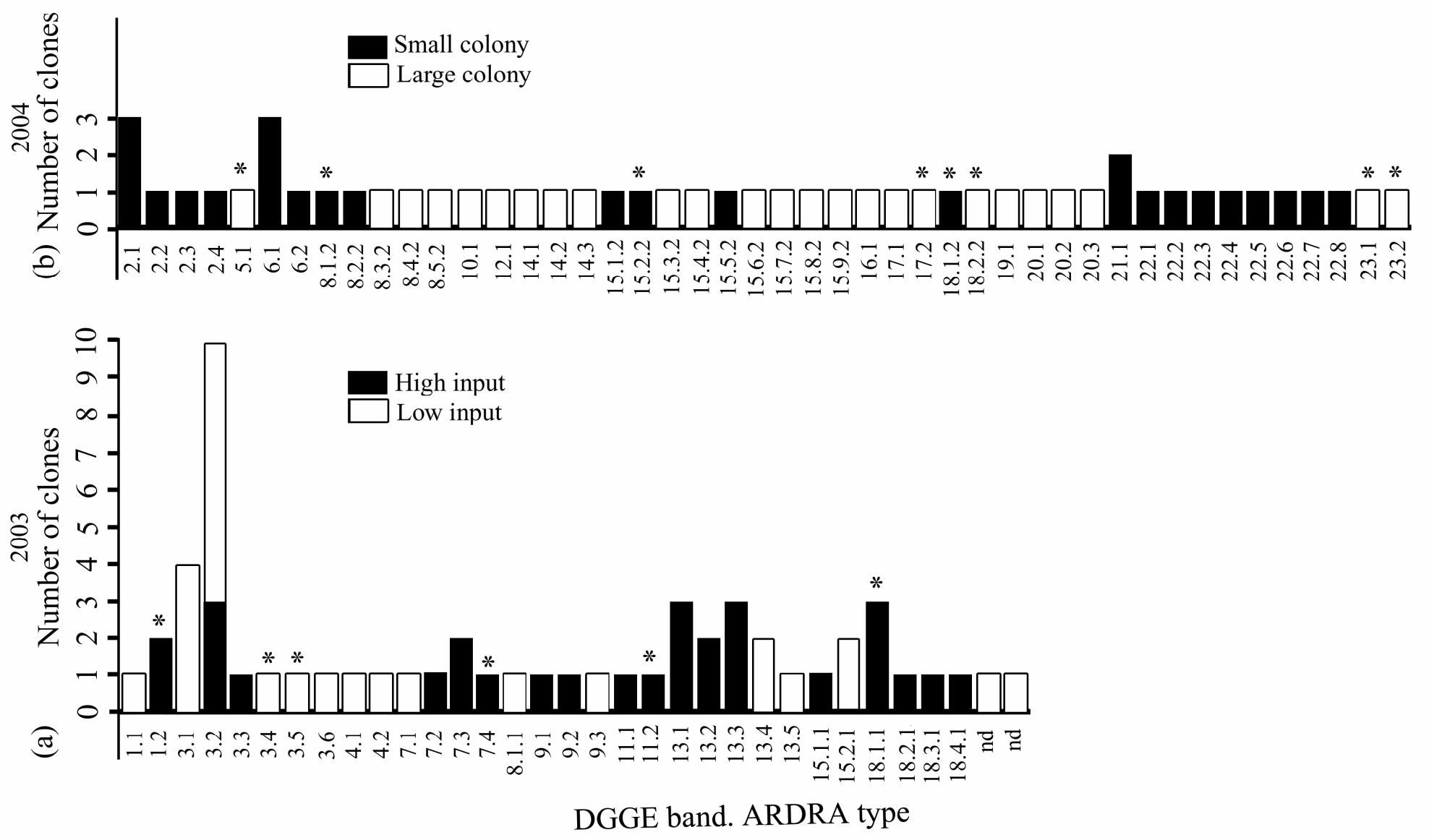
Figure 2.5. Distribution of ARDRA patterns for $16 \mathrm{~S}$ rDNA clones from small-celled bacteria from (a) 2003 (b) and 2004. Clones from 2003 were classified into two groups based on the source (filterable bacteria from high- or low-input soil) of the 16S rRNA sequences. Clones from 2004 were classified into two groups based the colony size of the filterable bacteria that the $16 \mathrm{~S}$ rRNA sequences were isolated from. Asterisks indicate putative chimeric sequences identified using Bellerophon. 


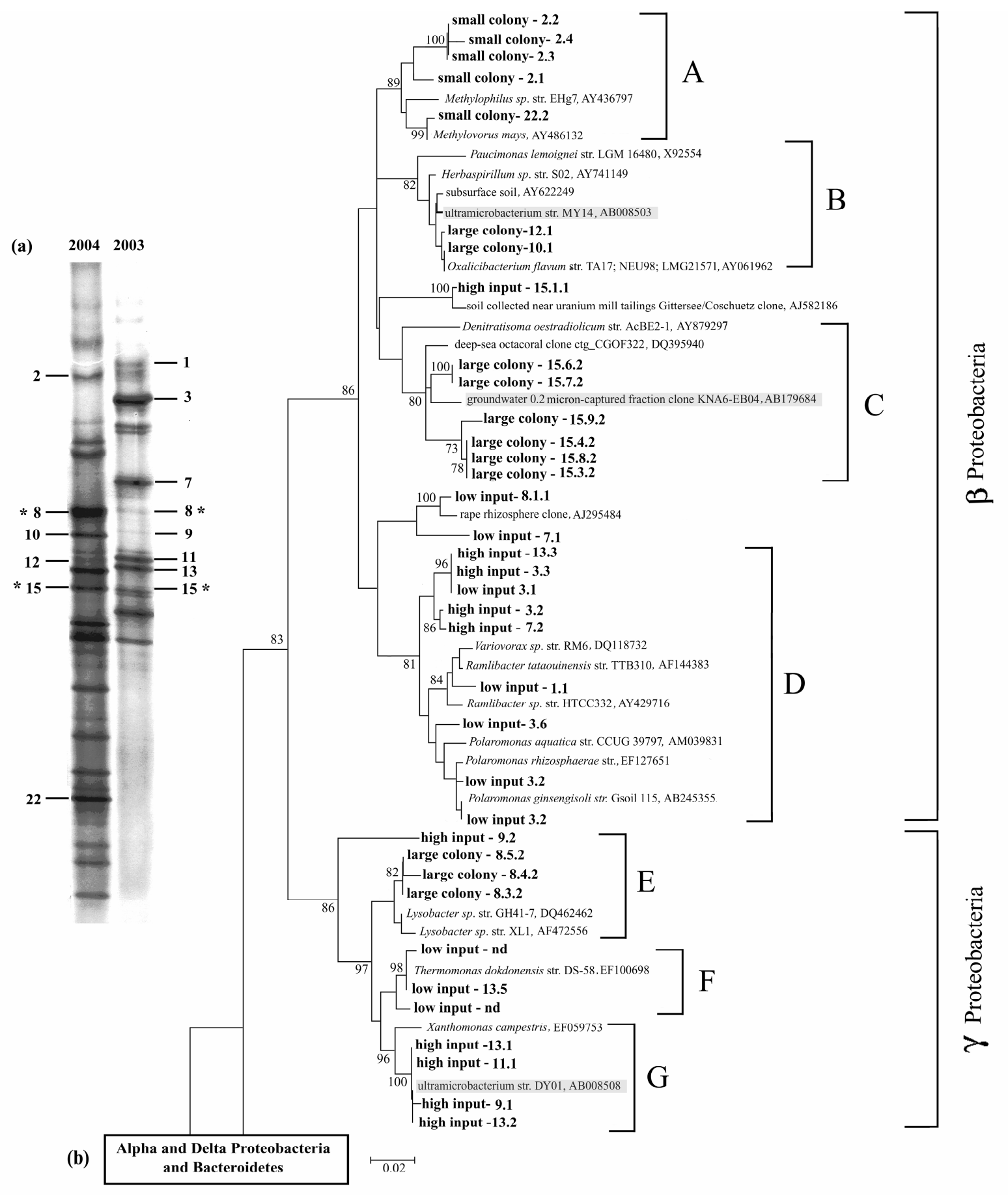


Figure 2.6. (a) PCR-DGGE of partial 16S rRNA genes and (b) neighbor-joining phylogenetic tree of $\beta$ and $\gamma$ Proteobacteria 16S rDNA sequences of clones from filterable bacteria from 2003 and 2004. Clone identifications refer to the soil source (high- or low-input) or the bacterial colony type (large or small colony) associated with the bacterial sources of the 16S rRNA genes and the DGGE band and ARDRA pattern associated with each clone. Asterisks indicate bands with 16S rDNA sequences detected in both 2003 and 2004 and gray boxes highlight important reference sequences discussed in the text. Sub-clusters are identified in each group using the letters A through G. Bootstrap values greater than $70 \%$ are presented at nodes. Scale bar represents 0.02 substitutions per nucleotide position. 


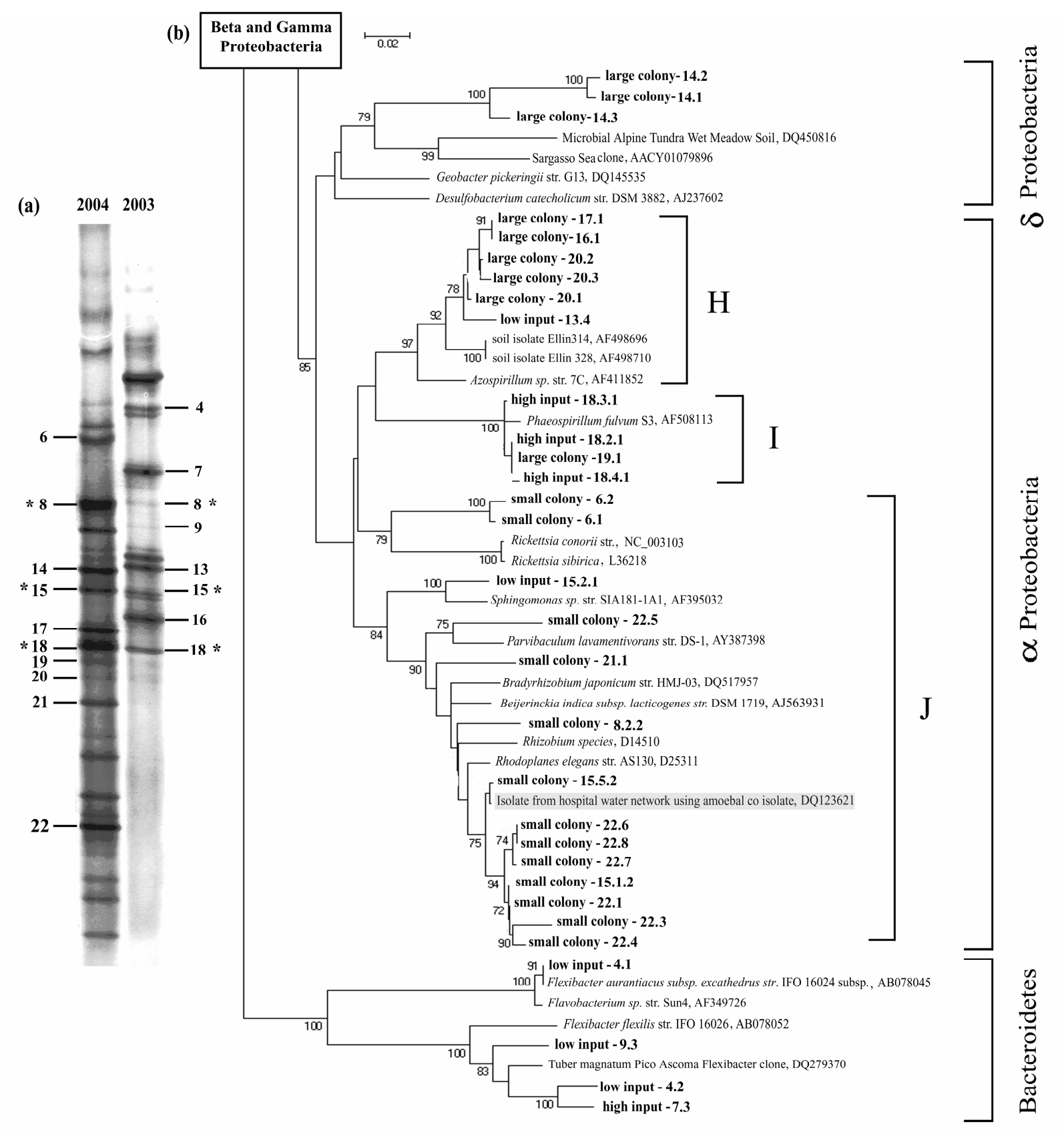


Figure 2.7. (a) PCR-DGGE of partial $16 \mathrm{~S}$ rRNA genes and (b) neighbor-joining phylogenetic tree of $\alpha$ and $\delta$ Proteobacteria and Bacteroidites 16S rDNA sequences of clones from small-celled bacteria from 2003 and 2004. Clone identifications refer to the soil source (high- or low-input) or the bacterial colony type (large or small colony) associated with the bacterial sources of the 16S rRNA genes and the DGGE band and ARDRA pattern associated with each clone. Asterisks indicate bands with 16S rDNA sequences detected in both 2003 and 2004 and gray boxes highlight important reference sequences discussed in the text. Sub-clusters are identified in each group using the letters $\mathrm{H}$ through J. Bootstrap values greater than $70 \%$ are presented at nodes. Scale bar represents 0.02 substitutions per nucleotide position. 


\title{
Chapter 3: Response of Culturable Bacterial Communities in Upland Pasture and Organic Farm Soils to Agronomic Treatment
}

\begin{abstract}
Culturable soil bacteria may exhibit significant short-term variation in community structure, providing a responsive indication of anthropogenic disturbances. In the present study, microbial biomass carbon $(\mathrm{MBC})$, potentially mineralizable nitrogen (PMN), community level physiological profiling (CLPP), and culture-dependent DGGE (CD DGGE) fingerprinting of the $16 \mathrm{~S}$ rRNA gene were used to compare culturable microbial communities in organic farm and pasture soils subjected to differing agronomic treatments. Multiple and simple correlation analyses revealed significant relationships between $\mathrm{MBC}$, PMN, and variables derived from principal component analysis (PCA) of CLPP data as well as non-metric multidimensional scaling (NMDS) of CD DGGE data. All measures clearly separated soil types, but varied in their ability to distinguish among treatments within a soil type. Overall, MBC, PMN, and CLPP were most responsive to additions of compost (organic farm) and manure (pasture), while CD DGGE resolved differences in legume cropping (organic farm) and inorganic fertilization (pasture). Assessment of culturable soil bacteria using CLPP and CD DGGE provided nonredundant and useful indications of selected agronomic perturbations.
\end{abstract}

Keywords: Culturable bacteria, Cultivable, DGGE, CLPP, Community structure, Functional diversity, Compost, Manure, Organic Farm, Pasture. 


\section{Introduction}

Well-functioning agricultural soils sustain biological productivity, promote environmental quality, and maintain plant and animal health (Doran and Parkin, 1994). Measurements of soil functionality encompass a variety of physical, chemical, and microbiological parameters. Microorganisms serve as dynamic indicators of a soil's quality due their essential roles in organic matter decomposition, nutrient cycling, and plant productivity (Kennedy and Papendick, 1995; Sun et al., 2004). Parameters that integrate diverse microbial populations into a single measure, such as microbial biomass carbon $(\mathrm{MBC})$ and potentially mineralizable nitrogen $(\mathrm{PMN})$, historically have proven to be useful and are widely employed measures of soil quality (Stenberg, 1999; Ibekwe et al., 2002). Microbial biomass $\mathrm{C}$ encompasses a small labile fraction of total soil organic carbon that responds actively to changes in soil fertility, supports soil aggregation, and can be related to environmental factors such as climate, soil moisture, texture, and organic matter quality (Templer et al., 2003). Potentially mineralizable nitrogen provides an index of a soil's nitrogen supplying capacity and has been positively correlated with other chemical and physical indicators of soil quality (Ibekwe et al., 2002).

More recently, workers have attempted to open the "black box" of soil microbial dynamics, seeking to assess and compare detailed changes in microbial populations resulting from implementation of differing agronomic practices (Tiedje et al., 1999). Various measures of microbial community structure have been proposed as appropriate indicators of changing soil quality (Stenberg, 1999; Schloter et al., 2003). Functional diversity assessed via community-level physiological profiling (CLPP) employs a culture-based technique that characterizes the relative growth of the soil microbial 
community on a variety of carbon substrates. CLPP has been used successfully to discriminate soil microbial communities based on soil type (Widmer et al., 2001; Girvan et al., 2003), amendment with crop residues and urine (Sharma et al., 1998; Williams et al., 2000; Bending et al., 2002; Malosso et al., 2005), and crop species and crop rotation (Bending et al., 2000; Miethling et al., 2000). A variety of non-culturing methodologies have been developed that rely on nucleic acid extraction followed by gene amplification to characterize the soil microbial community (Nakatsu, 2007; Thies, 2007). Cultureindependent molecular methods theoretically provide a better representation of total species richness, since they include novel, numerically-abundant, but previously unculturable groups such as the Acidobacteria and Verrucomicrobia (Amann, 1995; Hugenholtz et al., 1998; Øvreås and Torsvik, 1998; Barns et al., 1999; Girvan et al., 2003). The study of soil microbial communities is challenging, and currently no single methodology is without limitation nor provides a complete picture of total diversity (Farrelly et al., 1995; Konopka et al., 1998; Polz and Cavanaugh, 1998; Garland, 1999; Schmalenberger et al., 2001; Preston-Mafham et al., 2002; Thies, 2007). In order to provide more comprehensive profiles and a framework to evaluate the strengths and biases of each method, it is beneficial to examine multiple techniques in parallel to study bacterial communities (Girvan et al., 2003).

Despite the current prevalence of the culture-independent approach, evidence is emerging that culture-dependent profiles may be more responsive to anthropogenic perturbations (Ellis et al., 2003). In a recent study, I investigated a plate wash method to construct culture-dependent DGGE (CD DGGE) profiles of the 16S rRNA gene (Edenborn and Sexstone, 2007). The CD DGGE gels showed clear banding patterns of 
sufficient complexity and variability to investigate differences in microbial communities. In this paper CD DGGE, CLPP, MBC and PMN were used to compare and contrast bacteria in soils from a pasture and organic farm that have been subjected to different fertility regimes. The objectives of this study were to: to 1) evaluate the utility of CD DGGE to characterize the response of culturable bacterial communities to different soil fertility amendments and 2) compare and contrast the responsiveness of CD DGGE, CLPP, MBC and PMN microbial indicators to these agronomic treatments.

\section{Materials and Methods}

\section{Description of field sites and soil sampling}

The West Virginia University (WVU) Organic Research Farm is located in

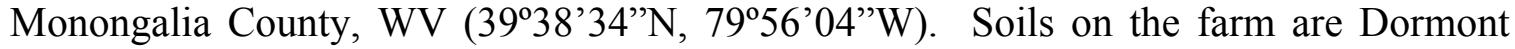
and Guernsy silt loams (fine loamy, mixed, superactive, mesic, Oxyaquic Hapludalfs). The market garden, established in 2000 , is a completely randomized design with four plots $(4.9 \times 7.6 \mathrm{~m})$ per treatment. Soil $\mathrm{pH}$ averaged 6.7 and was not significantly different between treatments (Childers, 2005). Treatments included fertility input (compost and green manure) and annual crop rotation among four plant families (Fabaceae, Solanaceae, Cucurbitaceae, and Asteraceae). High-input plots received

composted dairy manure (22.4 Mg ha ${ }^{-1}$ based on wet weight) and green manure (rye and vetch) applied and tilled into the soil 1-3 days prior to planting. Low-input plots received only green manure applied as described above. Details of compost analyses, soil fertility, and crop yield in the market garden have been reported by Childers (2005). In 2004, compost was applied to plots on April 19 (peas), May 11 (beans), and May 25 
(tomatoes/peppers). Composite (12 cores) surface soil samples $(15 \mathrm{~cm}$ depth $\times 2.5 \mathrm{~cm}$ diameter) were collected on June 8 and August 2 of 2004 from high- and low-input plots that had been planted with beans and peas (Legumes) and tomatoes and peppers (Solanaceae). Ten soil cores (16 cm depth $\times 2 \mathrm{~cm}$ diameter) were collected from each plot at $\sim 1.5$ meter intervals along two transects at midpoint between crop rows. Soil samples were bulked, placed in polyethylene bags, transported on ice to the laboratory, sieved (< $2 \mathrm{~mm}$ ) and refrigerated at $4^{\circ} \mathrm{C}$.

The West Virginia University Reedsville Experiment Farm is located in Preston County, WV $\left(39^{\circ} 30^{\prime} 55^{\prime} \mathrm{N}, 79^{\circ} 48^{\prime} 70^{\prime} \mathrm{W}\right)$. Soils on the farm are mapped in the Gilpin (fine-loamy, mixed, semiactive, mesic Typic Hapludults) and Wharton (fine-loamy, mixed, mesic Aquic Hapludults) soil series. Since 1998, this experimental pasture has been limed to maintain a $\mathrm{pH}$ circa 6.5 and fertilized with two levels of inorganic fertilizer inputs; i.e., high fertility (P $134 \mathrm{~kg} \mathrm{ha}^{-1}$ and $\mathrm{K} 390 \mathrm{~kg} \mathrm{ha}^{-1}$ ) or low fertility (P $67 \mathrm{~kg} \mathrm{ha}^{-1}$ and $\mathrm{K} 195 \mathrm{~kg} \mathrm{ha}^{-1}$ ). The pasture was subjected to the same annual grazing pressure (Prigge et al., 1999). The predominant pasture grasses were orchard grass (Dactylis glomerata L.), Kentucky bluegrass (Poa pratensis L.), and meadow fescue (Festuca elatior L.) interspersed with white clover (Trifolium repens) and red clover (Trifolium pratense).

In summer 2004, fenced experimental subplots were established on adjacent highand low-fertility pasture sites and amended with a manure treatment. The percentage of legumes averaged $36 \%$ and $10 \%$ in high- and low-fertility plots, respectively (Sutanto, 2005). Each plot was subdivided into quadrants (1 $\mathrm{m} \times 1 \mathrm{~m})$, which were randomly assigned to receive a manure patch or remain as an untreated control. Manure patches 
( $25 \mathrm{~cm}$ diameter, $5 \mathrm{~cm}$ height) were fabricated from fresh manure collected from the same fields. Four replicate quadrants from each treatment were sampled at day 0, 21, 40, 63, 123 after site establishment. On day 0 only the non-manured (control) soils were sampled. Twelve soil core samples ( $15 \mathrm{~cm}$ depth $\mathrm{x} 2.5 \mathrm{~cm}$ diameter) were collected from each quadrant. Core samples were bulked, placed in polyethylene bags, transported on ice to the laboratory, sieved $(<2 \mathrm{~mm})$ and refrigerated at $4^{\circ} \mathrm{C}$.

\section{$\underline{\text { Microbial biomass carbon and potentially mineralizable nitrogen }}$}

MBC was extracted from moist soil ( $80 \%$ water-filled porosity) according to the method of Islam and Weil (1998). Total carbon in soil extracts was measured using a Dohrmann ${ }^{\circledR}$ DC-190 TOC analyzer (Rosemount ${ }^{\circledR}$ Analytical Inc., Santa Clara, CA). PMN was determined according to the methods described in Keeney (1982). Duplicate field moist soil samples (5 gram) were placed in $20 \times 150 \mathrm{~mm}$ test tubes with $12.5 \mathrm{~mL}$ of sterile water. One replicate was extracted at time 0 with $12.5 \mathrm{~mL}$ of $4 \mathrm{M} \mathrm{KCl}$. The headspaces of the other replicates were filled with $\mathrm{N}_{2}$ to ensure an anaerobic incubation and then were incubated in the dark at $20^{\circ} \mathrm{C}$ for 7 days. At the end of 7 days, the incubated samples were shaken (60 minutes, $30 \mathrm{rpm}$ ) with an additional $12.5 \mathrm{~mL} 4 \mathrm{M}$ KCl. Supernatant was filtered through $0.45 \mu \mathrm{m}$ Millipore filter and frozen until further analysis. Ammonia in each sample was measured using a Lachat flow injection analyzer (Hach Company, Loveland, CO) using the phenolate method. 


\section{Community level physiological profiling}

The ability of soil microbial communities to utilize a variety of carbon sources was assessed using community-level physiological profiling originally developed by Garland and Mills (1991). Sterile Waring blenders were used to homogenize (1 min, max speed, 3x with intermittant cooling on ice) $20 \mathrm{~g}$ of soil in $180 \mathrm{~mL}$ Winogradsky Salts Solution (WSS; Zuberer, 1994). Homogenate was diluted $\left(10^{-3}\right)$ and used to inoculate $\left(100 \mu \mathrm{L}\right.$ well $\left.^{-1}\right)$ BIOLOG $^{\circledR}$ ECO Plate MicroPlates ${ }^{\mathrm{TM}}$ (Biolog Inc., Hayward, CA). The microplates were incubated at $25^{\circ} \mathrm{C}$ for five days. Utilization of the carbon source was monitored by measuring absorbance at $590 \mathrm{~nm}$. Readings were taken every 24 hours using an automated plate reader (SpectraMAX 340 pc, Molecular Devices, Sunnyvale, CA).

\section{Culture-dependent denaturing gradient gel electrophoresis}

Twenty grams (dry weight) of composite soil samples from each plot were placed in sterile Waring blenders and agitated for one minute at high speed (3x with intermittent cooling on ice) in $180 \mathrm{~mL}$ of sterile WSS. Blended suspensions were diluted $\left(10^{-2}\right)$ in sterile WSS and $100 \mu \mathrm{L}$ was plated onto each of four replicate agar plates (final dilution $=10^{-3}$ ) and incubated aerobically for two weeks at $25^{\circ} \mathrm{C}$. Cultured cells were washed sequentially from four replicate R2A plates using WSS (4 mL) and a sterile disposable inoculating loop. The resulting cell suspensions were vortexed and frozen $\left(-20^{\circ} \mathrm{C}\right)$. DNA was extracted from aliquots of each thawed cell suspension $(1.8 \mathrm{~mL})$ using the MoBio Microbial DNA extraction kit (MoBio Labs, Carlsbad, CA). The variable V3 region of the 16S rRNA gene from the domain Eubacteria was amplified using the PRBA338F 
primer with PRUN518R primer as previously described (Edenborn and Sexstone, 2007). Composite PCR products $(\sim 150 \mathrm{ng})$ were loaded into a polyacrylamide gel $(8 \%)$ with a $40 \%$ (16.8 g urea; $16 \mathrm{ml}$ formamide/100 $\mathrm{ml}$ ) to $60 \%$ ( $25.2 \mathrm{~g}$ urea; $24 \mathrm{ml}$ formamide/100 $\mathrm{ml}$ ) denaturing gradient and electrophoresed for $14-16$ hours at $50 \mathrm{~V}$ and $60^{\circ} \mathrm{C}$ using the DCode $^{\mathrm{TM}}$ Universal Mutation Detection System (BioRad). The gel was visualized by silver staining according to the protocol of Caetano-Anolles and Gresshoff (1994). The developed gel was scanned using Hewlett Packard ScanJet 7400c (Hewlett-Packard Co., Palo Alto, CA) at a resolution of 600 dpi and saved in uncompressed TIFF format for further analysis. A detailed description of this procedure is presented in Edenborn and Sexstone (2007).

\section{$\underline{\text { Data analysis }}$}

Differences between $\mathrm{MBC}$ organic farm (OF) and pastures (PAS) soils were tested using an analysis of variance (ANOVA) in a 2 X 3 factorial design (factor A: highand low-input (OF) or high- and low-fertility (PAS); factor B: time-crop combination (OF) or time-manure amendment combination (PAS)). PMN in organic farm soils was compared using a 2 X 2 Factorial (Factor A: high- and low-input; Factor B: time-crop combination). For pastures soils, the same factorial design used for MBC was used for PMN. Tukey's HSD test was used for post-ANOVA pair-wise comparisons.

Total well color development (TWCD) for BIOLOG® ECO plates was calculated as the sum of absorbance values determined after 63 hours of incubation. Average well color development (AWCD) was calculated from the mean for those 31 absorbance values. Substrate diversity $(H)$ was calculated as $H=-\sum p_{i} \ln \left(p_{i}\right)$, where $p_{i}$ is the 
proportion of total microbial activity on a particular carbon source. Substrate richness (S) was calculated from the total number of wells with absorbance values greater than 0.25 . Substrate evenness (E) was calculated as $E=H / \ln (S)$. Data were normalized by dividing each substrate absorbance value by the AWCD (Garland and Mills, 1991). Robust principal component analysis (PCA) was done on a covariance matrix of normalized data using alpha $=0$.

DGGE gels were analyzed using Quantity One gel analysis software (BioRad, Hercules, CA). Analysis of the bands was done by setting background subtraction at 15 using a rolling disk method and generating intensity profiles to evaluate and compare peak size, shape and location. Bands were picked manually for a limit of intensity $>0.05$. Similarity matrices were calculated with Sorensen's index based on the presence/absence of peaks. Analysis of similarity (ANOSIM) was used to determine significant differences between DGGE banding profiles. In ANOSIM, an R value greater than 0 indicates that objects (DGGE profiles) are more dissimilar between groups than within groups and a P value indicates the level of significance (Rees et al., 2004). Enhanced non-metric multidimensional scaling (NMDS) was used to ordinate DGGE data (Fromin et al., 2002; Rees et al., 2004). The ability of NMDS to provide a good representation of similarity data in two-dimensional space was evaluated based on Kruskal's stress values. Stress values < 0.15 indicate that the ordination plots presented were useful representations of the CD DGGE data (Rees et al., 2004).

Multiple and simple correlations analysis was used to assess associations between principal component, NMDS axis scores, MBC and PMN data. Statistical analyses were 
done in R (R Development Core Team 2004) or SAS (SAS Institute Inc., Cary, NC). ANOSIM and NMDS were done using the R package Vegan (Oksanen, 2005).

\section{Results}

$\underline{\text { Microbial biomass carbon and potentially mineralizable nitrogen }}$

In the present study, levels of $\mathrm{MBC}$ were found to be an order of magnitude higher in pasture soils compared with the organic farm (Table 3.1). In both systems, amendment with manure or compost and season resulted in significant differences in MBC. MBC levels in organic farm soils were significantly affected by input $(\mathrm{F}=17.57, \mathrm{P}$ $\left.<0.001^{* * *}\right)$ and the time-crop combination $\left(\mathrm{F}=7.51, \mathrm{P}<0.004^{* *}\right)$. The interaction between these two factors was not statistically significant $(\mathrm{F}=2.19, \mathrm{P}<0.134)$. Multiple comparison using Tukey's HSD test indicated that the MBC in high-input plots (June) was significantly different from the other soils except the high-input plots planted with legumes (August) (Table 3.1). In pastures, MBC was significantly affected by manure amendment and time $\left(\mathrm{F}=17.78, \mathrm{P}<0.001^{* * *}\right)$, but not fertilizer amendment $(\mathrm{F}=1.20, \mathrm{P}<$ 0.287). The interaction was not significant $(\mathrm{F}=2.58, \mathrm{P}<0.103)$. $\mathrm{MBC}$ was significantly higher in September than in May, and the greatest amount of MBC was found in plots that had been amended with manure (Table 3.1). Clear statistical differences between inorganic fertilizer applications were not demonstrated; however, lower levels of MBC generally were observed in low- compared with high-fertility plots, both in May and September.

Pasture soils on average contained four times more PMN than organic farm soils

(Table 3.1). In organic farm soils, a significant difference in PMN was found due to input $\left(\mathrm{F}=4.87, \mathrm{P}<0.048^{* *}\right)$ but neither time-crop combination $(\mathrm{F}=0.99, \mathrm{P}<0.339)$ nor the 
interaction of these two factors was significant $(\mathrm{F}=0.757, \mathrm{P}<0.402)$. When individual means were compared using Tukey's HSD, no differences were found in PMN between different soils (Table 3.1). In pastures, both fertilizer input $(\mathrm{F}=4.93, \mathrm{P}<0.040 * *)$ and time-manure amendment $\left(\mathrm{F}=7.43, \mathrm{P}<0.004^{* *}\right)$ were found to have a significant effect on $\mathrm{PMN}$ without any interaction $(\mathrm{F}=0.203, \mathrm{P}<0.979)$. Plots with manure contained significantly higher levels of PMN than plots that had not been amended with manure (Table 3.1).

\section{Community level physiological profiling}

Shannon diversity indices ranged between 3.26-3.35 and 3.27-3.29; richness values ranged from 28-30 and 28-29; and evenness from 0.975-0.982, and 0.975-0.977 for the organic farm and pasture soils, respectively. Using Tukey's HSD test to separate means, I observed no significant differences $(\mathrm{P}>0.05)$ in functional diversity indices based on soil type or agronomic treatment (data not shown).

Despite the lack of treatment discrimination by diversity parameters, ordination of the CLPP data using principal component analysis clearly distinguished low-input organic farm soils from other soils. Bryant and Yarnold (2005) suggest that the minimum number of samples should be at least five times the number of variables in order to achieve a reliable PCA analysis Thirty-one substrate vectors (substrates) also confound the interpretation of biplots. Therefore, I first performed PCA on all 31 substrates to identify the most strongly-loaded, non-colinear substrates. Ten of these substrates were then used for a subsequent PCA. These substrates were: L-arginine, Dcelliobiose, cyclodextrin, i-erythritol, 2-hydroybenzoic acid, D-lactose, L-phenylalanine, 
phenylethylamine, L-threonine, and D-xylose. Ordination of these data is presented in Figure 3.1 where the distinct cluster formed by low-input organic farm soils can be visualized. In this analysis, $75 \%$ of the variance was accounted for by the first three principal components. The first principal component was most strongly correlated with the utilization of L-phenylalanine (-0.94), D-lactose $(-0.68)$ and L-threonine $(-0.61)$. Principal component 2 was most strongly correlated with 2-hydroxybenzoic acid (0.87), and principal component 3 was most strongly correlated with phenylethylamine $(0.95)$ and L-arginine (0.69).

\section{$\underline{\text { Culture-dependent denaturing gradient gel electrophoresis }}$}

To facilitate comparison of all soils and treatments on a single gel, replicate PCR products from samples obtained in August or September were first pooled. The resultant CD DGGE profiles of $16 \mathrm{~S}$ rDNA showed distinct differences between culturable bacterial communities in organic farm and pasture soils (Figure 3.2a). Culturable bacterial communities in the two soil types were highly distinct (ANOSIMS; R=1.00, $\mathrm{P}$ $\left.<0.023^{* *}\right)$. Ordination of the data using NMDS demonstrated that legume cropping (OF) and fertilizer (PAS) had more impact on the structure of culturable soil bacterial communities than organic matter amendments (compost or manure) (Figure 3.2b).

Temporal changes in CD DGGE fingerprints were determined following application of manure pats to pasture soil treatment plots. Prior to application of manure (day 0), five replicate soil samples were collected from high- and low-fertility plots and the culturable bacterial communities characterized. Significant differences were found between the high- and low-fertility plots on day 0 (ANOSIMS; $\mathrm{R}=0.36, \mathrm{P}<0.018^{* *}$ ). 
NMDS analysis of these data is presented in Figure 3.3a. As the manure pats decomposed, additional samples were collected on days 21, 40, and 63. At each sampling time, PCR products from three replicate plots per treatment were combined to create a composite profile. There were significant differences in bacterial communities due to time (ANOSIMS; $\mathrm{R}=0.36, \mathrm{P}<0.013^{* *}$ ); however, no significant differences were observed due to treatment $(\mathrm{R}=-0.162, \mathrm{P}<0.835)$. Ordination of the data also revealed distinct clustering based on sampling time (Figure 3.3b).

In June and August, soils collected from three replicate plots per treatment at the organic farm were used for CD DGGE analysis. There were no significant differences in CD DGGE profiles from different treatments in June (ANOSIMS; $\mathrm{R}=0.44, \mathrm{P}<0.087$ ); however, significant differences were observed in August $\left(\mathrm{R}=0.454, \mathrm{P}<0.006^{* *}\right)$. Bacterial communities from tomato and pepper plots (high and low fertility) collected in both June and August clustered together (Figure 3.4a). In contrast, the communities from soils that had been planted with legumes clustered separately from those from soils planted with tomatoes and peppers and from each other (Figure 3.4b).

In this study, Kruskal's stress values for all analyses were $<0.15$, indicating that the ordination plots presented were useful representations of the CD DGGE data (Rees et al., 2004).

\section{Correlations between MBC, PMN, CLPP, and CD DGGE}

Multiple correlation analysis was used to explore potential relationships between the principal component scores from the PCA analysis of CLPP data (Figure 3.1) and other measured variables. Significant correlations were observed between the CLPP 
principal components and $\mathrm{MBC}\left(\mathrm{R}=0.71, \mathrm{P}<0.001^{* * *}\right)$ and $\mathrm{PMN}(\mathrm{R}=0.47, \mathrm{P}<$ $0.007^{* *}$ ). When organic farm and pasture sample were analyzed separately the correlations improved $\left(\mathrm{R}>0.85, \mathrm{P}<0.001^{* * *}\right)$ for $\mathrm{MBC}$ and $\mathrm{PMN}$ from both systems. Multiple correlations between the CLPP principal components (Figure 3.1) and the axis scores from NMDS of CD DGGE data from the organic farm samples in August 2004 (Figure 3.4b) also were highly significant (dimension 1: $\mathrm{R}=0.99, \mathrm{P}<0.001 * * *$; dimension 2: $\left.\mathrm{R}=0.98, \mathrm{P}<0.001^{* * *}\right)$. Multiple correlation analysis was not performed on pasture data because samples for CD DGGE and CLPP were collected on different sampling dates. Simple correlations were performed for both agronomic systems using axis scores from NMDS of CD DGGE data and the MBC and PMN data. In both soil systems, significant correlations were found between the DGGE axis scores and MBC (Figure 3.5) but not between DGGE axis scores and PMN (data not shown).

\section{Discussion}

Microbial biomass carbon and potentially mineralizable nitrogen

Microbial biomass carbon and potentially mineralizable nitrogen are broad indicators of soil quality that assess microorganisms at the level of the whole microbial community (Stenberg, 1999). In the present study, both MBC and PMN were responsive to compost and manure input to organic farm and pasture soils, respectively. The effects of compost amendment in organic farm soils generally were transitory. For example, MBC levels in the high-input plots planted with tomatoes and peppers were significantly higher than in low-input soils two weeks after application of compost, but decreased to similar levels by ten weeks. This decreasing trend in MBC following compost 
amendment may be due to increased carbon mineralization rates following regular soil tillage employed to control weeds in this organic production system (Childers, 2005). High-input legume plots at the organic farm sustained the highest levels of MBC throughout the sampling period, perhaps due to higher $\mathrm{N}$ availability in these plots. Both MBC and PMN in manure-treated high-fertility pastures remained significantly higher than other treatments 17 weeks following amendment. In the absence of manure, clear differences were not apparent among MBC and PMN as a function of inorganic fertilizer applications in pasture soils.

Changes in MBC and/or PMN due to crop rotation, legume cropping, manure amendment, and compost application (Moore et al., 2000; Andrews et al., 2002; Parham et al., 2002; Ginting et al., 2003; Girvan et al., 2003; Canali et al., 2004; Kang et al., 2005) have been observed previously. Reported effects of nitrogen additions on MBC and PMN have been contradictory. Some studies have shown increased MBC following N fertilizer application (Fraser et al., 1994; Omay et al., 1997), while others have found no effect (Moore et al., 2000; Cookson et al., 2005). Ginting et al. (2003) reported that soils receiving nitrogen fertilizer had PMN values lower than those receiving manure and compost but higher than those of control soils. In contrast, Kang et al. (2005) observed slightly higher levels of PMN in fertilized soils than in control soils, and Cookson et al. (2005) reported no differences in PMN in fertilized and unfertilized soils. Fisk and Fehey (2001) have suggested that biomass pools in fertilized soils may be smaller but more physiologically active than those found in unfertilized soil. 


\section{Community-level physiological profiling}

CLPP is a widely-used technique appropriate for screening relative shifts in microbial communities, conducting exploratory investigations, and corroborating other methods (Garland, 1999). Principal component analysis was first employed by Garland and Mills (1991) to reduce complex multivariate CLPP data into a smaller number of interpretable variables. In the present study I observed no statistically significant differences in calculated functional diversity indices (diversity, richness, evenness) resulting from different agronomic treatments within each system; however, ordination of CLPP data by PCA clearly distinguished low-input organic farm soils from other soils and identified substrates that best discriminated between the different samples. Utilization of strongly-loaded aromatic substrates such as L-phenylalanine and 2hydroxybenzoic acid determined much of the observed variation among soil treatments revealed by PCA. Positive substrate loadings discerned by PCA probably do not represent microbial physiologies that predominate in situ since the assay enriches and selects only a few bacterial types on each individual carbon source (Konopka et al., 1998; Preston-Mafham et al., 2002). However, it is reasonable that culturable bacteria capable of catabolizing aromatic substrates could serve as responsive indicator organisms that are capable of discriminating among agronomic treatments.

Evidence suggests that CLPP is a culture-based enrichment method that primarily characterizes fast-growing, copiotrophic bacteria that can be distinct from the dominant bacteria in soil inocula (Smalla et al., 1998; Garland, 1999). Therefore, the ecological significance of CLPP data often is questioned. In this study I used multiple correlation analysis to explore potential associations between CLPP data and MBC and PMN. My 
results indicated that CLPP principal component scores were significantly correlated with MBC and PMN in both systems. Although correlation does not imply causation, correlative relationships suggest that these variables respond in a similar manner to environmental perturbation (Cookson et al., 2007). Other workers also have found significant correlations between CLPP data, gross $\mathrm{N}$ flux, and soil respiration (Cookson et al., 2007). These results suggest a link between the functional diversity of culturable bacteria and soil ecosystem functions.

\section{$\underline{\text { Culture-dependent denaturing gradient gel electrophoresis }}$}

Ellis et al. (2003) compared metal-contaminated and uncontaminated soils, and provided strong evidence supporting the use of culturable bacteria to discriminate between soil microbial communities. Culture-independent DGGE profiles of the 16S rRNA gene were of limited value since they produced similar community fingerprints, regardless of the level of soil contaminants. When soil bacteria were first cultivated on agar plates the total number of organisms decreased with increasing metal content, and the resulting "communities" growing on the plates produced distinct DGGE fingerprints of $16 \mathrm{~S}$ rRNA. Ellis et al. (2003) hypothesized that culturable bacteria were an ecologically-relevant fraction of the soil community and provided unique information when compared with culture-independent methodologies, since they were responsive to environmental change. The clear difference in culturable communities observed by these workers was somewhat expected due to strong selection by high soil levels of toxic metals. Further work with CD DGGE is warranted to determine whether this technique 
can discriminate subtle community changes that might occur in agronomic systems that are characterized by high species diversity and minimal selective pressures.

Recently, I demonstrated that CD DGGE fingerprints resolved a unique and diverse fraction of the soil bacterial community that complemented fingerprints produced using a culture-independent approach (Edenborn and Sexstone, 2007). In that study, CD DGGE analyses resulted in clear banding patterns of sufficient complexity (16-32 major bands) and reproducibility to investigate differences in bacterial communities in a silt loam soil. In the present study, we employed CD DGGE to examine whether culturable bacterial communities varied with soil amendment. I found no statistically-significant differences in CD DGGE fingerprints of $16 \mathrm{~S}$ rDNA as a function of manure (PAS) or compost amendment (OF); however, significant differences were observed as a result of inorganic fertilizer amendment in pasture soils and legume cropping in organic farm soils. Chu et al. (2007) have observed previously that legumes and nitrogen availability impact bacterial community structure. Girvan et al. (2003) also hypothesized that soil type and legume cropping were the overriding factors controlling the structure of bacterial communities in agricultural soils. It is likely that the fertilizer effect I observed in pasture soils also involved a legume effect. For the past decade, experimental pastures at Reedsville, WV, have been subjected to equal grazing pressure and animal waste deposition but have received two different levels of phosphorus, potassium and lime amendments. The higher fertility treatment has been shown to favor the persistence of pasture legumes, such as red and white clover, in these soils (Bryan et al., 1987).

Natural selection acts on phenotype, and physiological characteristics are often linked to more than one gene. Therefore, it is insufficient merely to catalog $16 \mathrm{~S}$ rRNA 
genes to understand how environmental factors govern shifts in community structure. The ability to partition soil bacteria into distinct physiological subsets according to their growth characteristics on laboratory media provides a potential means to relate $16 \mathrm{~S}$ rRNA fingerprints to phenotype. Previously, I demonstrated that utilization of multiple media and incubation conditions increased the number of unique bands resolved by $\mathrm{CD}$ DGGE relative to culture-independent analyses (Edenborn and Sexstone, 2007). In the present study, multivariate analyses of CLPP profiles suggested that culturable bacteria catabolizing aromatic substrates were highly discriminatory. Langenheder et al. (2006) have suggested that bacterial community structure may be related more to narrow functions such as degradation of semilabile carbon compounds than to broad functions such as respiration and biomass production. If this is true, characterizing culturable bacterial communities with specific physiological capabilities or narrow niche preferences may improve our ability to distinguish between soils that have been impacted by anthropogenic perturbations. Culture-based studies can never duplicate the complex environment that exists in soil or completely characterize the vast diversity of bacteria revealed by culture-independent analyses. However, results from culture-based studies provide a framework for more sophisticated modes of analysis (Ward, 2006). Recently, some investigators have argued that culturable communities have no utility in contemporary microbial ecology and cannot be related to soil fertility (Ritz, 2007). I disagree. Rather, I support arguments presented by Nichols (2007) and agree with the contention that microbial cultivation is a re-emerging frontier that provides information that is not directly observable from culture-independent and sequencing efforts alone. 


\section{Conclusions}

The organic farm and upland pasture represent systems with contrasting soil types, land use, and fertility regimes. In this study, I used MBC, PMN, CLPP and CD DGGE of the 16S rRNA gene to compare microbial communities as a function of agronomic amendments. There were significant correlations between MBC and PMN and variables derived from analysis of the functional and genetic diversity of soil communities; however, each measurement technique exhibited a different response to the fertility amendments. Overall, MBC, PMN, and CLPP were most responsive to additions of manure and compost to soils; however, only CD DGGE revealed clear differences in soils that were amended with inorganic fertilizers and/or cropped with legumes. Because multivariate models are often used to evaluate the effects of agronomic perturbations on soil, it is necessary to identify variables that increase the ability to discriminate accurately between different systems. My study suggests that measures of microbial diversity do not provide redundant information in soil quality analysis, and that culturable bacterial communities provide useful indicators of select agronomic perturbations. 


\section{References Cited}

Amann, R.I., 1995. Fluorescently labeled, ribosomal RNA-targeted oligonucleotide probes in the study of microbial ecology. Molecular Ecology 4, 543-553.

Andrews, S.S., Mitchell, J.P., Mancinelli, R., Karlen, D.L., Hartz, T.K., Horwath, W.R., Pettygrove, G.S., Scow, K.M., Munk, D.S., 2002. On-farm assessment of soil quality in California's central valley. Agronomy Journal 94, 12-23.

Barns, S.M., Takala, S.L., Kuske, C.R., 1999. Wide distribution and diversity of members of the bacterial kingdom Acidobacterium in the environment. Applied and Environmental Microbiology 65, 1731-1737.

Bending, G.D., Putland, C., Rayns, F., 2000. Changes in microbial community metabolism and labile organic matter fractions as early indicators of the impact of management on soil biological quality. Biology and Fertility of Soils 31, 78-84.

Bending, G.D., Turner, M.K., Jones, J.E., 2002. Interactions between crop residue and soil organic matter quality and the functional diversity of soil microbial communities. Soil Biology and Biochemistry 34, 1073-1082.

Bryan, W.B., Mills, T.A., Rosica, F.X., 1987. Effects of grazing management and soil amendments on hill land pasture botanical composition. Applied Agricultural Research 1, 297-302.

Bryant, F.B., Yarnold, P.R., 2005. Principal-components analysis and exploratory and confirmatory factor analysis. In: Grimm, L.G., Yarnold, P.R. (Eds.), Reading and Understanding Mulitvariate Statistics. American Psychological Association, Washington, DC, pp. 99-136.

Caetano-Anolles, G., Gresshoff, P.M., 1994. Staining nucleic acids with silver: an alternative to radioisotopic and fluorescent labeling. Promega Notes 45, 13-18.

Canali, S., Trinchera, A., Intrigliolo, F., Pompili, L., Nisini, L., Mocali, S., Torrisi, B., 2004. Effect of long term addition of composts and poultry manure on soil quality of citrus orchards in Southern Italy. Biology and Fertility of Soils 40, 206-210.

Childers, T.B., 2005. The effects of low and high fertility treatments on soil quality, yields, pest incidence and labor requirements of a post-translational organic market garden system. M.S. Thesis. West Virginia University, Morgantown, WV.

Chu, H., Fujii, T., Morimoto, S., Lin, X., Yagi, K., Hu, J., Zhang, J., 2007. Community structure of ammonia-oxidizing bacteria under long-term application of mineral fertilizer and organic manure in a sandy loam soil. Applied and Environmental Microbiology 73, 485-491. 
Cookson, W.R., Abaye, D.A., Marschner, P., Murphy, D.V., Stockdale, E.A., Goulding, K.W.T., 2005. The contribution of soil organic matter fractions to carbon and nitrogen mineralization and microbial community size and structure. Soil Biology and Biochemistry 37, 1726-1737.

Cookson, W.R., Osmanb, M., Marschnerc, P., Abayed, D.A., Clarke, I., Murphya, D.V., Stockdaled, E.A., Watson, C.A., 2007. Controls on soil nitrogen cycling and microbial community composition across land use and incubation temperature. Soil Biology and Biochemistry 39, 744-756.

Doran, J.W., Parkin, T.B., 1994. Defining and assessing soil quality. In: Defining Soil Quality for a Sustainable Environment. SSSA Special Publication No. 35. Soil Science Society of America, Madison, WI, pp. 3-21.

Edenborn, S.L., Sexstone, A.J., 2007. DGGE fingerprinting of culturable soil bacterial communities complements culture-independent analyses. Soil Biology and Biochemistry 39, 1570-1579.

Ellis, R.J., Morgan, P., Weightman, A.J., Fry, J.C., 2003. Cultivation-dependent and independent approaches for determining bacterial diversity in heavy-metalcontaminated soil. Applied and Environmental Microbiology 69, 3223-3230.

Farrelly, V., Rainey, F.A., Stackebrandt, E., 1995. Effect of genome size and rrn gene copy number on PCR amplification of 16S rRNA genes from a mixture of bacterial species. Applied and Environmental Microbiology 61, 2798-2801.

Fisk, M., Fahey, T., 2001. Microbial biomass and nitrogen cycling responses to fertilization and litter removal in young northern hardwood forests. Biogeochemistry 53, 201-223.

Fraser, P.M., Haynes, R.J., Williams, P.H., 1994. Effects of pasture improvement and intensive cultivation on microbial biomass, enzyme activities, and composition and size of earthworm populations. Biology and Fertility of Soils 17, 185-190.

Fromin, N., Hamelin, J., Tarnawski, S., Roesti, D., Jourdain-Miserez, K., Forestier, N., Teyssier-Cuvelle, S., Gillet, F., Aragno, M., Rossi, P., 2002. Statistical analysis of denaturing gel electrophoresis (DGGE) fingerprinting patterns. Environmental Microbiology 4, 634-643.

Garland, J.L., 1999. Potential and limitations of BIOLOG for microbial community analysis. In: Bell, C.R., Brylinsky, M., Johnson-Green, P. (Eds.), Microbial Biosystems: New Frontiers. Proceedings of the 8th International Symposium on Microbial Ecology Atlantic Canada Society for Microbial Ecology, Halifax, NS

Garland, J.L., Mills, A.L., 1991. Classification and characterization of heterotrophic microbial communities on the basis of patterns of community-level sole-carbon- 
source utilization. Applied and Environmental Microbiology 57, 2351-2359.

Ginting, D., Kessavalou, A., Eghball, B., Doran, J.W., 2003. Greenhouse gas emissions and soil indicators four years after manure and compost applications. Journal of Environmental Quality 32, 23-32.

Girvan, M.S., Bullimore, J., Pretty, J.N., Osborn, A.M., Ball, A.S., 2003. Soil type is the primary determinant of the composition of the total and active bacterial communities in arable soils. Applied and Environmental Microbiology 69, 18001809 .

Hugenholtz, P., Goebel, B.M., Pace, N.R., 1998. Impact of culture-independent studies on the emerging phylogenetic view of bacterial diversity. Journal of Bacteriology $180,4765-4774$.

Ibekwe, A.M., Kennedy, A.C., Frohne, P.S., Papiernik, S.K., Yang, C.H., Crowley, D.E., 2002. Microbial diversity along a transect of agronomic zones. FEMS Microbiology Ecology 39, 183-191.

Islam, K.R., Weil, R.R., 1998. Microwave irradiation of soil for routine measurement of microbial biomass carbon. Biology and Fertility of Soils 27, 408-416.

Kang, G.S., Beri, V., Sidhu, B.S., Rupela, O.P., 2005. A new index to assess soil quality and sustainability of wheat-based cropping systems. Biology and Fertility of Soils 41, 389-398.

Keeney, D., 1982. Nitrogen - availability indices. In: Page, A.L., Miller, R.H., Keeney, D.R. (Eds.), Methods of Soil Analysis, Part 2-Chemical and Microbiological Properties, 2nd Edition. American Society of Agronomy, Inc. , Madison, WI, pp. 711-733.

Kennedy, A.C., Papendick, R.I., 1995. Microbial characteristics of soil quality. Journal of Soil and Water Conservation 50, 243-248.

Konopka, A., Oliver, L., Turco, J.R.F., 1998. The use of carbon substrate utilization patterns in environmental and ecological microbiology. Microbial Ecology 35, $103-115$.

Langenheder, S., Lindstrom, E.S., Tranvik, L.J., 2006. Structure and function of bacterial communities emerging from different sources under identical conditions. Applied and Environmental Microbiology 72, 212-220.

Malosso, E., English, L., Hopkins, D., O’Donnell, A., 2005. Community level physiological profile response to plant residue additions in Antarctic soils. Biology and Fertility of Soils 42, 60-65. 
Miethling, R., Wieland, G., Backhaus, H., Tebbe, C.C., 2000. Variation of microbial rhizosphere communities in response to crop species, soil origin, and inoculation with Sinorhizobium meliloti L33. Microbial Ecology 40, 43-56.

Moore, J.M., Klose, S., Tabatabai, M.A., 2000. Soil microbial biomass carbon and nitrogen as affected by cropping systems. Biology and Fertility of Soils 31, 200 210.

Nakatsu, C.H., 2007. Soil microbial community analysis using denaturing gradient gel electrophoresis. Soil Science Society of America Journal 71, 562-571.

Nichols, D., 2007. Cultivation gives context to the microbial ecologist. FEMS Microbiology Ecology 60, 351-357.

Oksanen, J., 2005. Vegan: community ecology package. http://cc.oulu.fi/ jariosa/.

Omay, A.B., Rice, C.W., Maddux, L.D., Gorden, W.B., 1997. Changes in soil microbial and chemical properties under long-term crop rotation and fertilization. Soil Science Society of America Journal 61, 1672-1678.

Øvreås, L., Torsvik, V., 1998. Microbial diversity and community structure in two different agricultural soil communities. Microbial Ecology 36, 303-315.

Parham, J.A., Deng, S.P., Raun, W.R., Johnson, G.V., 2002. Long-term cattle manure application in soil. Biology and Fertility of Soils 35, 328-337.

Polz, M.F., Cavanaugh, C.M., 1998. Bias in template-to-product ratios in multitemplate PCR. Applied and Environmental Microbiology 64, 3724-3730.

Preston-Mafham, J., Boddy, L., Randerson, P.F., 2002. Analysis of microbial community functional diversity using sole-carbon-source utilization profiles-a critique. FEMS Microbiology Ecology 42, 1-14.

Prigge, E.C., Bryan, W.B., Goldman-Innis, E.S., 1999. Early- and late-season grazing of orchardgrass and fescue hayfields overseeded with red clover. Agronomy Journal 91, 690-696.

R Core Development Team, 2004. R: A language and environment for statistical computing. Vienna, Austria. http://www.R-project.org.

Rees, G., Baldwin, D., Watson, G., Perryman, S., Nielsen, D., 2004. Ordination and significance testing of microbial community composition derived from terminal restriction fragment length polymorphisms: application of multivariate statistics. Antonie van Leeuwenhoek 86, 339-347.

Ritz, K., 2007. The plate debate: culturable communities have no utility in contemporary 
environmental microbial ecology. FEMS Microbiology Ecology 60, 358-362.

Schloter, M., Dilly, O., Munch, J.C., 2003. Indicators for evaluating soil quality Agriculture, Ecosystems and Environment 98, 255-262.

Schmalenberger, A., Schwieger, F., Tebbe, C.C., 2001. Effect of primer hybridizing to different evolutionarily conserved regions of the small-subunit rRNA gene in PCR-based microbial community analysis and genetic profiling. Applied and Environmental Microbiology 67, 3557-3563.

Sharma, S., Rangger, A., Insam, H., 1998. Effects of decomposing maize litter on community level physiological profiles of soil bacteria. Microbial Ecology 35, 301-310.

Smalla, K., Wachtendorf, U., Heuer, H., Liu, W.T., Forney, L.J., 1998. Analysis of BIOLOG GN substrate utilization patterns by microbial communities. Applied and Environmental Microbiology 64, 1220-1225.

Stenberg, B., 1999. Monitoring soil quality or arable land: microbiological indicators. Acta Agriculture Scandinavica 49, 1-24.

Sun, H.Y., Deng, S.P., Raun, W.R., 2004. Bacterial community structure and diversity in a century-old manure-treated agroecosystem. Applied and Environmental Microbiology 70, 5868-5874.

Sutanto, Y., 2005. Manure from grazing cattle: effects on soil microbial communities and soil quality in nothern West Virginia pastures. M.S. Thesis. West Virginia University, Morgantown, WV.

Templer, P., Findlay, S., Lovett, G., 2003. Soil microbial biomass and nitrogen transformations among five tree species of the Catskill mountains, New York, USA. Soil Biology and Biochemistry 35, 607-613.

Thies, J.E., 2007. Soil microbial community analysis using terminal restriction fragment length polymorphisms. Soil Science Society of America Journal 71, 579-591.

Tiedje, J.M., Asuming-Brempong, S., Nusslein, K., Marsh, T.L., Flynn, S.J., 1999. Opening the black box of soil microbial diversity. Applied Soil Ecology 13, 109122.

Ward, N., 2006. New directions and interactions in metagenomics research. FEMS Microbiology Ecology 55, 331-338.

Widmer, F., Fließbach, A., Laczkó, E., Schulze-Aurich, J., Zeyer, J., 2001. Assessing soil biological characteristics: a comparison of bulk soil community DNA-, PLFA-, and BIOLOG-analyses. Soil Biology and Biochemistry 33, 1029-1036. 
Williams, B., Grayston, S., Reid, E., 2000. Influence of synthetic sheep urine on the microbial biomass, activity and community structure in two pastures in the Scottish uplands. Plant and Soil 225, 175-185.

Zuberer, D.A., 1994. Recovery and enumeration of viable bacteria. In: Weaver, R.W. (Ed.), Methods of soil analysis, part 2. Microbiological and biochemical properties. Soil Science Society of America, Madison, Wisconsin, pp. 119-144. 
Table 3.1. Microbial biomass carbon $(\mathrm{MBC})$ and potentially mineralizable nitrogen $(\mathrm{PMN})$ in organic farm and pasture soils ${ }^{\mathrm{a}}$.

\begin{tabular}{|c|c|c|c|c|c|c|c|}
\hline \multicolumn{6}{|c|}{ Average Organic Farm } & \multicolumn{2}{|l|}{$235 \pm 77$} \\
\hline ID & Symbol $^{b}$ & System & Fertility Regime & Crop/Amendment & Sampling Date & $\mathrm{MBC}$ & PMN \\
\hline & & & & & & (mg C/kg) & $(\mathrm{mg} \mathrm{N} / \mathrm{kg})$ \\
\hline $\mathrm{C} 1$ & 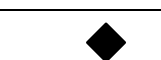 & Organic Farm & High Input $^{c}$ & Tomatoes/Peppers & June 2004 & $369 \pm 48$ a & ND \\
\hline $\mathrm{NC} 1$ & $\diamond$ & Organic Farm & Low Input ${ }^{\mathrm{d}}$ & Tomatoes/Peppers & June 2004 & $207 \pm 36 b$ & ND \\
\hline $\mathrm{C} 2$ & & Organic Farm & High Input & Tomatoes/Peppers & Aug 2004 & $199 \pm 13 b$ & $24 \pm 6 a$ \\
\hline CL2 & $\Delta$ & Organic Farm & High Input & Legumes & Aug 2004 & $282 \pm 29 \mathrm{ab}$ & $31 \pm 4$ a \\
\hline $\mathrm{NC} 2$ & $\diamond$ & Organic Farm & Low Input & Tomatoes/Peppers & Aug 2004 & $156 \pm 13 b$ & $18 \pm 4 \mathrm{a}$ \\
\hline NCL2 & $\triangle$ & Organic Farm & Low Input & Legumes & Aug 2004 & $195 \pm 12 b$ & $19 \pm 2 \mathrm{a}$ \\
\hline H1 & & Pasture & High Fertility $^{\mathrm{e}}$ & None & May 2004 & $1659 \pm 133 \mathrm{c}$ & $110 \pm 18$ abc \\
\hline L1 & $\square$ & Pasture & Low Fertility ${ }^{f}$ & None & May 2004 & $1931 \pm 79 \quad b c$ & $121 \pm 11 \mathrm{ab}$ \\
\hline $\mathrm{H} 2$ & & Pasture & High Fertility & None & Sept 2004 & $1915 \pm 126 \mathrm{bc}$ & $59 \pm 8 \quad \mathrm{c}$ \\
\hline HM2 & & Pasture & High Fertility & Manure & Sept 2004 & $2666 \pm 126 a$ & $125 \pm 10 a b$ \\
\hline L2 & $\bigcirc$ & Pasture & Low Fertility & None & Sept 2004 & $2214 \pm 79 \quad a b c$ & $85 \pm 11 \quad b c$ \\
\hline LM2 & $\square$ & Pasture & Low Fertility & Manure & Sept 2004 & $2443 \pm 196 a b$ & $142 \pm 13 \quad \mathrm{a}$ \\
\hline Average & rganic $\mathrm{Fr}$ & & & & & $235 \pm 77$ & $23 \pm 6$ \\
\hline Average & asture & & & & & $2138 \pm 374$ & $107 \pm 30$ \\
\hline
\end{tabular}


${ }^{a}$ Mean values $\mathrm{n}=4$ ( \pm SEM) followed by the same letter are not significantly different $(\mathrm{p}<0.05)$ as determined by Tukey's Studentized Range (HSD) Test.

${ }^{\mathrm{b}}$ Symbols used in Figures throughout paper.

${ }^{\mathrm{c}}$ High Input $=22.4 \mathrm{Mg} \mathrm{ha}^{-1}$ of composted dairy manure + green manure (rye + vetch) applied and tilled into soil 7-10 days prior to planting.

${ }^{\mathrm{d}}$ Low Input $=$ Green manure (rye + vetch) tilled into soil 7-10 days prior to planting.

${ }^{\mathrm{e}}$ High Fertility = Inorganic fertilizer, $\mathrm{P}, 134 \mathrm{~kg} \mathrm{ha}^{-1}$ and $\mathrm{K}, 390 \mathrm{~kg} \mathrm{ha}^{-1}$

${ }^{\mathrm{f}}$ Low Fertility = Inorganic fertilizer, $\mathrm{P}, 67 \mathrm{~kg} \mathrm{ha}^{-1}$ and $\mathrm{K}, 195 \mathrm{~kg} \mathrm{ha}^{-1}$ 


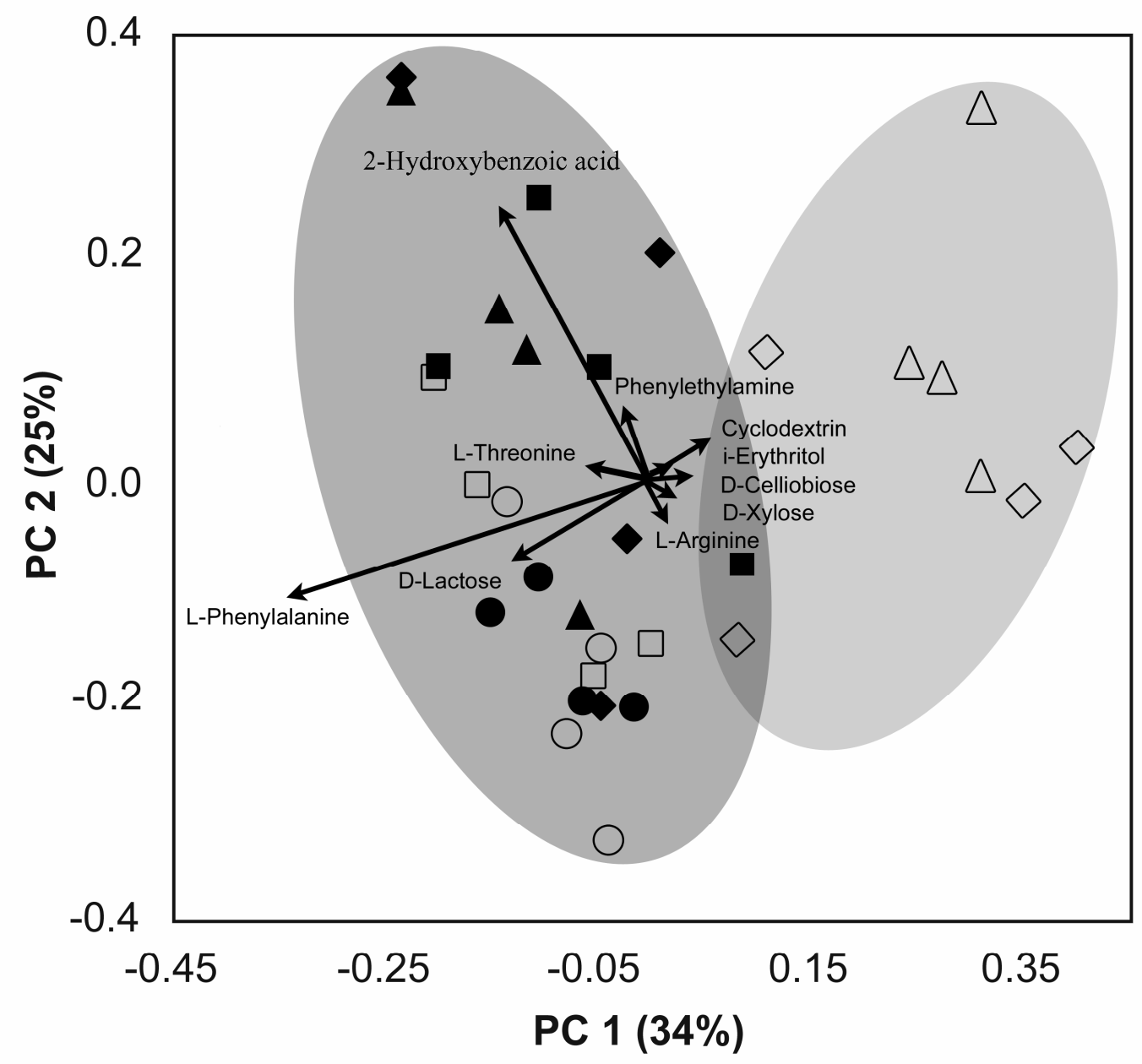

Figure 3.1. Ordination biplots of principal components (PC1 and PC2) from CLPP analysis of organic farm and pasture soils subjected to varying fertility regimes and crop rotations from August and September 2004. Symbol designations are as described in Table 1. 
(a)

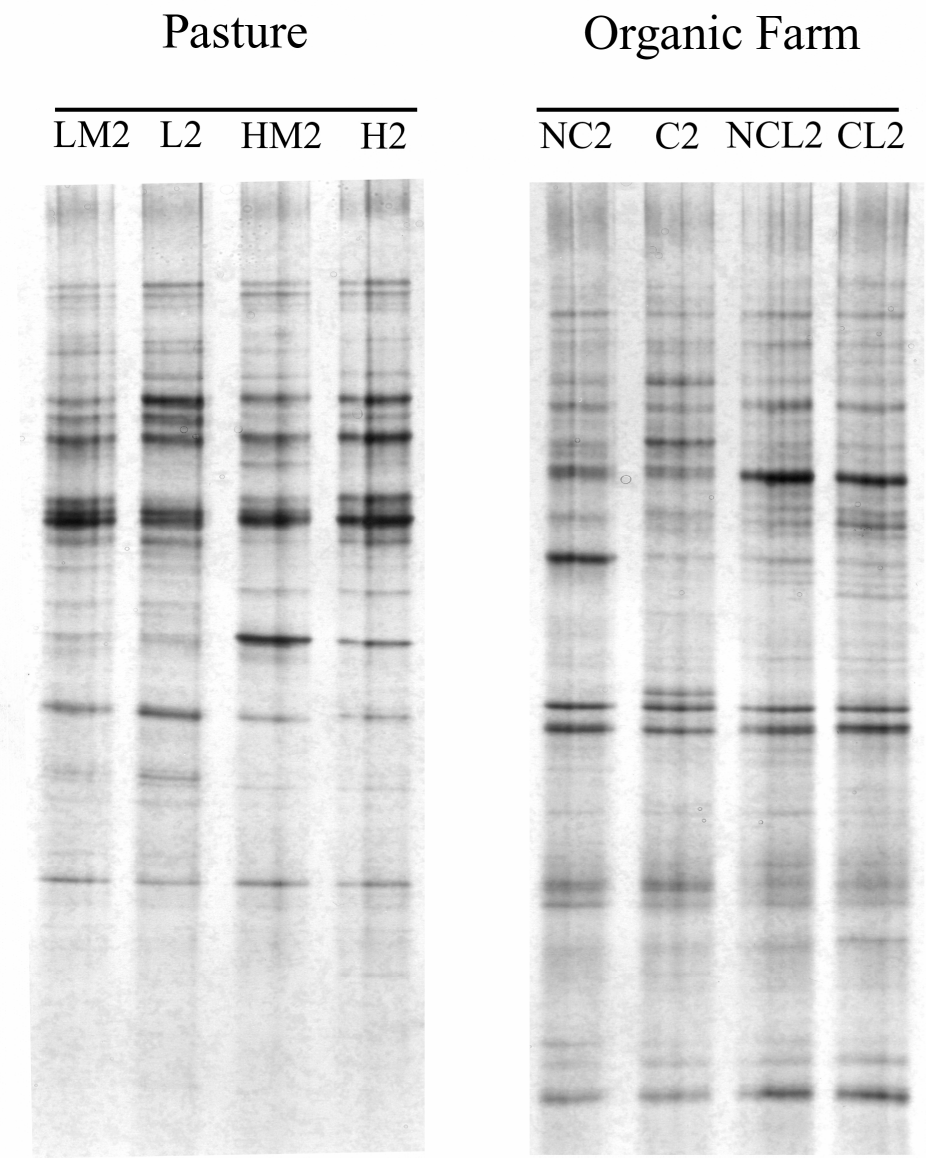

(b)

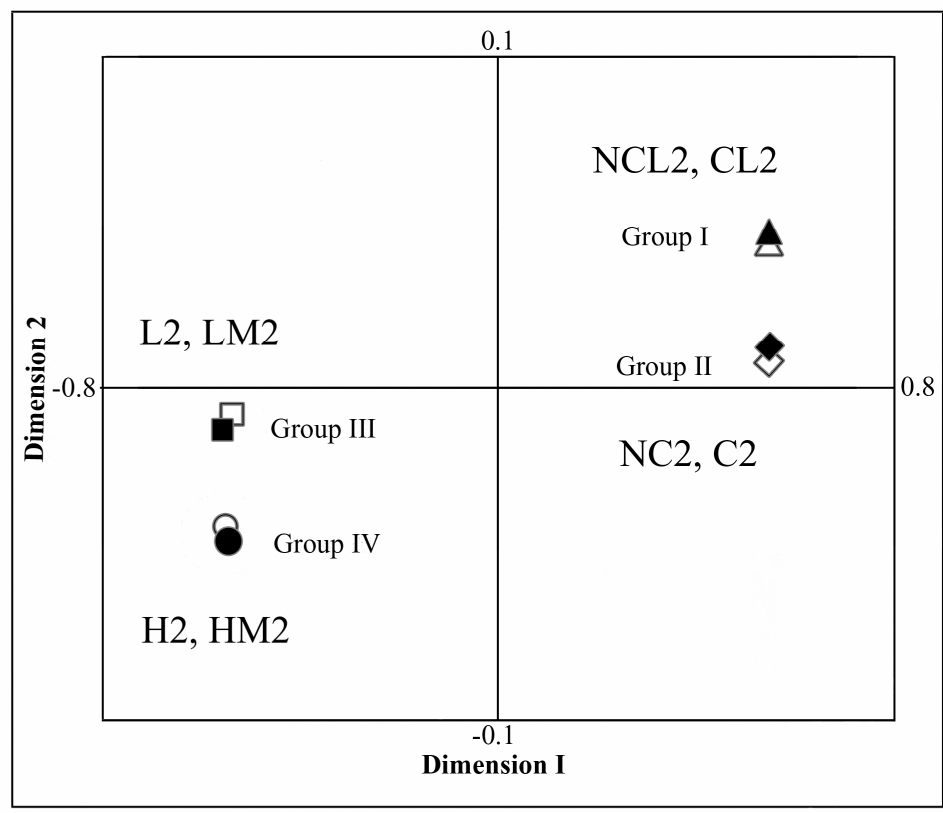


Figure 3.2. (a) DGGE gel of pooled PCR-amplified 16S rRNA genes from culture-dependent bacterial communities of organic farm and pasture from August-September 2004 and (b) ordination plots of dimensions 1 and 2 from NMDS analysis of CD DGGE data. Stress of the plot $=0.000053$. Symbol designations are as described in Table 1. 
(a)

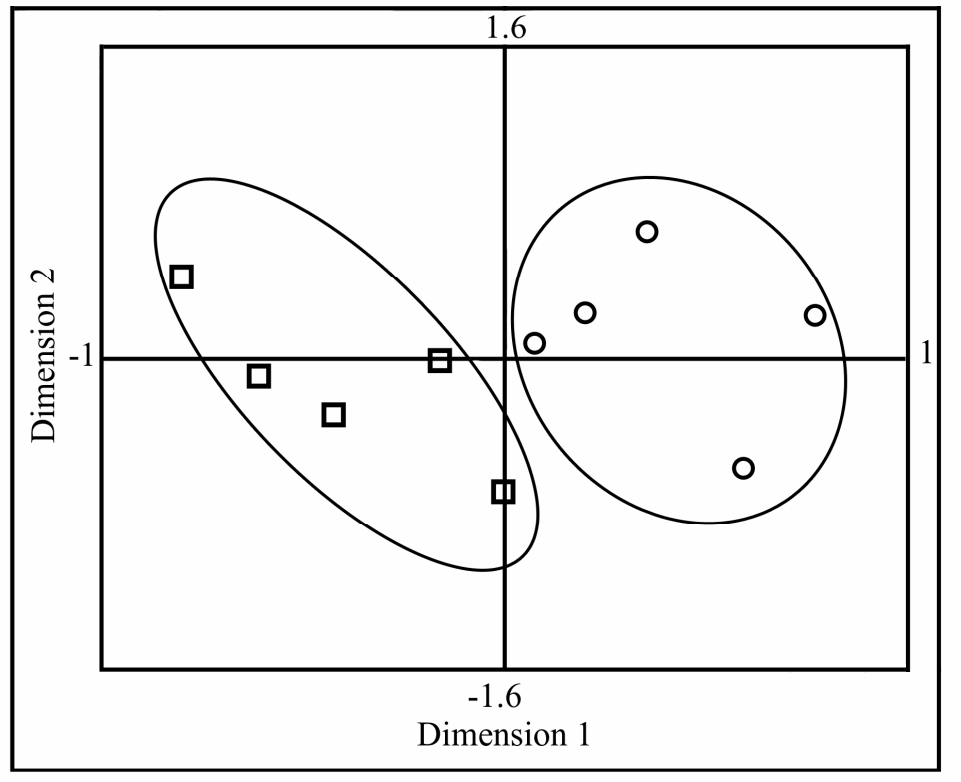

(b)

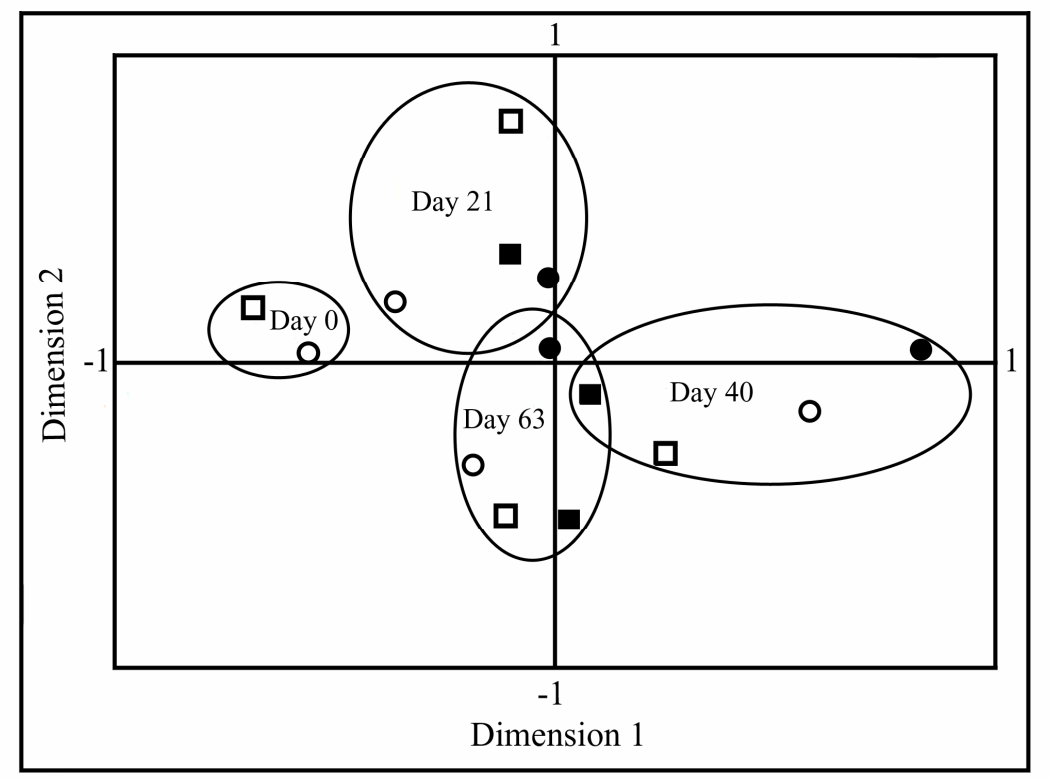

Figure 3.3. Ordination plots of DGGE data from pasture soils in: (a) May and (b) May-September, 2004. Stress of the plot = (a) 0.15 and (b) 0.15. Symbol designations are as described in Table $\mathbf{1}$. 
(a)

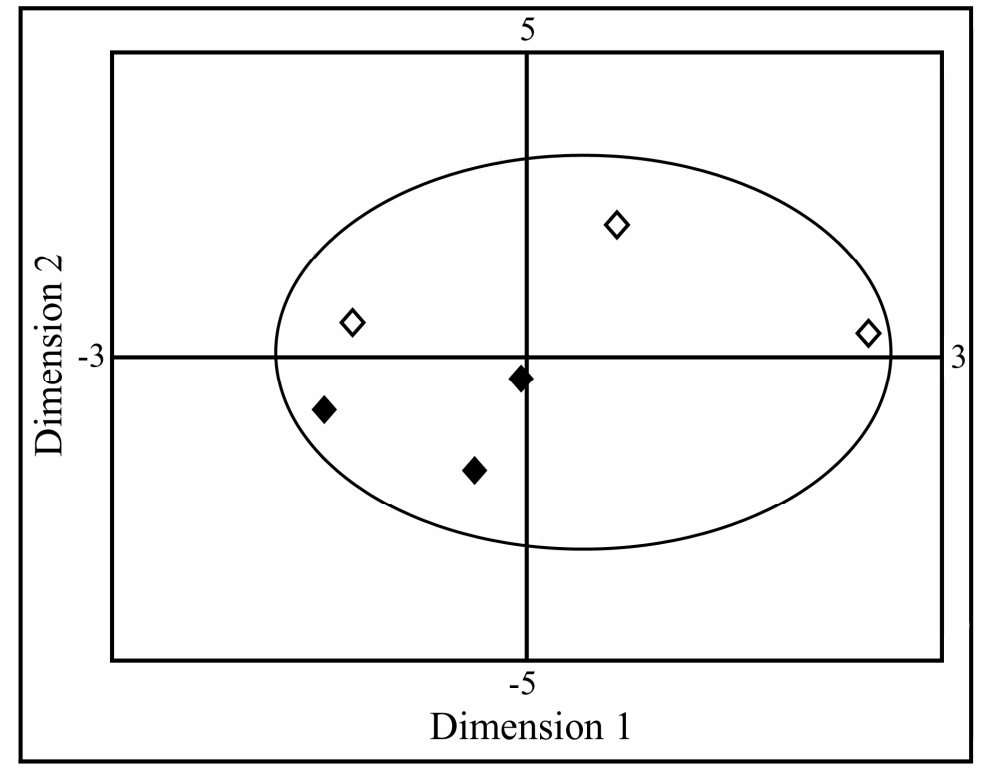

(b)

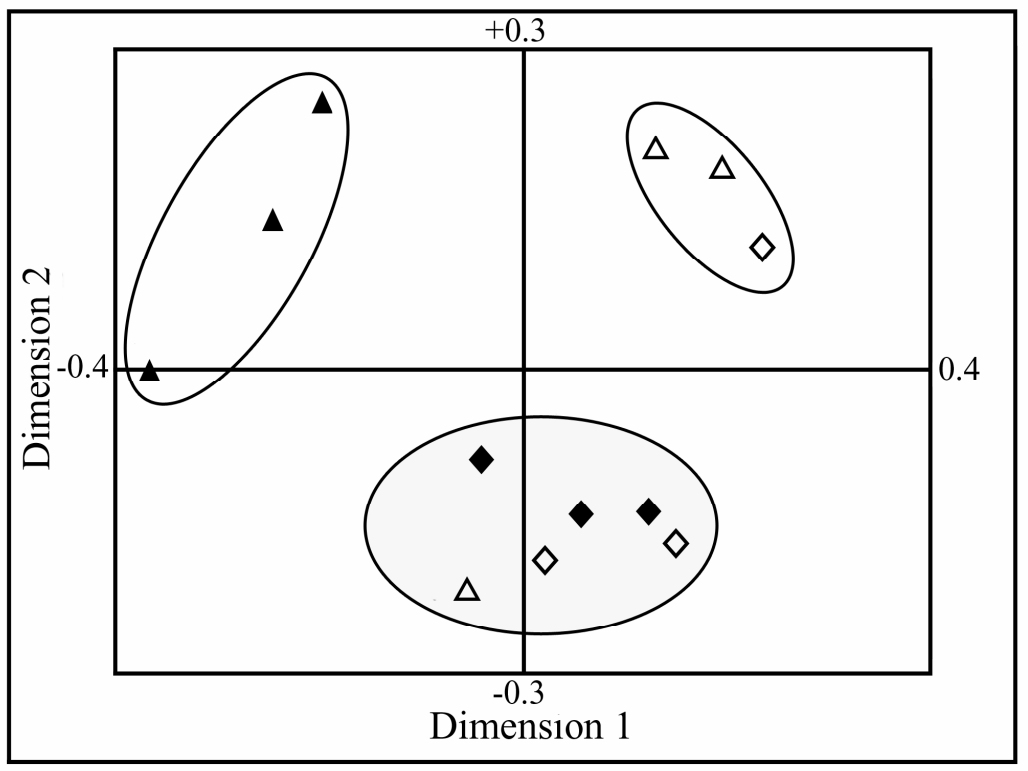

Figure 3.4. Ordination plots DGGE data from organic farm market garden soils in: (a) June and (b) August, 2004. Stress of the plot $=$ (a) 0.013 and (b) 0.13. Symbol designations are as described in Table 1. 
(a)

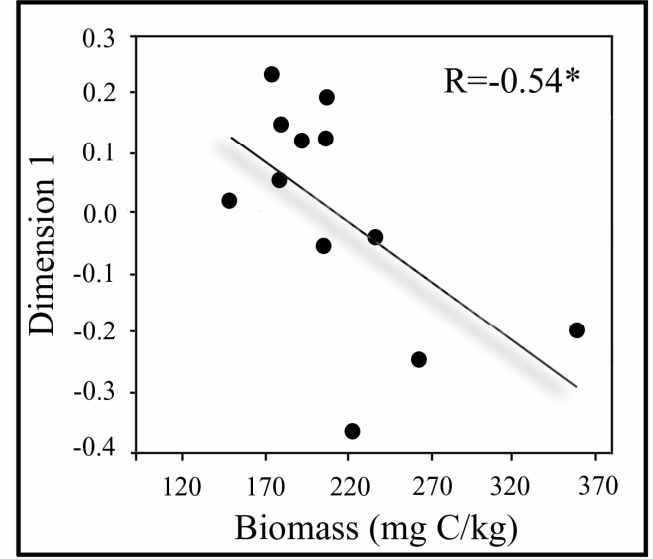

(c)

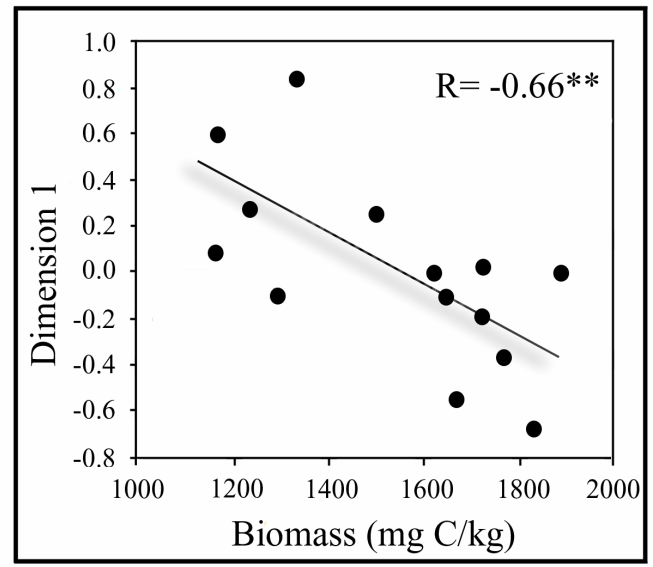

(b)

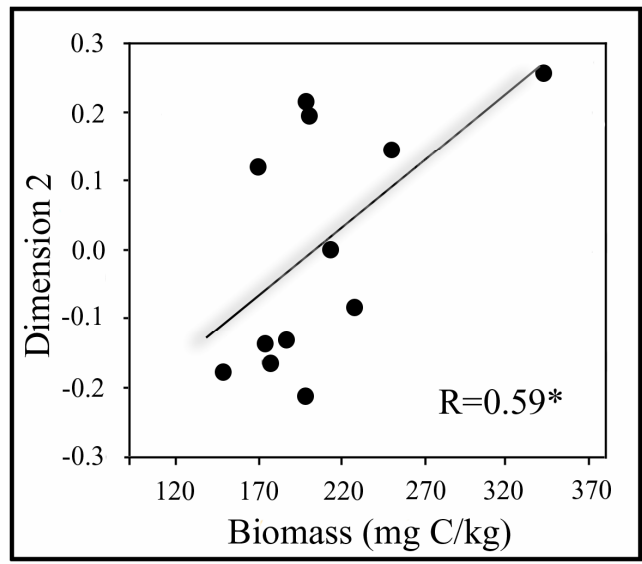

(d)

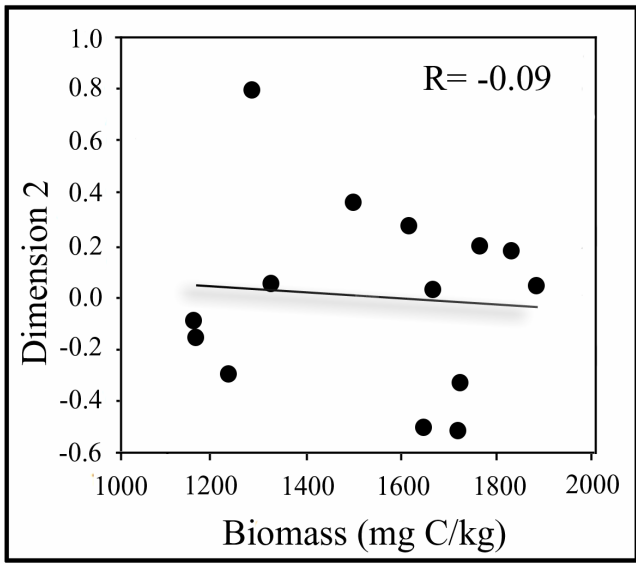

Figure 3.5. Scatterplots, trendlines and Pearson correlation coefficients between MBC and dimensions 1 and 2 from NMDS analysis of CD DDGE profiles from organic farm in August, 2004 (a, b) and pasture days 0, 21, 40 and 63 between May and September, 2004 (c, d). Significant correlations are indicated by: $* * \mathrm{P}<0.01$ and $* \mathrm{P}<0.05$. 


\title{
Chapter 4: Spatial Variability and Heterogeneity of Community-level Physiological Profiles in Tilled and Untilled Soils from an Organic Farm
}

\begin{abstract}
Spatial variability and heterogeneity of microbial substrate utilization in tilled and untilled plots was explored using community-level physiological profiling (CLLP) and multivariate and geostatistical analysis. Robust semivariograms were constructed based on the area under the kinetic curve for substrate utilization in BIOLOG GN2 plates. Microbial substrate utilization was spatially structured in untilled soils and some tilled soils. Rotary tillage disrupted the spatial structure of substrate utilization in the upper few centimeters of soil; however, bacterial utilization of amines and amides exhibited a tillage-induced loss of spatial structure at $13-14 \mathrm{~cm}$. Variability of microbial substrate utilization increased or decreased depending on the degree of perturbation. Spatial structure was more evident at lower soil depths in untilled soils, especially for amino acids, amines and amides. Flux of $\mathrm{CO}_{2}$ was not spatially dependent and was significantly correlated with utilization of the amines and amides.
\end{abstract}

Keywords: Tillage, Spatial heterogeneity, Spatial variability, Geostatistics, Communitylevel physiological profiling (CLPP), Microbial substrate utilization. 


\section{Introduction}

High spatial variability and heterogeneity of soil microenvironments hinders the development of accurate predictive models capable of relating biotic and abiotic factors to microbial community structure and activity at the field scale (Parkin, 1993). Spatial variability and heterogeneity of available carbon is thought to be an important factor regulating the structure and function of soil communities; however, details of in situ spatial distribution of soil microbial populations are just beginning to emerge (Ettema and Wardle, 2002).

Variability describes general changes in the value of a property over time and space. In contrast, heterogeneity refers to variability that exhibits spatial structure (Ettema and Wardle, 2002). Conventional parametric statistics such as the coefficient of variation can be used to quantify variability, while autocorrelation is used to determine heterogeneity in spatial data by quantifying the resemblance between neighbors as a function of spatial separation distances (Rossi et al., 1992; Ettema and Wardle, 2002; Legendre et al., 2002). Data that are spatially autocorrelated violate the assumption of independence required for parametric statistical procedures such as Analysis of Variance (ANOVA) and can inflate type I errors associated with significance testing of regression

or correlation coefficients (Rossi, 1992; Legendre et al., 2002). Therefore, a priori assessment of spatial dependence is essential for optimal experimental design and accurate statistical inference (Ettema and Wardle, 2002).

Although a complete understanding of microbial processes cannot be derived by studying the structure and function of microbial communities at a single spatial scale (Franklin and Mills, 2003), knowledge of plot-level heterogeneity is necessary when 
evaluating treatment effects (Parkin, 1993). Microbial dynamics may be controlled at the field scale by manipulation of soil structure through practices such as tillage (Elliott and Coleman, 1988). Spatial analyses are needed to accurately quantify the impact of agronomic practices such as tillage on microbial variables in soil.

Certified organic practices preclude the use of herbicides; therefore, rotary-tillage and manual cultivation routinely are employed to control weeds in the market garden of the West Virginia University Organic Research Farm (Childers, 2005). In a previous study, the effects of fertility and cropping on culturable microbial communities in market garden soils were evaluated using multivariate analyses (see Chapter 3). Since tillage was ubiquitous, potential impacts of this practice on market garden soil microbial communities remain unknown. Soil tillage has been shown to disrupt soil aggregation, accelerate the microbial decomposition of soil organic matter (Tisdall and Oades, 1982) and alter microbial community structure (Lupwayi et al., 2001; Feng et al., 2003). Mechanical perturbation is thought to affect bacterial diversity and activity by altering habitat space, water and substrate distribution, and the spatial arrangement of pores (Young and Ritz, 2000). Further, it induces changes in the distribution of soil organic matter as well as the macro- and micro-organisms that facilitate decomposition (Kladivko, 2001). In particular, tillage generally decreases soil organic carbon and nitrogen by exposing pools of previously protected organic matter to microbial degradation, thus negatively impacting soil aggregation and fertility (Kristensen et al., 2003). Such impacts are of considerable importance in organic farming systems, which cannot rely on inputs of inorganic fertilizers to sustain soil fertility and plant growth (Kuepper, 2001). 
Geostatistical analyses have been used previously to quantify the spatial heterogeneity of microbial cells (Nunan et al., 2002), microbial communities (Grundmann and Debouzie, 2000; Franklin et al., 2002; Franklin and Mills, 2003; Ritz et al., 2004), and microbial activities such as flux of trace gases from soil (Robertson et al., 2000). However, geostatistical analyses rarely have been used to evaluate data from community-level physiological profiling (CLPP), even though this technique is widely applied to assess the impact of agricultural practices on soil bacterial communities (Sharma et al., 1998; Bending et al., 2000; Miethling et al., 2000; Williams et al., 2000; Bending et al., 2002; Malosso et al., 2005). Therefore, in the present study, I performed an exploratory investigation of spatial variability and heterogeneity of bacterial substrate utilization patterns in tilled and untilled organic farm soils at the inter- and intra-plot scale using multivariate and geostatistical techniques. The primary objective of this study was to assess the feasiblity of using geostatistial analysis with CLPP data.

\section{Materials and Methods}

$\underline{\text { Site description, experimental design and soil sampling }}$

West Virginia University (WVU) Organic Research Farm is located in Monongalia County, WV $\left(39^{\circ} 38^{\prime} 34^{\prime \prime} \mathrm{N}, 7^{\circ} 56^{\prime} 04^{\prime \prime} \mathrm{W}\right)$. Soils on the farm are Dormont and Guernsy silt loams (fine loamy, mixed, superactive, mesic, Oxyaquic Hapludalfs). Surface layers extend to $\sim 25 \mathrm{~cm}$ and subsoil to $\sim 90 \mathrm{~cm}$. Tillage plots were established on July 30, 2003, in a grassland area that had been uncultivated for ten years. Six plots (4.7 $\mathrm{m} \times 4.7 \mathrm{~m}$ per plot) were established for two treatments (3 till and 3 no-till) (Figure 4.2a). Vegetation on all plots was cut back, raked, and mowed to $5 \mathrm{~cm}$. Three plots were 
tilled to $15 \mathrm{~cm}$ by running a rotary tiller through the soil in a single pass and three plots were left untilled. All plots were covered with black landscaping fabric (DuPont, Wilmington, DE) to prevent erosion of the soil. On days 0,15 and 139 (following the first tillage event), twelve $15-\mathrm{cm}$ deep cores were randomly collected from each plot. On day 347 after the primary tillage event, twelve soil cores were taken from each plot, and divided into three vertical sections $(0-5 \mathrm{~cm} ; 5-10 \mathrm{~cm} ; 10-15 \mathrm{~cm})$ (Figure 4.2a). All samples were placed into plastic bags and immediately transported back to the lab, where they were stored at $4^{\circ} \mathrm{C}$ overnight. Prior to analysis, soils were sieved $(<2 \mathrm{~mm})$, and dry weight equivalents were determined.

After soil samples were collected on day 347 , soils in the till plots were tilled again using a rotary tiller. Plots were left uncovered following the second tillage event. On day 456 after the second tillage event, soil samples were collected for geospatial analysis. Sampling points were identified, marked with nails and Licor collars $\left(80 \mathrm{~cm}^{2}\right)$ made of PVC pipe were centered around each nail. A single 15-cm soil core was removed from the center of the Licor collar after $\mathrm{CO}_{2}$ flux measurements were completed. Two 1-cm sections $(2-3 \mathrm{~cm}$ and $13-14 \mathrm{~cm})$ were excised from each core in the field, crumbled, placed in sterile whirl-pak bags, and stored on ice until transport back to the lab.

\section{$\underline{\text { Heterotrophic plate counts }}$}

Twenty grams of each composite soil sample from day 347 were blended for three 1-minute intervals (with intermittent cooling on ice) in $200 \mathrm{ml}$ of Winogradsky's salt solution (WSS; Zuberer, 1994). Blended soils were then diluted $\left(10^{-2}\right.$ to $\left.10^{-6}\right)$ in $0.1 \%$ 
Bactopeptone (Difco, Detroit, MI) and spread on R2A media with a sterile glass rod. Colony forming units (CFUs) were counted at two weeks using a Quebec colony counter.

Microbial biomass carbon and in situ $\mathrm{CO}_{2}$ flux.

Microbial biomass carbon (MBC) was extracted from moist soil ( $80 \%$ water-filled porosity) according to the method of Islam and Weil (1998). Total carbon in soil extracts was measured using a Dohrmann ${ }^{\circledR}$ DC-190 TOC analyzer (Rosemount ${ }^{\circledR}$ Analytical Inc., Santa Clara, CA). In situ $\mathrm{CO}_{2}$ flux was measured using a LICOR 6400 Portable Photosynthesis System (Li-Cor Inc., Lincoln, NE) according to the manufactures instructions.

\section{Community level physiological profiling}

The capability of soil microbial communities to utilize a variety of carbon sources was assessed using community-level physiological profiling (CLPP) originally developed by Garland and Mills (1991). Sterile Waring blenders were used to homogenize (1 min, max speed, $3 \mathrm{x}$ with intermittent cooling on ice) $20 \mathrm{~g}$ of soil collected on day 347 in 180 mL Winogradsky Salts Solution (WSS). Soil samples collected for the geostatistical analysis were disrupted by placing 1 gram of sieved soil in $9 \mathrm{ml}$ of WSS and agitating samples on a rotary shaker for 60 minutes at $30 \mathrm{rpm}$. Homogenate was diluted $\left(10^{-3}\right)$ and used to inoculate $\left(100 \mu \mathrm{L}\right.$ well $\left.^{-1}\right)$ BIOLOG $^{\circledR}$ Ecoplates or GN2 MicroPlates $^{\mathrm{TM}}$ (Biolog Inc., Hayward, CA). The microplates were incubated at $25^{\circ} \mathrm{C}$ for five days. The utilization rate of each carbon source was monitored by measuring absorbance at $590 \mathrm{~nm}$. Readings were taken every 24 hours using an automated plate reader (SpectraMAX 340 
pc, Molecular Devices, Sunnyvale, CA) and values less than 0.25 were set to zero. The Average Well Color Development (AWCD) was used as an indicator of general microbial activity and was calculated as the average optical density across all wells in a given plate or all wells associated with substrate guilds (carbohydrates, polymers, carboxylic acids, amines/amides, and amino acids) (Zak et al., 1994). Substrate diversity (H) was calculated as $\mathrm{H}=-\sum \mathrm{p}_{\mathrm{i}} \ln \mathrm{p}_{\mathrm{i}}$, where $\mathrm{p}_{\mathrm{i}}$ is the proportion of total microbial activity on a particular carbon source. Substrate richness (S) was calculated from the total number of wells with absorbance values greater than 0.25 . Substrate richness per guild was calculated from the number of wells with absorbance values greater than AWCD within each guild. Substrate evenness (E) was calculated as $E=H / \ln (S)$. The area under the kinetic curve (AUC) was calculated using an Excel-based trapezoidal approximation (Guckert et al., 1996).

$\underline{\text { Statistical analysis }}$

Prior to statistical analysis, data were checked for normality using a normal quantile plot and a Shapiro-Wilk goodness of fit test. Data were normalized by transformation when necessary. The mean, standard deviation and coefficient of variation $(\% \mathrm{CV})$ were calculated for each treatment class and differences in MBC and heterotrophic plate counts were tested using an analysis of variance (ANOVA) in a $2 \mathrm{X} 3$ factorial design (factor A: tillage, factor B: time of sampling or sampling depth). Tukey's HSD test was used for post-ANOVA pair-wise comparisons. BIOLOG data from days 1, 15, 139 and 347 were normalized by dividing each substrate absorbance value by the AWCD (Garland and Mills, 1991), and principal component analysis (PCA) was done on 
a covariance matrix using JMP software (SAS Institute, Cary, NC). For PCA analysis of CLPP data used for geostatistical analysis, the AUC for each substrate was normalized by dividing by the average AUC for the plate. Pearson product moment correlation coefficients were used to evaluate associations between the AUC data and $\mathrm{CO}_{2}$ flux. Correlation analysis was done using the Hmisc package in $\mathrm{R}$ ( $\mathrm{R}$ Development Core Team, 2004).

\section{$\underline{\text { Geostatistical analysis }}$}

Stein and Ettema (2003) previously developed a sampling schemes to estimate experimental variogram parameters in roto-tilled plots. The locations of the 28 sampling points in these designs were determined using spatial simulated annealing (SSA) and the Warrick and Meyers criterion. The Warrick and Meyers criterion evaluates the quality of sampling points by assessing the distribution of sampling points over the distances classes and SSA is an iterative algorithm used to optimize the design based on the selected criterion. An optimal design is achieved when a sufficient number of samples ( $>$ 30) are evenly distributed over all the distance classes. In this study, a rescaled ( $4.3 \times 4.3$ m (14 ft x $14 \mathrm{ft}$ ) version of Stein and Ettema's sampling scheme for bare plots (Figure

\section{2 b).}

Spatial dependence (autocorrelation) was evaluated by analyzing the semivariance $(\gamma(\mathrm{h}))$ as a function of distance Eq. (1).

$$
\text { (1) } \gamma(\mathrm{h})=\frac{1}{2 \mathrm{~N}(\mathrm{~h})}\left(\sum\left(\mathrm{z}\left(\mathrm{s}_{\mathrm{i}}\right)-\mathrm{z}\left(\mathrm{s}_{\mathrm{i}}+\mathrm{h}\right)\right)\right.
$$


Where:

$\mathrm{N}(\mathrm{h})$ is the number of observation pairs separated by distance $\mathrm{h}$

$\mathrm{z}\left(\mathrm{s}_{\mathrm{i}}\right)$ is the value of interest at location $\mathrm{s}_{\mathrm{i}}$

$\mathrm{z}\left(\mathrm{s}_{\mathrm{i}}+\mathrm{h}\right)$ is the value at a location at distance $\mathrm{h}$ from $\mathrm{s}_{\mathrm{i}}$

Graphing semivariance versus the distance results in a semivariogram. Modeling the semivariogram reveals information about the spatial structure of a soil parameter such as the scale of heterogeneity and the spatially-dependent predictability of the property (Ettema and Wardle, 2002). Many soil variables exhibit spherical semivariograms (Figure 4.2). Information that can be obtained from the semivariogram includes the sill $\left(\mathrm{C}+\mathrm{C}_{0}\right.$, estimate of total population variance), the range or patch size (distance beyond which the data are independent), the nugget $\left(\mathrm{C}_{0}\right.$, variance due to sampling error or spatial dependence at scales not studied), and C (the spatially-dependent variance) (Rossi et al., 1992; Ettema and Wardle, 2002).

In this analysis, isotropic semivariograms were constructed using an active lag distance of 3 meters and lag class intervals ranging from 0.30 to 0.40 . The active lag distance is the range over which semivariance will be calculated, and the lag class interval defines how pairs of points will be grouped into lag classes. Gaussian, exponential or linear models with the best fit (highest $r^{2}$ ) and a sufficient number of distance pairs in each lag class are presented in this paper. The ratio of the nugget to the sill (N/S) was used to define three groups based on the level of spatial dependence, where data with $\mathrm{N} / \mathrm{S}<0.25=$ strong spatial dependence; N/S between 0.25 and $0.75=$ moderate spatial dependence and N/S $>0.75=$ no spatial correlation (Cambardella et al., 1994). 
Variography and punctual kriging were done using GS+ software v 7.0 (Gamma Design Software, St. Plainwell, MI).

\section{Results and Discussion}

Exploratory data were obtained prior to implementing the geostatistical study. Replicate $(n=3)$ tilled and untilled plots were established immediately adjacent to the market garden on soils previously undisturbed for a decade (Figure 4.1a). Based on samples collected to a $15-\mathrm{cm}$ depth, CLPP parameters (diversity, richness, evenness) obtained from 31 substrate BIOLOG ECO plates did not show obvious changes between treatments at day 1, 15, and 139 following tillage (Appendix 1.1). Variability of the CLPP parameters, indicated by the \% CV, was higher at day 1 in tilled compared with untilled plots. Principal component analysis (PCA) failed to separate tillage treatments (Appendix 1.2). At day 347 following tillage, samples again were collected, this time in 5-cm increments to a depth of $15 \mathrm{~cm}$. PCA analyses of CLPP data clearly separated samples with depth within each tillage treatment (Figure 4.3) but not among tillage treatments (data not shown). Again, principal components were considerably more variable in tillage plots (Figure 4.3). These data were supported by determinations of microbial biomass carbon (MBC) and heterotrophic plate counts (Table 4.1), values of which significantly decreased with depth, but at a given depth were not significantly different due to tillage. The only apparent differences in microbial biomass involved the higher coefficient of variation (\% CV) observed with depth in tilled compared with untilled plots. Collectively, the exploratory data did not reveal clear separation of tillage 
effects by parametric and multivariate statistics, but did suggest differences in both variability and heterogeneity among treatment plots.

The impact of tillage on soil structure depends on the degree of soil perturbation and the type of tillage practice that is used (Young and Ritz, 2000). The higher variability initially observed in the tilled plots could have been due to incomplete disruption of soil structure by the minimal rotary-tillage employed. Prior to the second year, plots were tilled vigorously twice to achieve greater soil homogenization. At 475 days following this second tillage event (day 822), soil samples were collected from two different depths $(2-3 \mathrm{~cm}$ and $13-14 \mathrm{~cm})$ to investigate intra-plot variability and heterogeneity of CLPP data obtained using 95 substrate BIOLOG GN2 plates. A modified design (Figure 4.1b) based on 28 samples per treatment was employed (Stein and Ettema; 2003). Since the cost per test for CLPP analysis with BIOLOG GN2 plates is high ( $\$ 10.00$ per sample), sampling designs must consider pragmatic factors such as affordability. This sampling design using only 26 BIOLOG plates per treatment was employed, which allowed construction of exploratory isotropic semivariograms with the necessary number of samples per lag class (Stein and Ettema, 2003).

Using parametric analyses, the calculated CV for the diversity, richness, and evenness demonstrated greater variability in untilled compared with tilled plots (Appendix 1.2). Specifically notable were the much larger CVs associated with the amines/amides, particularly at the $13-14 \mathrm{~cm}$ depth. PCA analysis of the area under the curve (AUC) data also suggested slightly more variability in the untilled verses tilled plots (Figure 4.4). PCA clearly separated soils by depth, but not by tillage treatment. 
To assess the effects of tillage on the spatial heterogeneity of CLPP, semivariograms were constructed using values calculated from all 95 BIOLOG substrates or from each of five separate substrate guilds (polymers, carbohydrates, carboxylic acids, amines/amides, and amino acids). The AUC was used as a response variable for the geospatial analysis because kinetic parameters are thought to be superior to other summary statistics for CLPP analysis (Preston-Mafham et al., 2002). All AUC data were normally distributed except for the polymers and amine guilds at a depth of 13-14 cm. These data were normalized using a Box Cox transformation prior to analyses. The semivariogram is a geostatistical tool that models the similarity between data as a function of their separation distance (Rossi et al., 1992). To produce reliable semivariograms, it is recommended that a minimum of $30-50$ distance pairs are represented in each lag class (Rossi et al., 1992). When a bin size between 0.3 to $0.4 \mathrm{~m}$ and an active lag distance of $3 \mathrm{~m}$ were used, the mean number of samples in each lag class ranged from 33 to 43 (Table 4.2, 4.3). Several lag classes contained fewer than 30 distance pairs due to the exclusion of outliers; however, the minimum never fell below 27.

Gaussian, exponential and linear models were fit to the data for the combined substrates and individual substrate guilds (Table 4.2, 4.3, Figure 4.5 a,b,c,d). Goodness of fits to these models $\left(\mathrm{r}^{2}\right.$ ranging from 0.55 to 0.97$)$ reveal that microbial substrate utilization is spatially structured in no-till and some tilled organic farm soils. Robust models could not be constructed for tilled soils collected from the $3-4 \mathrm{~cm}$ depth, indicating no spatial dependence in these data (Table 4.2, 4.3). Structural variance (C) accounted for $56 \%$ of the variance in the Gaussian and exponential models $\left(r^{2}>0.50\right)$ 
(Table 4.2, 4.3). The degree of spatial dependence, characterized by the nugget/sill ratio, ranged from strong to moderate. Strong spatial dependencies were found for the combined substrates and the amino acids in the no-till plots at a depth of 13-14 cm (Table 4.2, 4.3). When substrate guilds were examined separately, the ranges of spatial structure tended to be greater in untilled soils compared to tilled soils. In the absence of tillage, the carbohydrates were spatially structured at both depth classes, but the amines/amides and amino acids only exhibited spatial structure at depths of 13-14 cm. The data from the carbohydrates had the best fit of all the spatial models (Table 4.3; Figures 4.5c,d).

Ritz et al., (2004) characterized spatial structure in grassland soils using CLPP and other microbial parameters. They reported that CLPP principal components as well as AWCD for amino acids were spatially autocorrelated over ranges from 2.1 to $5.9 \mathrm{~m}$ and accounted for $60-85 \%$ of the total variance. Although I observed similar values for the structural variance (56 to $87 \%$ ), the analyses suggested that some of the ranges ( $>4.5$ m) exceeded the dimensions of the plot, particularly in untilled soils. This may be due to different response variables (AWCD vs. AUC), the experimental design (depths of the soil samples) or it may reflect real differences in the soils, topography or management strategies. The ranges also were larger than others observed at this scale using DNA fingerprint analysis (1.3 to $3 \mathrm{~m}$; Franklin and Mills, 2003) and PFLA analysis (0.73 to 5.7 m; Ritz et al., 2004).

In the present study, spatial structure of microbial substrate utilization was characterized at two different depths. Data indicated large differences in the variability and heterogeneity of microbial substrate utilization over very small vertical distances. 
Spatial structure was more explicit at lower soil depths probably because intensive rotary tillage disrupts microorganisms primarily in the upper few centimeters of soil. Doran (1987) reported that MBC and PMN were much higher in no-tilled soils than in the surface layers of tilled soils; however, there were very little differences below $7.5 \mathrm{~cm}$. De Fede and Sexstone (2001) observed large differences in AWCD and PCA using GN2 plates between A and B horizon soils. Nunan et al. (2002) studied the spatial distribution of bacteria in an arable field by quantifying the number and location of bacteria in soil via fluorescence microscopy of ultra-thin sections of soil cores. They found that bacteria in the topsoil were only spatially structured at the microscale level $(\mu \mathrm{m}$ to $\mathrm{cm})$, while communities in the subsoil were structured at multiple spatial scales. Finally, Franklin et al. (2002) reported that the patch size for bacterial abundance and microbial community structure was much smaller in the vertical versus the horizontal direction. These results support the premise that complex spatial patterns are present at different soil depths and the effects of tillage are pronounced over very small vertical distances.

The respiratory activities of plant roots, mesofauna and microorganisms are related to microbial substrate utilization; therefore, we measured $\mathrm{CO}_{2}$ flux as part of the geostatistical study. Previous studies also have demonstrated that soil $\mathrm{CO}_{2}$ flux often exhibits high temporal and spatial variability (Parkin and Kaspar, 2004) and can be spatially dependent (Stoyan et al., 2000). In the present study, we were unable to fit $\mathrm{CO}_{2}$ flux data to any of the spatial models and a t-test $(\mathrm{P}<0.09)$ indicated that there were no significant differences in the average $\mathrm{CO}_{2}$ flux in tilled $\left(2.48 \pm 0.66 \mathrm{~g} \mathrm{CO}_{2} \mathrm{~m}^{-2} \mathrm{~d}^{-1}\right)$ and untilled $\left(2.83 \pm 0.85 \mathrm{~g} \mathrm{CO}_{2} \mathrm{~m}^{-2} \mathrm{~d}^{-1}\right)$ plots. The $\% \mathrm{CVs}$ calculated from gas flux data were $27 \%$ and $30 \%$ for the till and no-till plots, respectively. Correlation analysis revealed that 
there was a significant association between $\mathrm{CO}_{2}$ flux and the AUC data from the amines/amides (Table 4.4). The microbial processes that regulate the relationship between $\mathrm{CO}_{2}$ and soil nitrogen dynamics are ecosystem-specific and fluctuate with nitrogen and carbon status and time (Hu et al., 2006). Therefore, a more comprehensive study would be needed to better determine if the utilization of amines and amides is associated with $\mathrm{CO}_{2}$ flux over time.

It is useful to investigate spatial patterns at multiple scales, because the factors that affect change are scale-dependent (Ettema and Wardle, 2002). Previous studies have established that microorganisms can be spatially structured at macro, meso, and microscales (Grundmann and Debouzie, 2000; Franklin et al., 2002; Nunan et al., 2002; Franklin and Mills, 2003). We focused on assessing the spatial variability and heterogeneity of substrate utilization at the plot scale because a plot-level scale is commonly used to evaluate the effects of agronomic treatments (Parkin, 2002). Our data support observations by Ritz et al. (2004) that CLPP data were associated with geostatistical ranges measured over meters at a given sampling depth, but also demonstrated that vertical spatial dependency varied over a scale of 0.1 meters. Subsurface soils exhibited the greatest spatial dependency, particularly in untilled soils. The lack of spatial structure in tilled surface soils (or the relatively small geostatistical ranges of $<2 \mathrm{~m}$ observed in subsurface tilled soil) suggests that application of classical parametric and multivariate statistics are appropriate to discern treatment differences in culturable microbial populations at the plot scale as was done in Chapter 3 of this dissertation. The large geostatistical range of spatial dependence $(\sim 20 \mathrm{~m})$ observed in 
untilled soils would necessitate a different plot size and design to effectively study this agronomic treatment in a rigorous and larger experiment.

\section{References Cited}

Bending, G.D., Putland, C., Rayns, F., 2000. Changes in microbial community metabolism and labile organic matter fractions as early indicators of the impact of management on soil biological quality. Biology and Fertility of Soils 31, 78-84.

Bending, G.D., Turner, M.K., Jones, J.E., 2002. Interactions between crop residue and soil organic matter quality and the functional diversity of soil microbial communities. Soil Biology and Biochemistry 34, 1073-1082.

Cambardella, C.A., Moorman, T.B., Novak, J.M., Parkin, T.B., Karlen, D.L., Turko, R.F., Konopka, A.E., 1994. Field-scale variability of soil properties in central Iowa soils. Soil Science Society of America Journal 58, 1501-1511.

Childers, T.B., 2005. The effects of low and high fertility treatments on soil quality, yields, pest incidence and labor requirements of a post-translational organic market garden system. M.S. Thesis. West Virginia University, Morgantown, WV.

De Fede, K.L., Sexstone, A.J., 2001. Differential response of size-fractionated soil bacteria in BIOLOG microtiter plates. Soil Biology and Biochemistry 33, $1547-$ 1554.

Doran, J.W., 1987. Microbial biomass and mineralizable nitrogen distributions in notillage and plowed soils. Biology and Fertility of Soils 5, 68-75.

Elliott, E.T., Coleman, D.C., 1988. Let the soil work for us. Ecological Bulletin 39, $23-$ 32.

Ettema, C.H., Wardle, D.A., 2002. Spatial soil ecology. TRENDS in Ecology and Evolution 17, 177-183.

Feng, Y., Motta, A.C., Reeves, D.W., Burmester, C.H., van Santen, E., Osborne, J.A., 2003. Soil microbial communities under conventional-till and no-till continuous cotton systems. Soil Biology and Biochemistry 35, 1693-1703.

Franklin, R.B., Mills, A.L., 2003. Multi-scale variation in spatial heterogeneity for microbial community structure in an eastern Virginia agricultural field. FEMS Microbiology Ecology 44, 335-346.

Franklin, R.B., Blum, L.K., McComb, A.C., Mills, A.L., 2002. A geostatistical analysis 
of small-scale spatial variability in bacterial abundance and community structure in salt marsh creek bank sediments. FEMS Microbiology Ecology 42, 71-80.

Garland, J.L., Mills, A.L., 1991. Classification and characterization of heterotrophic microbial communities on the basis of patterns of community-level sole-carbonsource utilization. Applied and Environmental Microbiology 57, 2351-2359.

Grundmann, G.L., Debouzie, D., 2000. Geostatistical analysis of the distribution of $\mathrm{NH}_{4}-$ and $\mathrm{NO}_{2}$ - oxidizing bacteria and serotypes at the millimeter scale along a soil transect. FEMS Microbiology Ecology 34, 57-62.

Guckert, J.B., Carr, G.J., Johnson, T.D., Hamm, B.G., Davidson, D.H., Kumagai, Y., 1996. Community analysis of BIOLOG: Curve integration for statistical analysis of activated sludge microbial habitats. Journal of Microbiological Methods 27, 183-197.

Hu, S., Tu, C., Chen, X., Gruver, J., 2006. Progressive N limitation of plant response to elevated $\mathrm{CO}_{2}$ : A microbiological perspective. Plant and Soil 289, 47-58.

Islam, K.R., Weil, R.R., 1998. Microwave irradiation of soil for routine measurement of microbial biomass carbon. Biology and Fertility of Soils 27, 408-416.

Kladivko, E.J., 2001. Tillage systems and soil ecology. Soil and Tillage Research 61, 6176.

Kristensen, H.L., Debosz, K., McCarty, G.W., 2003. Short-term effects of tillage on mineralization of nitrogen and carbon in soil. Soil Biology and Biochemistry 35, 979-986.

Kuepper, G., 2001. Pursuing conservation tillage systems for organic crop production. ATTRA's Organic Matters. http://attra.ncat.org/attrapub/organicmatters/conservationtillage.html

Legendre, P., Dale, M.R.T., Fortin, M.-J., Gurevitch, J., Hohn, M., Myers, D., 2002. The consequences of spatial structure for the design and analysis of ecological field surveys. Ecography 25, 601-615.

Lupwayi, N.Z., Arshad, M.A., Rice, W.A., Clayton, G.W., 2001. Bacterial diversity in water-stable aggregates of soils under conventional and zero tillage management. Applied Soil Ecology 16, 251-261.

Malosso, E., English, L., Hopkins, D., O’Donnell, A., 2005. Community level physiological profile response to plant residue additions in Antarctic soils. Biology and Fertility of Soils 42, 60-65.

Miethling, R., Wieland, G., Backhaus, H., Tebbe, C.C., 2000. Variation of microbial 
rhizosphere communities in response to crop species, soil origin, and inoculation with Sinorhizobium meliloti L33. Microbial Ecology 40, 43-56.

Nunan, N., Wu, K., Young, I.M., Crawford, J.W., Ritz, K., 2002. In situ spatial patterns of soil bacterial populations, mapped at multiple scales, in an arable soil. Microbial Ecology 44, 296-305.

Parkin, T.B., 1993. Spatial variability of microbial processes in soil-a review. Journal of Environmental Quality 22, 409-417.

Parkin, T.B., Kaspar, T.C., 2004. Temporal variability of soil carbon dioxide flux: Effect of sampling frequency on cumulative carbon loss estimation. Soil Science Society of America Journal 68, 1234-1241.

Preston-Mafham, J., Boddy, L., Randerson, P.F., 2002. Analysis of microbial community functional diversity using sole-carbon-source utilization profiles - a critique. FEMS Microbiology Ecology 42, 1-14.

R Core Development Team, 2004. R: A language and environment for statistical computing. Vienna, Austria. http://www.R-project.org

Ritz, K., McNicol, J.W., Nunan, N., Grayston, S., Millard, P., Atkinson, D., Gollotte, A., Habeshaw, D., Boag, B., Clegg, C.D., Griffiths, B.S., Wheatley, R.E., Glover, L.A., McCaig, A.E., Prosser, J.I., 2004. Spatial structure in soil chemical and microbiological properties in an upland grassland. FEMS Microbiology Ecology $49,191-205$.

Robertson, G.P., Paul, E.A., Harwood, R.R., 2000. Greenhouse gases in intensive agriculture: Contributions of individual gases to the radiative forcing of the atmosphere. Science 289, 1922-1925.

Rossi, R.E., Mulla, D.J., Journel, A.G., Franz, E.H., 1992. Geostatistical tools for modeling and interpreting ecological spatial dependence. Ecological Monographs $62,277-314$.

Sharma, S., Rangger, A., Insam, H., 1998. Effects of decomposing maize litter on community level physiological profiles of soil bacteria. Microbial Ecology 35, 301-310.

Stein, A., Ettema, C., 2003. An overview of spatial sampling procedures and experimental design of spatial studies for ecosystem comparisons. Agriculture, Ecosystems and Environment 94, 31-47.

Stoyan, H., De-Polli, H., Böhm, S., Robertson, G., Paul, E., 2000. Spatial heterogeneity of soil respiration and related properties at the plant scale. Plant and Soil 222, 203-214. 
Tisdall, J.M., Oades, J.M., 1982. Organic matter and water stable aggregates. Soil Science Society of America Journal 33, 141-163.

Williams, B., Grayston, S., Reid, E., 2000. Influence of synthetic sheep urine on the microbial biomass, activity and community structure in two pastures in the Scottish uplands. Plant and Soil 225, 175-185.

Young, I.M., Ritz, K., 2000. Tillage, habitat space and function of soil microbes. Soil and Tillage Research 53, 201-213.

Zak, J.C., Willig, M.R., Moorhead, D.L., Wildman, H.G., 1994. Functional diversity of microbial communities: A quantitative approach. Soil Biology and Biochemistry 26, 1101-1108.

Zuberer, D.A., 1994. Recovery and enumeration of viable bacteria. In: Weaver, R.W. (Ed.), Methods of soil analysis, part 2. Microbiological and biochemical properties. Soil Science Society of America, Madison, Wisconsin, pp. 119-144. 
Table 4.1. Means and coefficients of variation ( $\% \mathrm{CV})$ for biomass and heterotrophic plate count data for vertical subsections of soil collected on day 347.

\begin{tabular}{llllrrrr}
\hline Treatment & $\begin{array}{c}\text { Depth } \\
(\mathrm{cm})\end{array}$ & \multicolumn{2}{c}{$\begin{array}{c}\text { Biomass } \\
(\mathrm{mg} \mathrm{C} / \mathrm{kg})\end{array}$} & \multicolumn{2}{c}{$\begin{array}{c}\text { Plate Count } \\
(\text { Log CFU/ml) }\end{array}$} \\
\hline \multirow{2}{*}{ No Till } & $0-5$ & 481.81 & $\mathrm{a}$ & 16.67 & 9.04 & $\mathrm{a}$ & 1.39 \\
& $5-10$ & 110.84 & $\mathrm{~b}$ & 31.75 & 8.57 & $\mathrm{~b}$ & 2.28 \\
& $10-15$ & 85.29 & $\mathrm{~b}$ & 22.37 & 8.02 & $\mathrm{c}$ & 1.33 \\
Till & $0-5$ & 765.34 & $\mathrm{a}$ & 11.69 & 9.04 & $\mathrm{a}$ & 0.88 \\
& $5-10$ & 188.42 & $\mathrm{~b}$ & 40.28 & 8.58 & $\mathrm{~b}$ & 1.84 \\
& $10-15$ & 100.98 & $\mathrm{~b}$ & 85.66 & 7.93 & $\mathrm{c}$ & 1.11 \\
\hline
\end{tabular}

${ }^{\text {a }}$ Mean values followed by the same letter are not significantly different $(\mathrm{P}<0.05)$ as determined by Tukey's Studentized Range (HSD) test. 
Table 4.2. Summary of results from geostatistical analysis of AUC data for all BIOLOG GN2 substrates from day 822 .

\begin{tabular}{|c|c|c|c|c|c|c|c|c|c|}
\hline Treatment & Depth & Model Type & $\mathrm{r}^{2}$ & $\begin{array}{c}\text { Mean (SD) } \\
\text { distance pairs } \\
\text { per lag class }\end{array}$ & $\begin{array}{l}\text { Nugget } \\
\text { (N) }\end{array}$ & $\begin{array}{l}\text { Sill } \\
(\mathrm{S})\end{array}$ & $\begin{array}{l}\text { Range } \\
\text { (R) }\end{array}$ & $\begin{array}{c}\text { Spatial } \\
\text { Dependence } \\
(\mathrm{N} / \mathrm{S})\end{array}$ & $\begin{array}{c}\% \\
\text { Structura } \\
\text { Variance }\end{array}$ \\
\hline Till & $3-4 \mathrm{~cm}$ & Exponential & 0.04 & $37(4.7)$ & - & - & - & - & - \\
\hline No Till & $3-4 \mathrm{~cm}$ & Exponential & 0.61 & $36(4.6)$ & 248 & 807 & $>4.3$ & Moderate & 69 \\
\hline Till & $13-14 \mathrm{~cm}$ & Gaussian & 0.97 & $40(6.9)$ & 141 & 321 & 4.9 & Moderate & 56 \\
\hline No Till & $13-14 \mathrm{~cm}$ & Gaussian & 0.83 & $33(6.4)$ & 76 & 592 & 2.7 & Strong & 87 \\
\hline
\end{tabular}


Table 4.3. Summary of results from geostatistical analysis of AUC data from substrate classes from BIOLOG GN2 plates from day 822 .

\begin{tabular}{|c|c|c|c|c|c|c|c|c|c|c|}
\hline $\begin{array}{l}\text { Substrate } \\
\text { Class }\end{array}$ & Treatment & Depth & Model Type & $\mathrm{r}^{2}$ & $\begin{array}{c}\text { Mean (SD) } \\
\text { distance pairs } \\
\text { per lag class }\end{array}$ & $\begin{array}{l}\text { Nugget } \\
(\mathrm{N})\end{array}$ & $\begin{array}{l}\text { Sill } \\
(\mathrm{S})\end{array}$ & $\begin{array}{c}\text { Range } \\
\text { (R) }\end{array}$ & $\begin{array}{c}\text { Spatial } \\
\text { Dependence } \\
(\mathrm{N} / \mathrm{S})\end{array}$ & $\begin{array}{c}\% \\
\text { Structural } \\
\text { Variance }\end{array}$ \\
\hline \multicolumn{11}{|l|}{ Polymers } \\
\hline & No Till & $3-4 \mathrm{~cm}$ & Exponential & 0.60 & $43(7.2)$ & 398 & 1207 & $>4.3$ & Moderate & 67 \\
\hline & Till & $13-14 \mathrm{~cm}$ & Gaussian & 0.73 & $39(7.2)$ & 149 & 496 & 1.3 & Moderate & 70 \\
\hline \multicolumn{11}{|l|}{ Carbohydrates } \\
\hline & No Till & $3-4 \mathrm{~cm}$ & Gaussian & 0.94 & $43(7.2)$ & 479 & 1185 & 4.7 & Moderate & 60 \\
\hline & No Till & $13-14 \mathrm{~cm}$ & Gaussian & 0.55 & $36(6.1)$ & 392 & 1494 & $>4.3$ & Moderate & 74 \\
\hline & Till & $13-14 \mathrm{~cm}$ & Exponential & 0.91 & $35(4.1)$ & 204 & 501 & 2.9 & Moderate & 59 \\
\hline \multicolumn{11}{|l|}{$\begin{array}{l}\text { Carboxylic } \\
\text { acids }\end{array}$} \\
\hline \multirow{2}{*}{ Amines/Amides } & No Till & $13-14 \mathrm{~cm}$ & Exponential & 0.52 & $37(4.7)$ & 153 & 617 & $>4.3$ & Moderate & 75 \\
\hline & No Till & $13-14 \mathrm{~cm}$ & Gaussian & 0.74 & $33(6.2)$ & 203 & 823 & 2.3 & Moderate & 75 \\
\hline \multirow{2}{*}{ Amino Acids } & No Till & $13-14 \mathrm{~cm}$ & Gaussian & 0.80 & $36(6.1)$ & 148 & 1106 & 4.6 & Strong & 87 \\
\hline & Till & $13-14 \mathrm{~cm}$ & Linear & 0.58 & $37(4.7)$ & 286 & 410 & 3.0 & Moderate & 30 \\
\hline
\end{tabular}


Table 4.4. Pearson correlation coefficients between $\mathrm{CO}_{2}$ flux and $\mathrm{AUC}$ data for substrate classes from BIOLOG GN2 plates.

\begin{tabular}{lllll}
\hline & Top & \multicolumn{3}{c}{ Bottom } \\
\hline & Till & No Till & Till & No Till \\
\hline All substrates & 0.17 & 0.24 & 0.18 & -0.02 \\
Polymers & -0.01 & 0.16 & 0.12 & -0.04 \\
Carbohydrates & 0.15 & 0.20 & 0.30 & -0.12 \\
Carboxylic acids & 0.19 & 0.28 & 0.12 & 0.04 \\
Amines/Amides & $0.38 *$ & 0.04 & -0.04 & 0.01 \\
Amino Acids & 0.11 & 0.33 & 0.03 & 0.13 \\
\hline
\end{tabular}

* Significant correlations $(\mathrm{P}<0.05)$. 
(a)

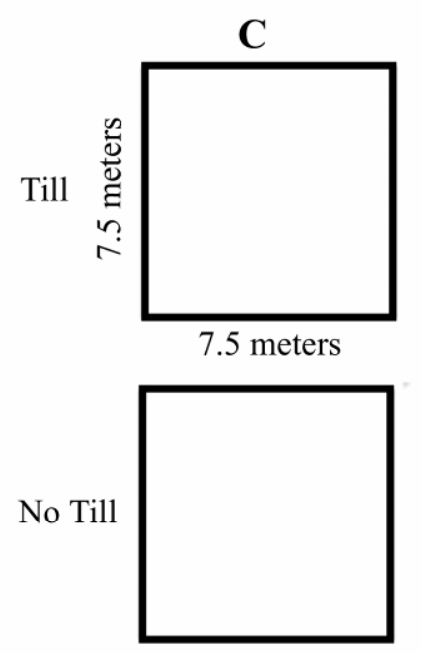

C
B
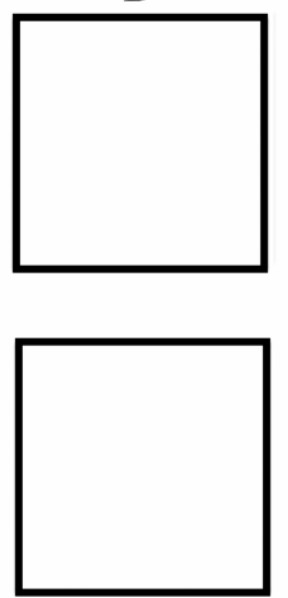

B
A
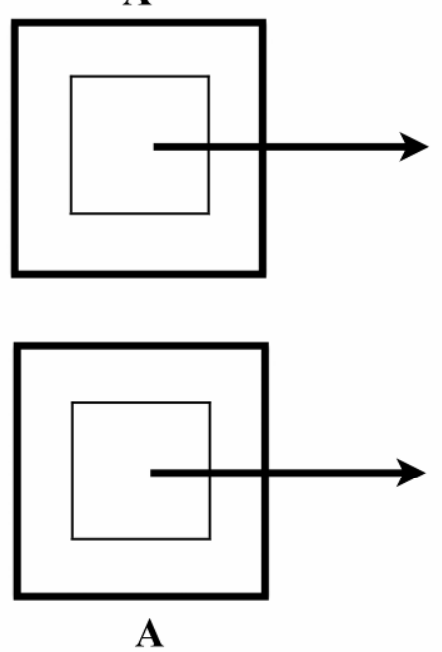

(b)

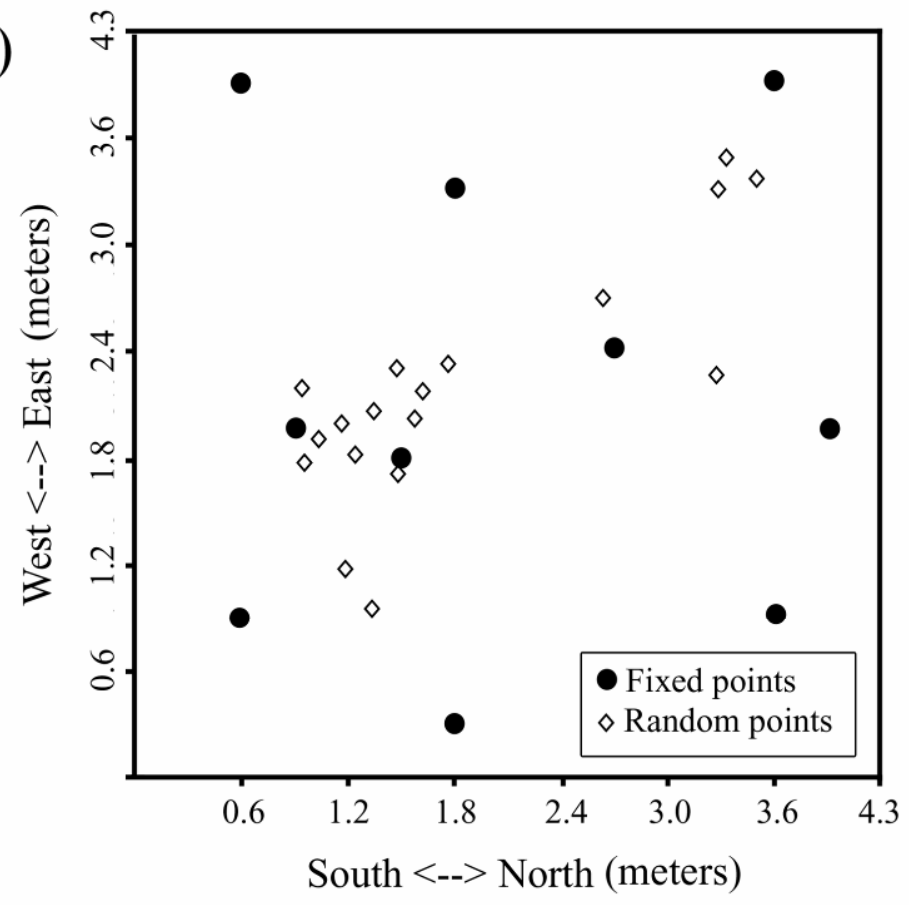

Geospatial Study

(456 days following second tillage)

GN2 Plates

$\mathrm{CO}_{2}$ Flux

Plate Count

CLPP Ecoplates

Figure 4.1. Dimensions and layout of plots for analyses done on day 347 following the primary tillage event (a) and sampling scheme and analyses for geospatial study done in A plots on day 456 following the second tillage event (b). 


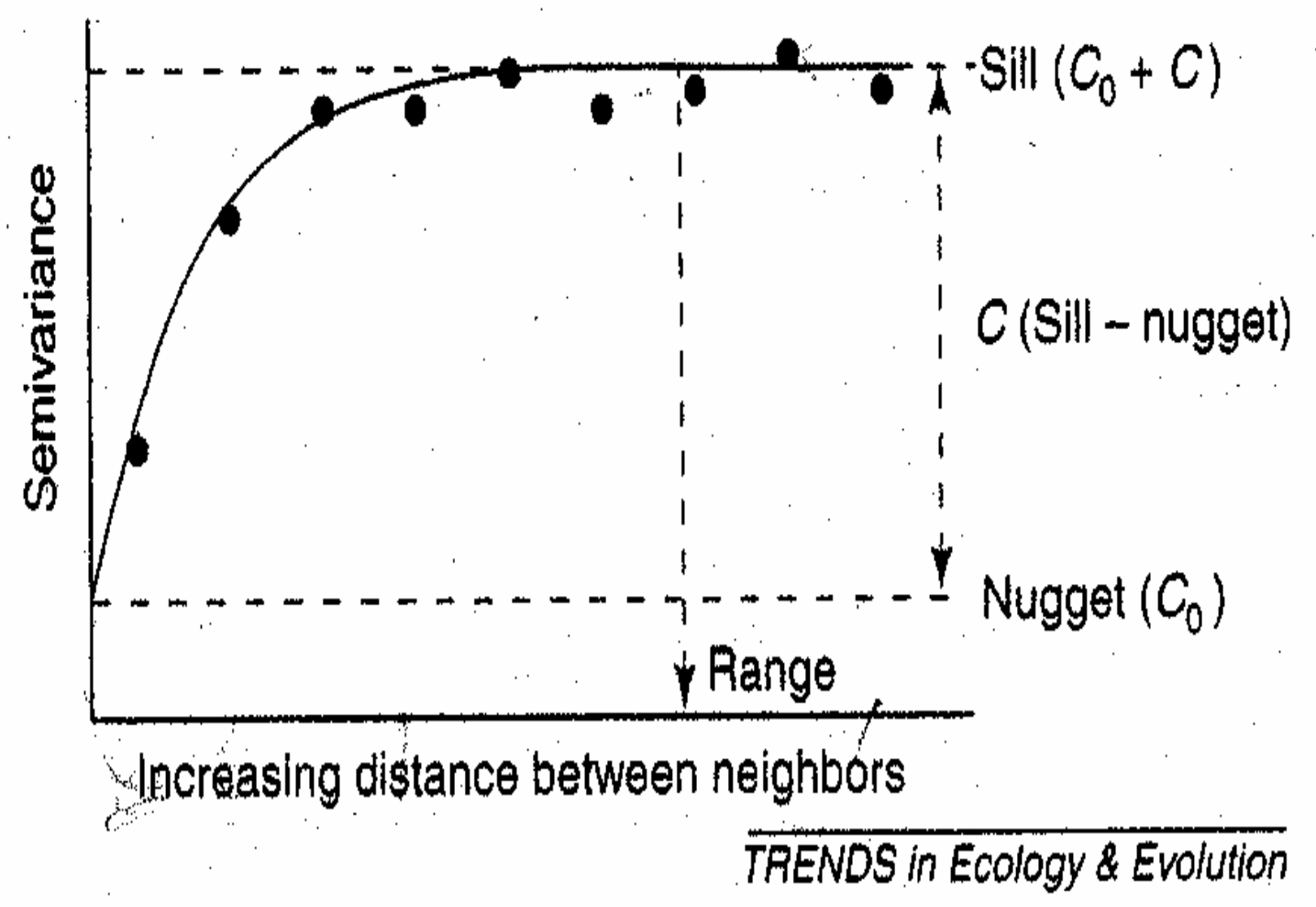

Figure 4.2. Generalized spherical semivariogram (From: Ettema and Wardle, 2002). 
(a)

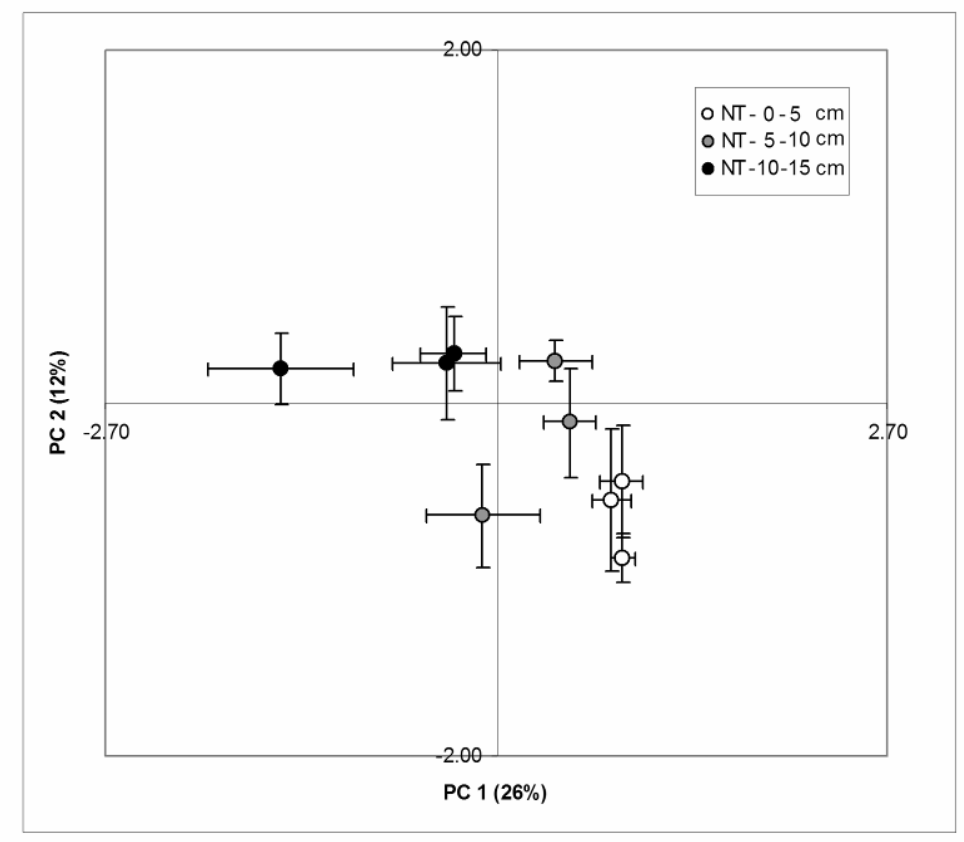

(b)

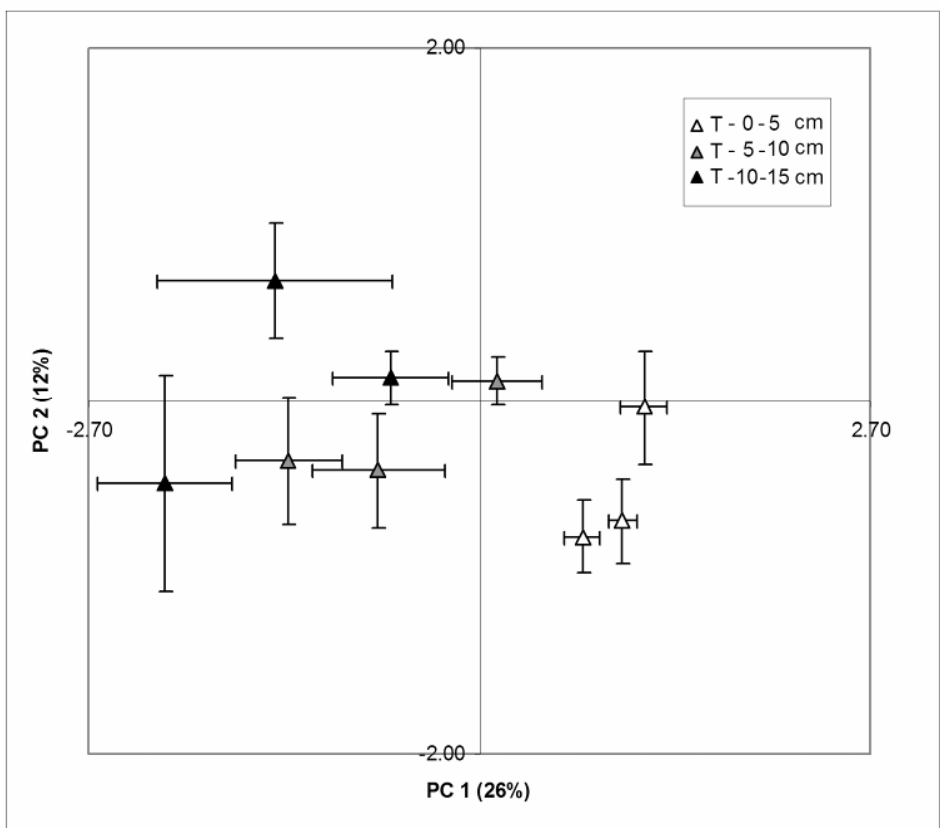

Figure 4.3. Ordination biplots of principal components (PC1 and PC2) from CLPP analysis of vertical subsections (a) no till and (b) till soils collected from plots A, B and C on day 347 following the initial tillage event in July 2003. PCA analysis was done on AWCD readings from BIOLOG Ecoplates. Error bars represent the standard deviations for PC1 and PC2. 


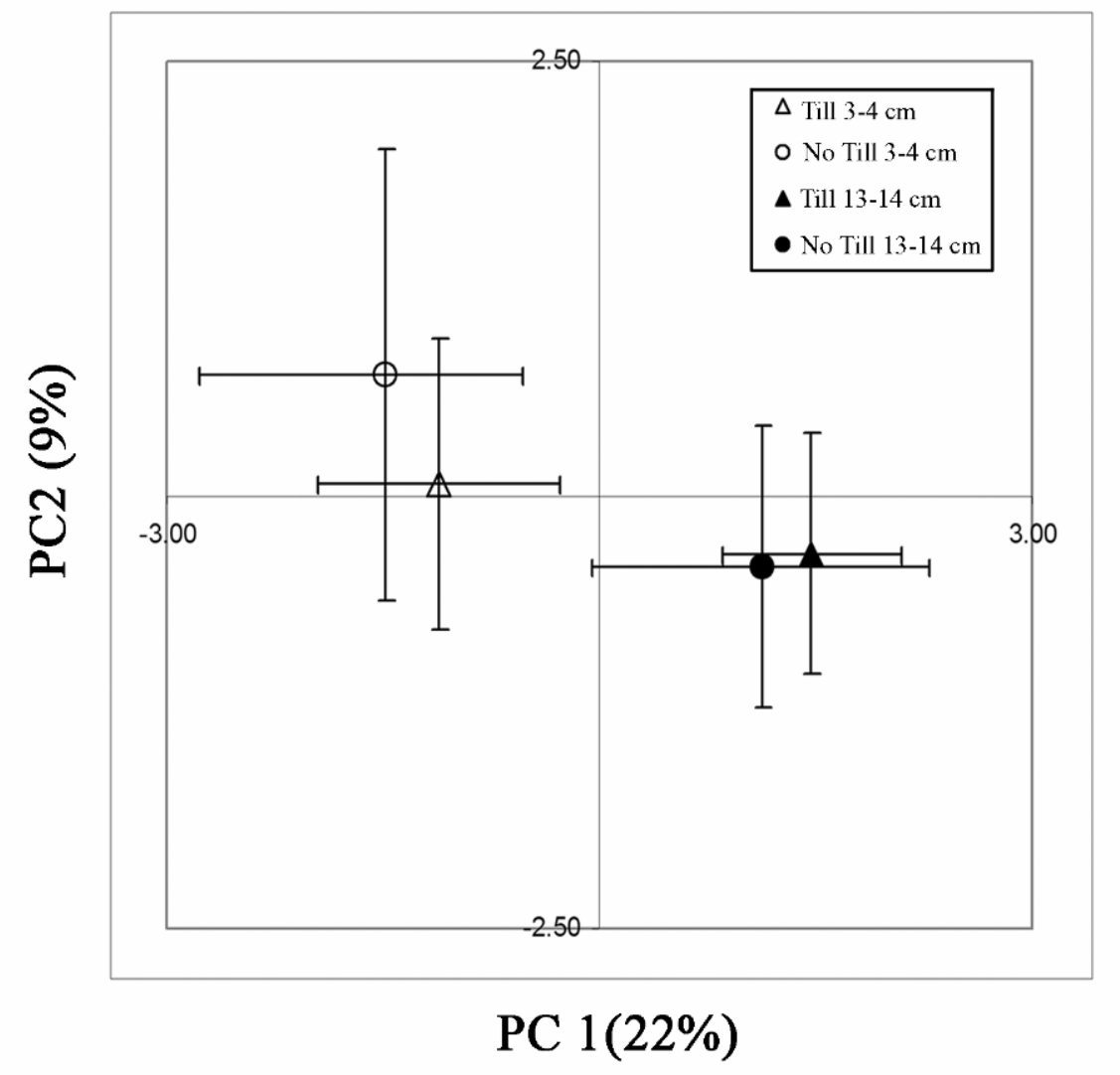

Figure 4.4. Ordination biplots of principal components (PC1 and PC2) from CLPP analysis of vertical subsections of till and no-till soils collected on day 822 following the primary and secondary tillage events. PCA analysis was done on standardized values for the area under the kinetic curve from BIOLOG GN2 plates. Error bars represent the standard deviations for PC1 and PC2. 
(a)

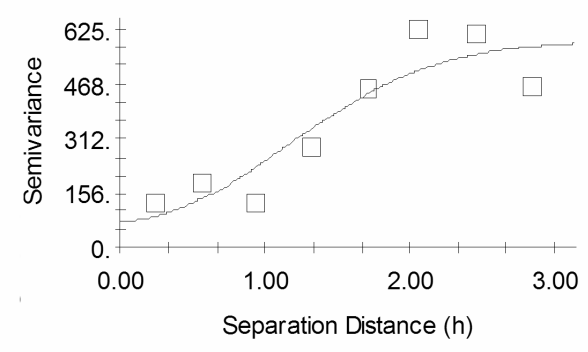

(c)

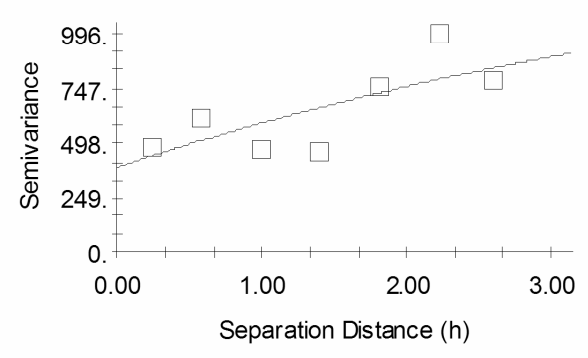

(b)

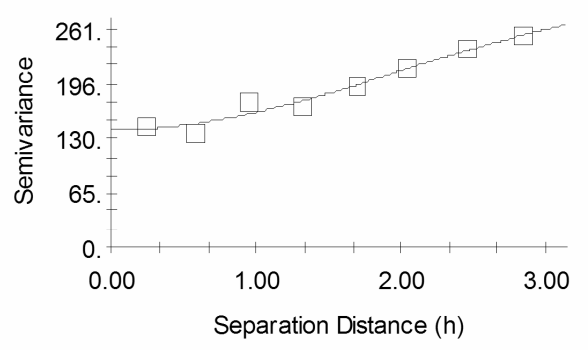

(d)

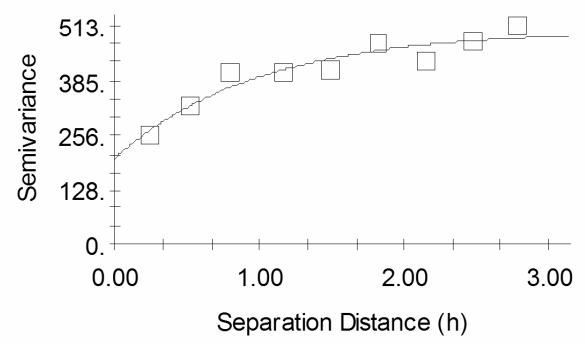

Figure 4.5. Semivariograms of AUC at $13-14 \mathrm{~cm}$ for (a) all substrates in the no-till plot, (b) all substrates in the till plot, (c) carbohydrates in the no-till plot (d), and carbohydrates in the till plot. 


\section{APPENDIX 1.1}

Means and coefficients of variation (\% CV) for CLPP parameters for BIOLOG Ecoplates for vertical subsections of soil collected on days $0,13,139$ and 347 .

\begin{tabular}{|c|c|c|c|c|c|c|c|c|c|c|}
\hline \multirow[t]{2}{*}{ Treatment } & \multirow[t]{2}{*}{ Day } & \multirow{2}{*}{$\begin{array}{c}\text { Depth } \\
(\mathrm{cm})\end{array}$} & \multicolumn{2}{|c|}{ AWCD } & \multicolumn{2}{|c|}{ Diversity $(\mathrm{H})$} & \multicolumn{2}{|c|}{ Richness (S) } & \multicolumn{2}{|c|}{ Evenness (E) } \\
\hline & & & Mean & $\% \mathrm{CV}$ & Mean & $\% \mathrm{CV}$ & Mean & $\% \mathrm{CV}$ & Mean & $\% \mathrm{CV}$ \\
\hline \multirow[t]{3}{*}{ No Till } & 1 & $0-15$ & 1.63 & 4.6 & 3.30 & 0.4 & 29.78 & 2.2 & 0.97 & 0.5 \\
\hline & 15 & $0-15$ & 1.50 & 6.1 & 3.31 & 1.1 & 29.22 & 2.9 & 0.98 & 0.4 \\
\hline & 139 & $0-15$ & 1.50 & 5.7 & 3.27 & 0.8 & 29.33 & 4.2 & 0.97 & 0.7 \\
\hline \multirow[t]{3}{*}{ Till } & 1 & $0-15$ & 1.44 & 13.3 & 3.25 & 1.9 & 28.11 & 6.8 & 0.97 & 0.5 \\
\hline & 15 & $0-15$ & 1.49 & 7.9 & 3.31 & 0.5 & 30.00 & 2.4 & 0.97 & 0.6 \\
\hline & 139 & $0-15$ & 1.46 & 7.0 & 3.27 & 1.3 & 30.11 & 2.6 & 0.96 & 1.1 \\
\hline \multirow[t]{3}{*}{ No Till } & 347 & $0-5$ & 1.86 & 6.1 & 3.39 & 0.5 & 30.72 & 1.5 & 0.99 & 0.3 \\
\hline & 347 & $5-10$ & 1.61 & 6.4 & 3.34 & 0.7 & 30.11 & 2.2 & 0.98 & 0.5 \\
\hline & 347 & $10-15$ & 1.51 & 9.4 & 3.27 & 1.7 & 29.22 & 4.5 & 0.97 & 0.9 \\
\hline \multirow[t]{3}{*}{ Till } & 347 & $0-5$ & 1.82 & 9.7 & 3.38 & 0.6 & 30.78 & 1.4 & 0.99 & 0.4 \\
\hline & 347 & $5-10$ & 1.43 & 6.9 & 3.28 & 1.6 & 29.00 & 4.1 & 0.98 & 0.8 \\
\hline & 347 & $10-15$ & 1.27 & 14.0 & 3.17 & 2.9 & 26.56 & 8.7 & 0.97 & 1.2 \\
\hline
\end{tabular}




\section{APPENDIX 1.2}

Means and coefficients of variation (\% CV) for CLPP parameters from BIOLOG GN2 plates for vertical subsections of soil collected on day 822 .

\begin{tabular}{|c|c|c|c|c|c|c|c|c|c|c|}
\hline \multirow[b]{2}{*}{ Substrate Group } & \multirow[b]{2}{*}{ Depth } & \multirow[b]{2}{*}{ Treatment } & \multicolumn{2}{|c|}{ AWCD } & \multicolumn{2}{|c|}{ Diversity $(\mathrm{H})$} & \multicolumn{2}{|c|}{ Richness (S) } & \multicolumn{2}{|c|}{ Evenness (E) } \\
\hline & & & Mean & $\% \mathrm{CV}$ & Mean & $\% \mathrm{CV}$ & Mean & $\% \mathrm{CV}$ & Mean & $\% \mathrm{CV}$ \\
\hline \multicolumn{11}{|l|}{ Polymer } \\
\hline & $2-3 \mathrm{~cm}$ & Till & 1.67 & 17.0 & 1.55 & 5.8 & 5 & 6.4 & 0.98 & 2.8 \\
\hline & & No Till & 1.66 & 26.0 & 1.53 & 7.5 & 5 & 9.9 & 0.98 & 3.0 \\
\hline & $13-14$ & Till & 1.01 & 22.0 & 0.96 & 23.2 & 3 & 27.8 & 0.93 & 6.6 \\
\hline & & No Till & 1.12 & 25.1 & 1.02 & 25.5 & 3 & 29.7 & 0.93 & 7.3 \\
\hline \multicolumn{11}{|l|}{ Carbohydrates } \\
\hline & $2-3 \mathrm{~cm}$ & Till & 1.81 & 11.7 & 3.21 & 2.0 & 27 & 4.0 & 0.97 & 1.1 \\
\hline & & No Till & 1.66 & 22.0 & 3.18 & 4.1 & 26 & 9.6 & 0.98 & 1.5 \\
\hline & $13-14$ & Till & 1.45 & 14.4 & 2.87 & 4.7 & 20 & 13.3 & 0.96 & 1.8 \\
\hline & & No Till & 1.45 & 18.8 & 2.88 & 6.5 & 20 & 16.9 & 0.96 & 2.0 \\
\hline \multicolumn{11}{|l|}{ Carboxylic Acids } \\
\hline & $2-3 \mathrm{~cm}$ & Till & 1.15 & 13.4 & 3.01 & 2.6 & 23 & 8.2 & 0.96 & 1.0 \\
\hline & & No Till & 1.02 & 25.1 & 2.92 & 5.0 & 21 & 16.5 & 0.96 & 1.1 \\
\hline & $13-14$ & Till & 1.05 & 10.3 & 2.93 & 2.3 & 22 & 7.5 & 0.95 & 1.1 \\
\hline & & No Till & 1.12 & 11.5 & 2.96 & 3.0 & 23 & 10.1 & 0.95 & 1.3 \\
\hline \multicolumn{11}{|l|}{ Amines/Amides } \\
\hline & $2-3 \mathrm{~cm}$ & Till & 1.16 & 20.0 & 1.31 & 10.0 & 4 & 17.0 & 0.94 & 4.9 \\
\hline & & No Till & 0.96 & 29.9 & 1.18 & 14.6 & 4 & 20.8 & 0.92 & 20.1 \\
\hline & $13-14$ & Till & 1.05 & 12.2 & 1.17 & 9.4 & 4 & 17.8 & 0.93 & 6.3 \\
\hline & & No Till & 1.06 & 25.2 & 1.18 & 23.0 & 4 & 23.1 & 0.88 & 20.4 \\
\hline \multicolumn{11}{|l|}{ Amino Acids } \\
\hline & $2-3 \mathrm{~cm}$ & Till & 1.65 & 10.9 & 2.83 & 2.2 & 19 & 5.8 & 0.97 & 1.1 \\
\hline & & No Till & 1.50 & 20.2 & 2.79 & 3.4 & 18 & 8.1 & 0.97 & 1.2 \\
\hline & $13-14$ & Till & 1.59 & 9.6 & 2.76 & 1.8 & 18 & 6.0 & 0.96 & 0.9 \\
\hline & & No Till & 1.62 & 14.2 & 2.76 & 3.2 & 18 & 8.1 & 0.96 & 1.0 \\
\hline
\end{tabular}




\title{
CURRICULUM VITAE
}

\author{
EDUCATION \\ Ph.D. Agricultural Sciences \\ with a concentration in environmental microbiology \\ (2007) \\ West Virginia University \\ Division of Plant and Soil Sciences, Morgantown, WV \\ Dissertation: Molecular and functional characterization \\ of bacterial communities in soils from an organic farm and pasture.
}

Doctoral Studies in Aquatic Ecology (1991-1992) - Kent State University, Kent, OH

M.S. Biology (1990) - Clarion University of Pennsylvania, Clarion, PA;

Thesis: Manganese toxicity and bioconcentration in the green algae Mougeotia sp.

(Chlorophyceae)

B.S. Medical Technology (1997) - Clarion University of Pennsylvania, Clarion PA Certification: American Society of Clinical Pathologist (ASCP) - (MT-204770)

B.S. Biology, summa cum laude (1987) - Clarion University of Pennsylvania

\section{Teaching Positions}

\section{EMPLOYMENT}

- Assistant Professor of Biology (8/07) - West Virginia Wesleyan College, Buckhannon, WV.

- Biology Instructor (12/99-4/06) - Clarion University of Pennsylvania, Department of Biology, Pittsburgh Site, Venango and Main Campuses, PA. Courses: Microbiology, Anatomy and Physiology, and Biology

- Adjunct Faculty (8/99-5/00) - Jefferson Community College, Steubenville, OH. Course: Anatomy and Physiology

- Graduate Teaching Fellow (8/92-8/93) - Kent State University, Kent, OH. Courses: General Biology and Microbiology

- Graduate Teaching Assistant (1/88-5/90) - Clarion University of Pennsylvania, Department of Biology, Clarion, PA. Courses: Botany and Zoology 


\section{Research and Clinical Positions}

- Doctoral Research Assistant (8/02-Present) - West Virginia University, Division of Plant and Soil Science, Morgantown, WV

- Research Associate (7/98-1/99) - Department of Infectious Diseases, Children's Hospital of Pittsburgh, Pittsburgh, PA

- Medical Technologist (10/97-7/98) - Jefferson Hospital, South Hills Health Care System, Pittsburgh, PA

- Environmental Microbiologist (6/90-6/92) - U.S. Bureau of Mines, Pittsburgh, PA Research Center, Pittsburgh, PA

- Biological Technician (Summers 87, 88) - U.S. Department of the Interior, Office of Surface Mining and Reclamation Enforcement, Pittsburgh, PA

\section{PUBLICATIONS}

Edenborn, S.L. and A.J. Sexstone. (2007). DGGE fingerprinting of culturable soil bacterial communities complements culture-independent analyses. Soil Biology and Biochemistry. 39 (7):1570-1579.

Salinas, K.A., S.L. Edenborn, A.J. Sexstone, and J.B. Kotcon. (2007). Bacterial preferences of the bacterivorous soil nematode Cephalobus brevicauda (Cephalobidae): effect of bacterial type and size. Pedobiologia. 50 (1): 55-64.

Edenborn, H.M. and S.L. Edenborn. (2006). Microbial diversity in soil: A microscopic world under every footstep. In: McKinstry, R.B., Ripp, C. and Lisy, E. (Eds.) Biodiversity Conservation Handbook: State, Local, and Private Protection of Biological Diversity, Environmental Law Institute Press, Washington, DC. Pp. 159-173.

Edenborn, H.M., L.A. Brickett, D.H. Dvorak, and S.L. Edenborn. (1993). Monitoring iron and manganese diagenesis in constructed wetlands with continuous gradient gels. Biohydrometallurgical Technologies 1:631-639.

Dvorak, D.H., R.S. Hedin, S.L. Gustafson (Edenborn), and H.M. Edenborn (1991). Treatment of metal-contaminated water using bacterial sulfate reduction: results from pilot-scale reactors. International Conference on the Abatement of Acidic Drainage. Montreal, Canada, pp.301-314.

R.S. Hedin, D.H. Dvorak, S.L. Gustafson (Edenborn), D.M. Hyman, P.E. McIntire, 
R.W. Nairn, R.C., Neupert, A.C. Woods and H.M Edenborn. (1991). Use of a constructed wetland for the treatment of acid mine drainage at the Friendship Hill National Historic Site, Fayette County, PA. Final Report Presented to the National Park Service.

\section{PRESENTATIONS/ABSTRACTS}

Edenborn, S.L. and A.J. Sexstone. (2006). Characterization of soil bacterial communities on culture plates using denaturing gradient gel electrophoresis of the $16 \mathrm{~S}$ rRNA gene. Annual Meeting of the American Society of Agronomy, Crop Science Society of America, and Soil Science Society of America, Indianapolis, Indiana.

Chapman, J.A., S.L. Edenborn and A.J. Sexstone. (2006). Modification of bacterial communities in a pasture soil by the feeding activity of earthworms. Annual Meeting of the American Society of Agronomy, Crop Science Society of America, and Soil Science Society of America, Indianapolis, Indiana.

Edenborn, H.M., S.L. Edenborn, B. Ji, J.H. Doherty, and B. B. Casper. (2005). Observations on the relationships between bacteria and grasses at Eastern serpentine barrens and Midwestern prairie sites. Annual meeting of the Allegheny Branch of American Society for Microbiologists, Clearfield, PA.

Friedland, J.M., S.L. Edenborn, and A.J. Sexstone. (2004). Diversity of microbial populations within a constructed wetland treating wastewater. Annual Meeting of the American Society of Agronomy, Crop Science Society of America, and Soil Science Society of America, Seattle, Washington.

Edenborn, S.L., Y. Sutanto, J. Chapman, and A.J. Sexstone. (2004). Culturedependent assessment of bacterial diversity in northern West Virginia soils. Annual Meeting of the American Society of Agronomy, Crop Science Society of America, and Soil Science Society of America, Seattle, Washington.

Salinas, K.A., J.B. Kotcon, and S. L. Edenborn. (2003). The effects of a bacterial biological control agent on taxis of Clarkus papillatus in a laboratory bioassay. Annual Meeting of the Society of Nematologist, Cornell University, Ithaca, New York.

Edenborn, H.M., L.A. Brickett, D.H. Dvorak, and S.L. Edenborn. (1993). Monitoring manganese diagenesis in constructed wetlands with continuous gradient gels. International Biohydrometallurgy Symposium, Jackson Hole, WY.

Edenborn, H.M., L.A. Brickett, D.H. Dvorak, and S.L. Edenborn. (1992). Monitoring manganese diagenesis in a constructed wetland using continuous gradient gels. 
Geological Society of America Annual Meeting. Cincinnati, OH. (Received best poster award).

Gustafson (Edenborn), S.L., R.S. Hedin and H.M. Edenborn. (1991). Rates of iron and manganese removal in waters from wetlands receiving acid mine drainage: The role of indigenous microorganisms. Gordon Research Conference in Applied and Environmental Microbiology, Colby-Sawyer College, New London, NH.

Gustafson (Edenborn), S.L. and S.A. Jatkar. (1991). Algal taxonomy of coal mine drainage sites and correlation with drainage chemistry. Abstract \# 141. The Fourth International Phycological Congress, Duke University, Durham, North Carolina.

Gustafson (Edenborn), S.L., and H.M. Edenborn. (1991). Biological removal of manganese in acid mine drainage by a mixed algal-bacterial community. Abstract \# 54, $91^{\text {st }}$ Annual Meeting of the American Society for Microbiology, Dallas, Texas.

Gustafson (Edenborn), S.L., R.S. Hedin, R.W. Nairn and H.M. Edenborn. (1991). The importance of bacterial-iron oxidation and sulfate reduction in wetlands constructed to treat acid mine crainage. Symposium on the Biogeochemistry of Wetlands, Center for Wetland Resources, Louisiana State University, Baton Rouge, LA.

Edenborn, H.M., D.H. Dvorak, R.S. Hedin, and S.L. Gustafson (Edenborn). (1990). Treatment of metal-contaminated water via bacterial sulfate reduction in wetlands and pilot-scale reactors. National Association of Abandoned Mine Land Program, Breckenridge, $\mathrm{CO}$.

\section{HONORS AND AWARDS}

Gamma Sigma Delta, Honor Society of Agriculture (2007); Provost Fellowship, Kent State University (1992); Commonwealth of Pennsylvania University Biologists; Outstanding Student Award (1987); Penn State University Student Travel Award to Symposium in Plant Physiology (1987); Beta Beta Beta National Biological Honor Society (1986); Phi Eta Sigma Freshman Honor Society (1984).

\section{PROFESSIONAL SOCIETIES}

American Society for Microbiology (ASM) 